Florida International University FIU Digital Commons

FIU Electronic Theses and Dissertations

University Graduate School

7-15-2009

\title{
Mineral chemistry and origin of the olivine-rich zone of the Palisades sill
}

Kevin Xavier Chau

Florida International University

DOI: $10.25148 /$ etd.FI14060148

Follow this and additional works at: https://digitalcommons.fiu.edu/etd

Part of the Geology Commons

\section{Recommended Citation}

Chau, Kevin Xavier, "Mineral chemistry and origin of the olivine-rich zone of the Palisades sill" (2009). FIU Electronic Theses and Dissertations. 2116.

https://digitalcommons.fiu.edu/etd/2116

This work is brought to you for free and open access by the University Graduate School at FIU Digital Commons. It has been accepted for inclusion in FIU Electronic Theses and Dissertations by an authorized administrator of FIU Digital Commons. For more information, please contact dcc@fiu.edu. 


\section{FLORIDA INTERNATIONAL UNIVERSITY \\ Miami, Florida}

MINERAL CHEMISTRY AND ORIGIN OF THE OLIVINE-RICH ZONE OF THE

PALISADES SILL

A thesis submitted in partial fulfillment of the

requirements for the degree of

MASTER OF SCIENCE

in

GEOSCIENCES

by

Kevin Xavier Chau

2009 
To: Dean Kenneth Furton

College of Arts and Sciences

This thesis, written by Kevin Xavier Chau, and entitled Mineral Chemistry and Origin of the Olivine-rich Zone of the Palisades Sill, having been approved in respect to style and intellectual content, is referred to you for judgment.

We have read this thesis and recommend that it be approved.

Grenville Draper

Rosemary Hickey-Vargas

Andrew Macfarlane

Gautam Sen, Major Professor

Date of Defense: July 15, 2009

The thesis of Kevin Xavier Chau is approved.

Dean Kenneth Furton College of Arts and Sciences

Dean George Walker University Graduate School

Florida International University, 2009 
(C) Copyright 2009 by Kevin Xavier Chau

All rights reserved. 


\section{ACKNOWLEDGMENTS}

I would like to thank Dr. Gautam Sen for his help, enthusiasm, and respect. I could not have done this work had it not been for his ability to teach and encourage, while also allowing me the freedom to conduct research on a subject of my choosing. I would also like to thank him for the amount of work he has put in to help me in this project.

I would also like to thank my committee members, Grenville Draper, Rosemary Hickey-Vargas, and Andrew Macfarlane, for their thoughts, input, and assistance. They have provided me with invaluable advice and knowledge, and this work would not have been half as good without them.

Finally, I would like to thank my family for their love and support, without whom I would not have been able to pursue a career in science and research. And Lola, for reminding me what is important. 
ABSTRACT OF THE THESIS

MINERAL CHEMISTRY AND ORIGIN OF THE OLIVINE-RICH ZONE OF THE

\section{PALISADES SILL}

by

Kevin Xavier Chau

Florida International University, 2009

Miami, Florida

Professor Gautam Sen, Major Professor

The Palisades Sill contains an olivine-rich zone that has attracted scientific attention for over one hundred years. Despite the amount of focus, a definitive explanation for the origin of this layer has not been reached. Through the use of detailed petrographic analyses and electron microscopy, the aim of this study was to collect data on mineral phases from the Palisades Sill in order to better understand the history. Extremely broad ranges in mineral compositions indicate that the olivine-rich zone evolved through in situ equilibrium crystallization, implying that it was injected once the main body of the sill had already been emplaced and partly solidified, a result that confirms certain previous work. 
$\begin{array}{ll}\text { I. INTRODUCTION } & 1\end{array}$

$\begin{array}{ll}\text { II. PREVIOUS WORK } & 6\end{array}$

$\begin{array}{ll}\text { III. METHODS } & 14\end{array}$

$\begin{array}{lr}\text { IV. PETROGRAPHY } & 16\end{array}$

$\begin{array}{ll}\text { Chill Margin } & 16\end{array}$

Interior of the Sill $\quad 17$

Olivine-rich Zone $\quad 19$

Summary and Discussion of Petrography 21

V. GEOCHEMISTRY AND MINERAL CHEMISTRY OF THE PALISADES

SILL WITH EMPHASIS ON THE OLIVINE-RICH ZONE 28

Olivine $\quad 30$

Plagioclase Feldspar $\quad 34$

Pyroxenes $\quad 35$

Summary and Discussion of Geochemistry and Mineral Chemistry 36

$\begin{array}{ll}\text { VI. DISCUSSION } & 46\end{array}$

Magma Mixing and the Olivine-rich Zone $\quad 48$

VII. CONCLUSIONS 52

Sequence of Events $\quad 53$

Future Work $\quad 54$

LIST OF REFERENCES $\quad 56$

$\begin{array}{lr}\text { APPENDICES } & 59\end{array}$ 


\section{LIST OF FIGURES}

FIGURE

PAGE

1. The Central Atlantic Magmatic Province ............................................

2. Location map of the Palisades Sill...............................................

3. Outcrop of the Palisades Sill...................................................... 5

4. Mineral assemblage of the Palisades Sill compared to height.......................

5. Vertical variation of whole rock Mg\# of the Palisades Sill...........................................11

6. Photomicrograph of the chill margin........................................24

7. Photomicrograph of the interior of the sill........................................

8. Photomicrograph of the interior of the sill....................................... 25

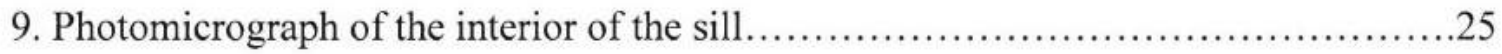

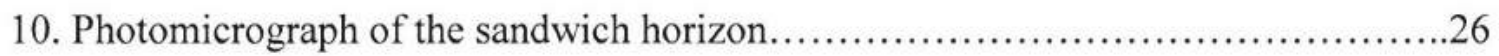

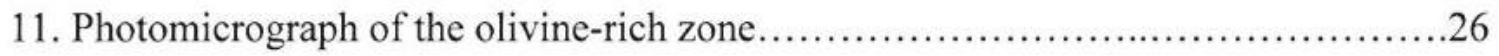

12. Photomicrograph of the olivine-rich zone ...................................27

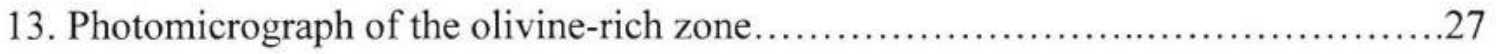

14. Whole rock $\mathrm{TiO}_{2}$ vs. height in the Palisades Sill...............................29

15. Whole rock $\mathrm{Na}_{2} \mathrm{O}+\mathrm{K}_{2} \mathrm{O}$ vs. height in the Palisades Sill.........................29

16. Forsterite content vs. pseudo-stratigraphic height................................. 38

17. Frequency graphs showing forsterite content in samples from the ORZ .............39

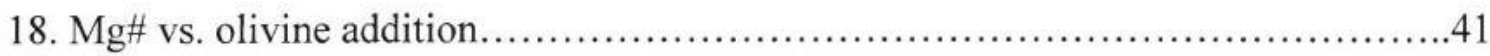

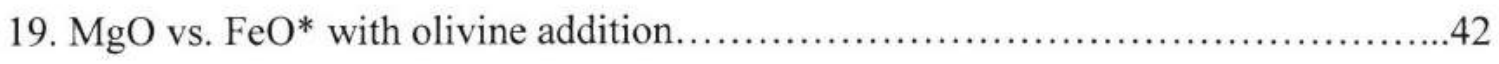

20. Anorthite content vs. pseudo-stratigraphic height...............................43

21. Frequency graphs showing anorthite content in samples from the ORZ....................44 
22. Pyroxene data from samples of the ORZ plotted on pyroxene quadrilaterals.........45 
CHAPTER I

\section{INTRODUCTION}

The Palisades Sill is a large diabase sill that was emplaced as part of a $200 \mathrm{Ma}$ large igneous province known as the Central Atlantic Magmatic Province (CAMP; Figure 1) during the opening of the Mid-Atlantic Ocean (McHone and Butler, 1984; Marzoli et al., 1999). This 300 meter-thick sill outcrops in New York and New Jersey (Figure 2) where it is thought to have fed the Watchung Mountain basalts of New Jersey. Longregarded as a classic example of in situ igneous differentiation, the Palisades Sill has been studied extensively for over one hundred years (Lewis, 1908a; Walker, 1940; Erickson and Kulp, 1961; Walker, 1969; Dallmeyer, 1975; Shirley, 1987; Dunning and Hodych, 1990; Steiner et al., 1992). Its prominence and ideal location along the banks of the Hudson River and its accessibility, coupled with its striking physical presence (the cliffs have been known as The Palisades for hundreds of years; Figure 3), have drawn generations of researchers to this intrusion.

The upper and lower boundaries of the Palisades sill are marked by an upper and a lower chill margin along the contacts with the sedimentary wall rocks above and below Chill margin rocks are exceptionally fine-grained relative to the interior of the sill because such rocks formed by quick quenching of the magma along the cooler wall rocks. The interior rocks are moderately coarse-grained, ranging from $1 \mathrm{~mm}$ to $20 \mathrm{~mm}$ in length, and exhibit classic diabasic texture. The most differentiated granophyric rocks form what is known as the Sandwich Horizon, roughly $50 \mathrm{~m}$ below the upper chill margin (Walker, 1969). 


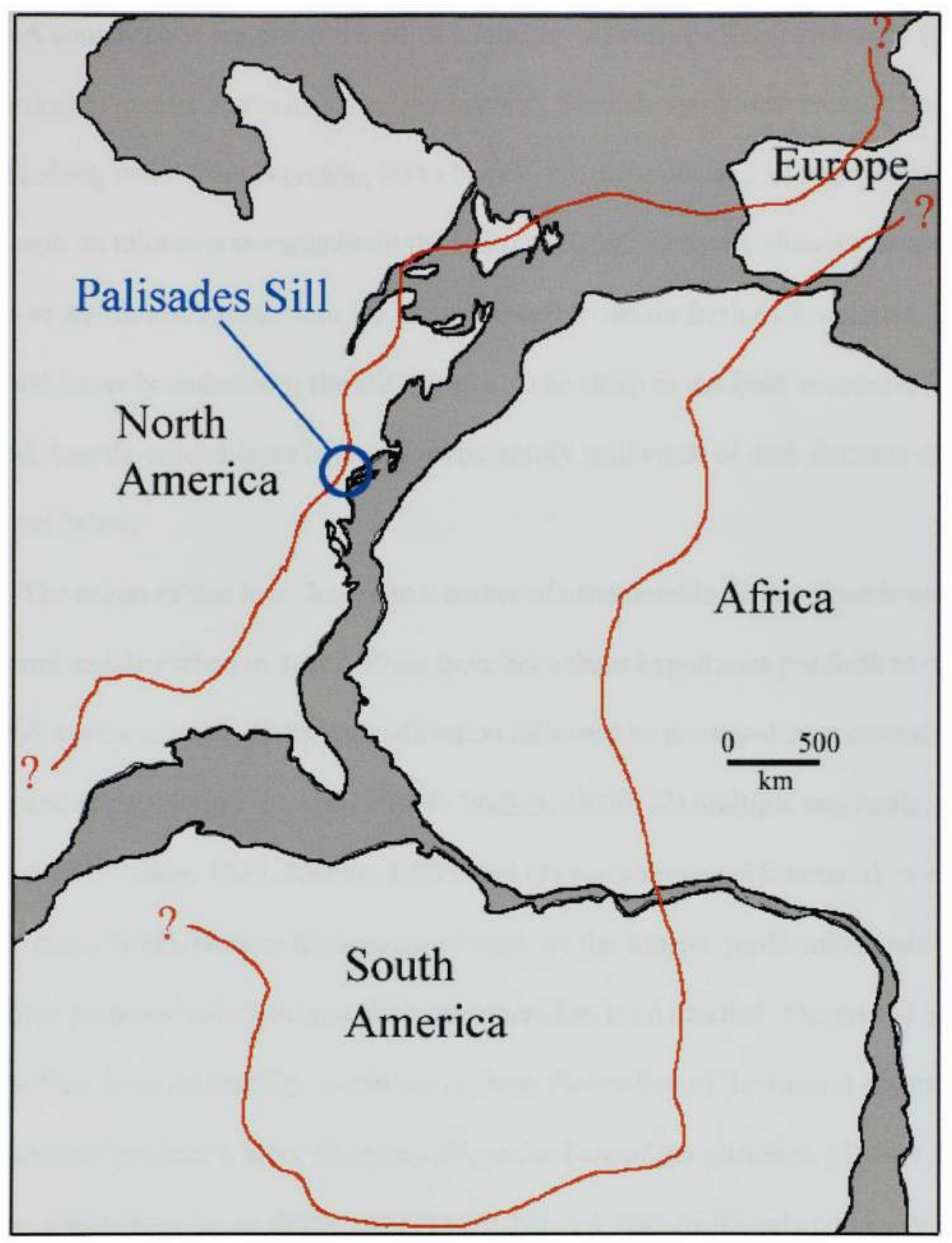

Figure 1. The Central Atlantic Magmatic Province. This is a plate reconstruction showing the present-day continents at $200 \mathrm{Ma}$ with the approximated extent of the Central Atlantic Magmatic Province outlined in red. The location of the Palisades Sill is marked in the blue circle. Adapted from McHone (2000). 
A conspicuous feature of the sill is a laterally extensive olivine-rich zone (ORZ) that occurs ten meters above its lower contact with the underlying wall rocks. The ORZ is exposed along strike from Bayonne, $\mathrm{NJ}$ to Nyack, $\mathrm{NY}$ for a distance of approximately 50 $\mathrm{km}$, though its thickness is variable. In the field, the ORZ is heavily altered to clay, and one has to dig almost a meter into the intrusion wall to obtain fresh rock samples. The upper and lower boundaries of the ORZ appear to be sharp in the field, recognized as a recessed, heavily eroded layer in an otherwise sturdy wall made of dark diabasic rocks above and below.

The origin of this layer has been a matter of considerable debate since it was first discovered and described in detail. There have been three hypotheses put forth to explain the ORZ's presence: (1) olivine crystallization followed by density-driven crystal settling and accumulation (Lewis, 1908; F. Walker, 1940), (2) multiple magmatic injections (K. Walker, 1969; Shirley, 1987), and (3) a mathematical internal flow model (Steiner et al., 1992). Despite the amount of work on the subject, problems remain with each of the proposed solutions and little agreement has been reached. The crystal settling model suffers from an inability to explain (1) how the settling of the earliest-crystallized olivines would produce a layer 10 meters above the base of the intrusion, (2) why the contacts of this layer are so sharp, and (3) why there are compositional and geochemical variations between the Palisades diabase and the olivine-rich diabase. The expectation is for the layer of olivine to be at the base, and for there to be a gradational boundary signaling the phasing out of the mineral's nucleation. The multiple injection model is problematic in that (1) no explanation has been offered as to how a relatively small magmatic pulse could lift $90 \%$ of the massive body of the Palisades (the approximate 
percent of the sill that lies above the ORZ) in order to create space for itself, and (2) why a secondary pulse would form a layer paralleling the orientation of the main intrusion instead of showing discordance. The internal flow model lacked the practicality of using actual samples from the Palisades Sill and relied exclusively on modeling. Additionally, flow segregation models have the same problem as the crystal-settling hypothesis in that they cannot explain the compositional evidence discussed above.

The question remains: did simple olivine crystallization and settling, a separate magmatic pulse(s), or perhaps other processes originate the olivine-rich zone? In this study, I present new petrographic information and detailed electron microprobe analyses of the constituent minerals of the ORZ. Work of this detail has not been conducted and may prove beneficial. One significant observation is that the constituent minerals show evidence of extreme differentiation at the scale of individual thin sections. Such local differentiation within the ORZ was more efficient than the bulk differentiation process, which was responsible for the entire chemical evolution trend within the Palisades sill. My main conclusions are: (1) the ORZ does indeed represent a separate magma pulse that was emplaced while the sill was largely solidified, and (2) compaction processes, which are normally an effective means of moving interstitial melt out of the surrounding mineral matrix, were not at all effective in the ORZ, which allowed the interstitial pockets of melt to persist and to allow extreme differentiation at the scale of a few millimeters. 


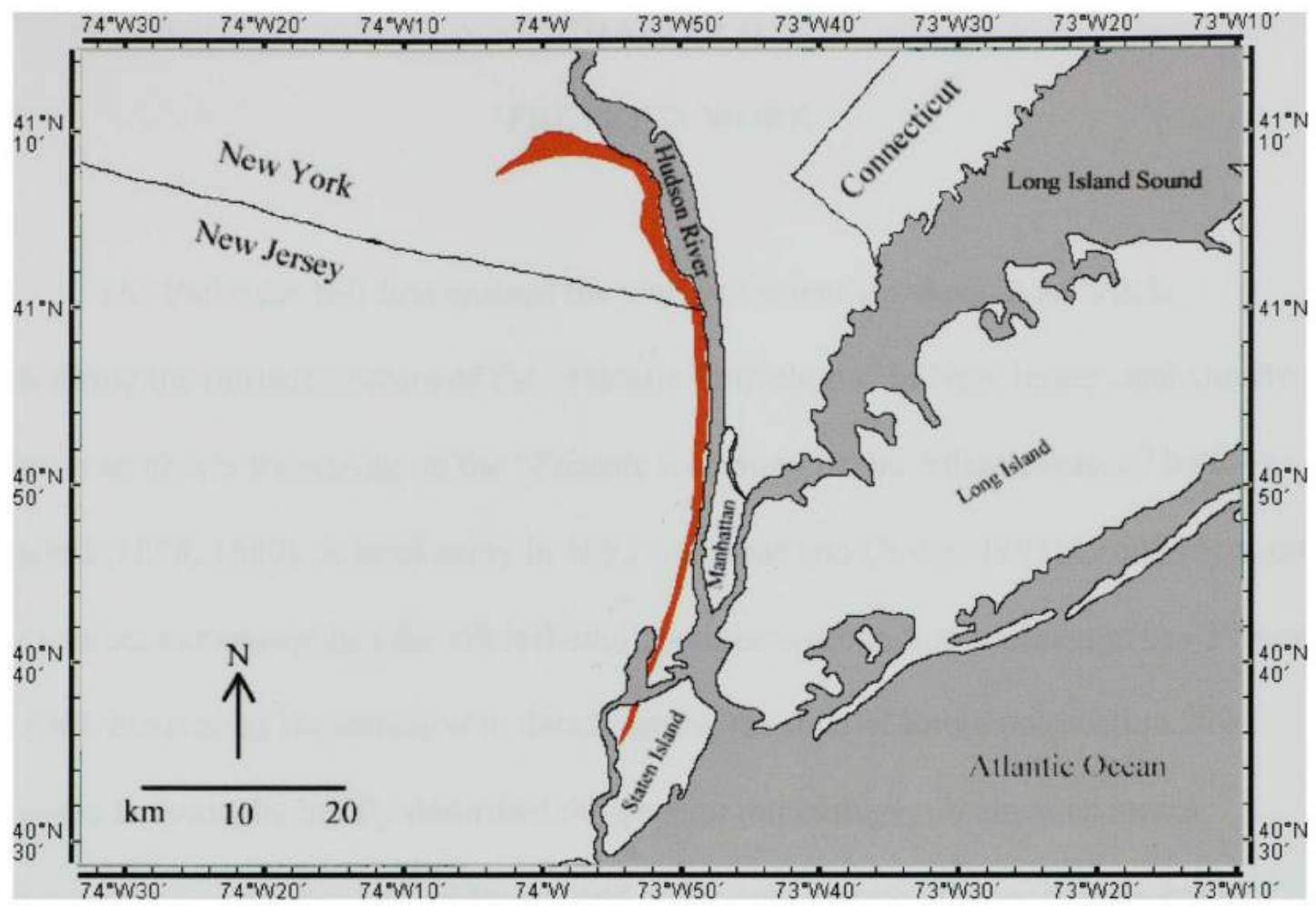

Figure 2. Location map of the Palisades Sill. The outcrop is colored in red.

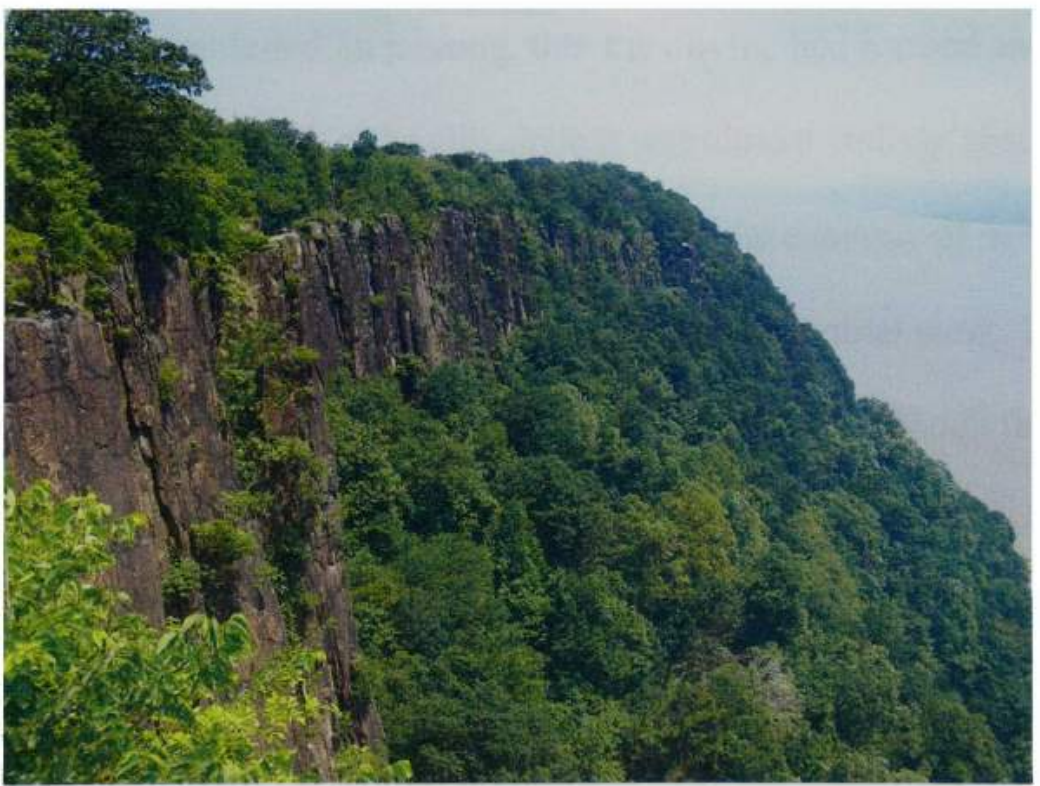

Figure 3. Outcrop of the Palisades Sill as seen from Palisades Interstate Park. View is to the north. The Hudson River is in the background. 


\section{CHAPTER II \\ PREVIOUS WORK}

The Palisades Sill first entered the world of scientific study in an article describing the intrusive nature of the "Triassic Trap sheets" of New Jersey, and shortly after in an article theorizing on the "Triassic formation of the Atlantic states," both by Russell $(1878,1880)$. A brief study in 1893 (Andreae and Osann, 1893) would focus on the contact metamorphism the sill inflicted upon the surrounding sediments. Lewis' work in 1908 focused on the intrusion in detail, setting the tone of future publications for decades to come; he briefly described the general mineralogy, obtained chemical compositions on augites and feldspars, and accurately reported the modal percent of olivine in, what he referred to as, the olivine-diabase ledge (up to 25\%) (Lewis, 1908b). Most significantly, he mentioned, in passing, that the olivine had formed and simply settled to its present horizon within the sill, since it was almost entirely absent from the rest of the intrusion; the Palisades Sill was touted as a prime example of in situ igneous differentiation and crystal settling (Lewis, 1908a). Bowen's seminal work, The Evolution of Igneous Rocks, included this concept, helping it spread further through the academic landscape (Bowen, 1928).

F. Walker (1940) conducted a detailed study of the sill with the aim of determining whether the olivine-rich layer was, in fact, a product of crystal settling. In addition to greatly expanding on Lewis's basic mineral assemblage, he described the field characteristics, obtained micrometric and chemical data, discussed the detailed petrology, and provided many figures and illustrations where before there had been none (F. 
Walker, 1940). One of Walker's most notable observations was the gradual increase of the $\mathrm{Na}$ component in plagioclase as one moved up the sill, with a reversal back to $\mathrm{Ca}$ enrichment near the upper chill margin, as well as an analogous relation with the Fe component in augite (F. Walker, 1940). F. Walker's argument in favor of gravitation settling was a textural comparison of samples from the olivine-rich zone and the main body; by showing that ratios of pyroxene to plagioclase in both cases were identical, he certified his conviction that the olivine-rich diabase was not a separately-intruded rock.

Erickson and Kulp (1961) determined the first age for the Palisades Sill using ${ }^{40} \mathrm{Ar} /{ }^{40} \mathrm{~K}$ dating. Their analysis of a biotite crystal from the sill provided an age of $190 \pm 5$ Ma, though their complete suite of analyses on whole rocks and minerals ranged from 142 to $202 \mathrm{Ma}$.

In 1969, Kenneth Walker took on the task or reinvestigating the sill, devoting an entire GSA Special Paper to this goal (K. Walker, 1969). His work started with the basics, describing mineralogy and petrography (Figure 4), and field relations, but moved on to newer techniques unavailable to prior workers, such as analyses of major and trace element profiles on minerals and whole-rock samples. Looking at the vertical columnar joints, K. Walker (1969) explained that, had the sill been emplaced and then tilted to its present orientation, the joints would also be tilted. The sill, then, had to have been emplaced and crystallized in its current orientation (this further works to prove that the Newark Basin and its border fault have also not significantly moved since the early Mesozoic) (K. Walker, 1969). The whole-rock geochemical trends show the general topheavy evolution described by F. Walker, but, most importantly, a significant reversal coinciding with the olivine-rich zone (Walker, 1969). With the advantage of more 
modern analytical techniques, K. Walker (1969) interpreted this as proof of a separate magmatic injection into the already-emplaced main body of the sill. Furthermore, using simple field observations, K. Walker (1969) argued that, were the olivine-rich layer truly the product of settling of first-forming olivine grains, they would not only lie closer to the lower contact of the sill, but the layer would be more uniform in location and in thickness. The inconsistent thickening and thinning of this layer coupled with its changing depth within the sill as a whole, argued $\mathrm{K}$. Walker, was proof of the inability of gravitational settling to explain its existence (Walker, 1969).

Dallmeyer (1975) used ${ }^{40} \mathrm{Ar}{ }^{39} \mathrm{Ar}$ dating on upper and lower chill margin samples, obtaining a date of $193 \pm 9 \mathrm{Ma}$. This fell within the previous range (Erickson and Kulp, 1961) and matched recently-calculated interpolations for the age of the Atlantic Ocean based on seafloor-spreading rates (Dallmeyer, 1975).

Puffer et al. (1982) worked on rocks from Rockland County, New York, where the northern-most portion of the sill is located. Aside from sampling the sill, they worked on basalt lava flows and a dike from the area. After comparing their geochemical data, they concluded that there was a definite relation between the Palisades Sill, the New City Park Dike, the Ladentown Basalt, and the Union Hill Basalt (Puffer et al., 1982). They proposed a sequence in which there were multiple pulses of magma intruded into the Palisades, some of which resulted in extruded basalts of varying compositions. Although a two-magma model is compatible with their results, Puffer et al. (1982) preferred a three-magma model, to allow for the compositional ranges and stratigraphic observations. Interestingly, though arriving at the same, multiple-injection theory for the sill as $\mathrm{K}$. 


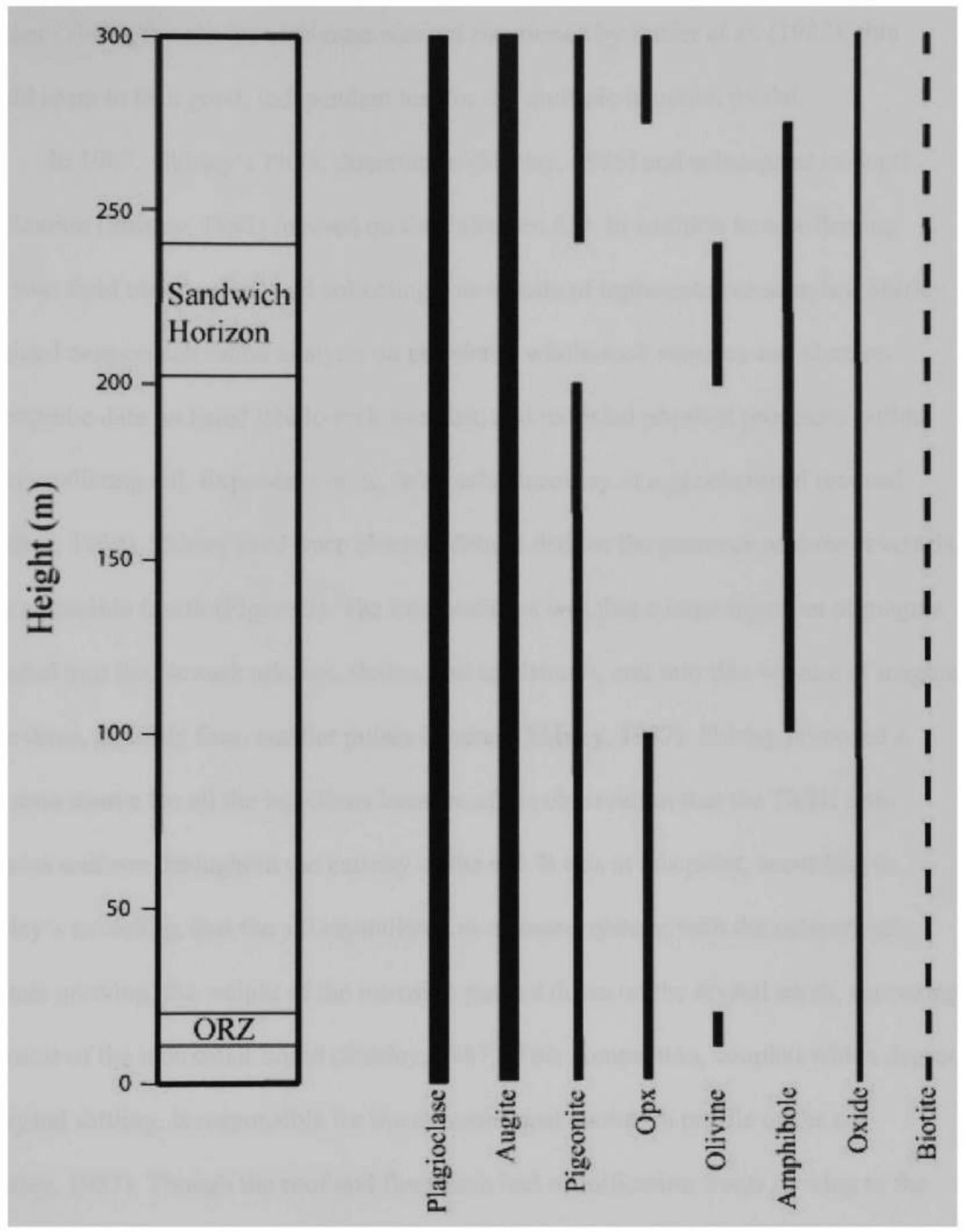

Figure 4. Schematic diagram showing the sections of the Palisades sill and the corresponding approximate mineral assemblage compared to pseudo-stratigraphic height. ORZ stands for olivine-rich zone, OPX for orthopyroxene. The relative width of the bars corresponds to modal abundances; the dashed line indicates very minor presence. The term pseudo-stratigraphy is used because the internal layering of the intrusion does not compose a true stratigraphic sequence. Adapted from Walker, 1969. 
Walker (1969), the olivine-rich zone was not mentioned by Puffer et al. (1982); this would seem to be a good, independent test for the multiple injection model.

In 1987, Shirley's Ph.D. dissertation (Shirley, 1986) and subsequent in-depth publication (Shirley, 1987) focused on the Palisades Sill. In addition to re-affirming previous field observations and collecting a new suite of representative samples, Shirley obtained neutron activation analysis on powdered whole-rock samples and electron microprobe data on fused whole-rock samples, and modeled physical processes within the crystallizing sill. Expanding on K. Walker's discovery of a geochemical reversal (Walker, 1969), Shirley used trace element data to deduce the presence of three reversals, with a possible fourth (Figure 5). The interpretation was that a large injection of magma intruded into the Newark arkoses, shales, and sandstones, and into this volume of magma were three, possibly four, smaller pulses injected (Shirley, 1987). Shirley proposed a common source for all the injections because of his observation that the $\mathrm{Th} / \mathrm{Hf}$ ratio remains uniform throughout the entirety of the sill. It was at this point, according to Shirley's modeling, that the sill crystallized as a closed system; with the network of crystals growing, the weight of the intrusion pushed down on the crystal mesh, squeezing out most of the interstitial liquid (Shirley, 1987). This compaction, coupled with a degree of crystal settling, is responsible for the asymmetrical evolution profile of the sill (Shirley, 1987). Though the roof and floor both had solidification fronts moving to the center of the intrusion, the interstitial liquid in the lower section was pushed higher up through successive compaction and accumulation of crystals at the base of the liquid lens until the final location of the last liquid was $50 \mathrm{~m}$ from the top contact (Shirley, 1987). 


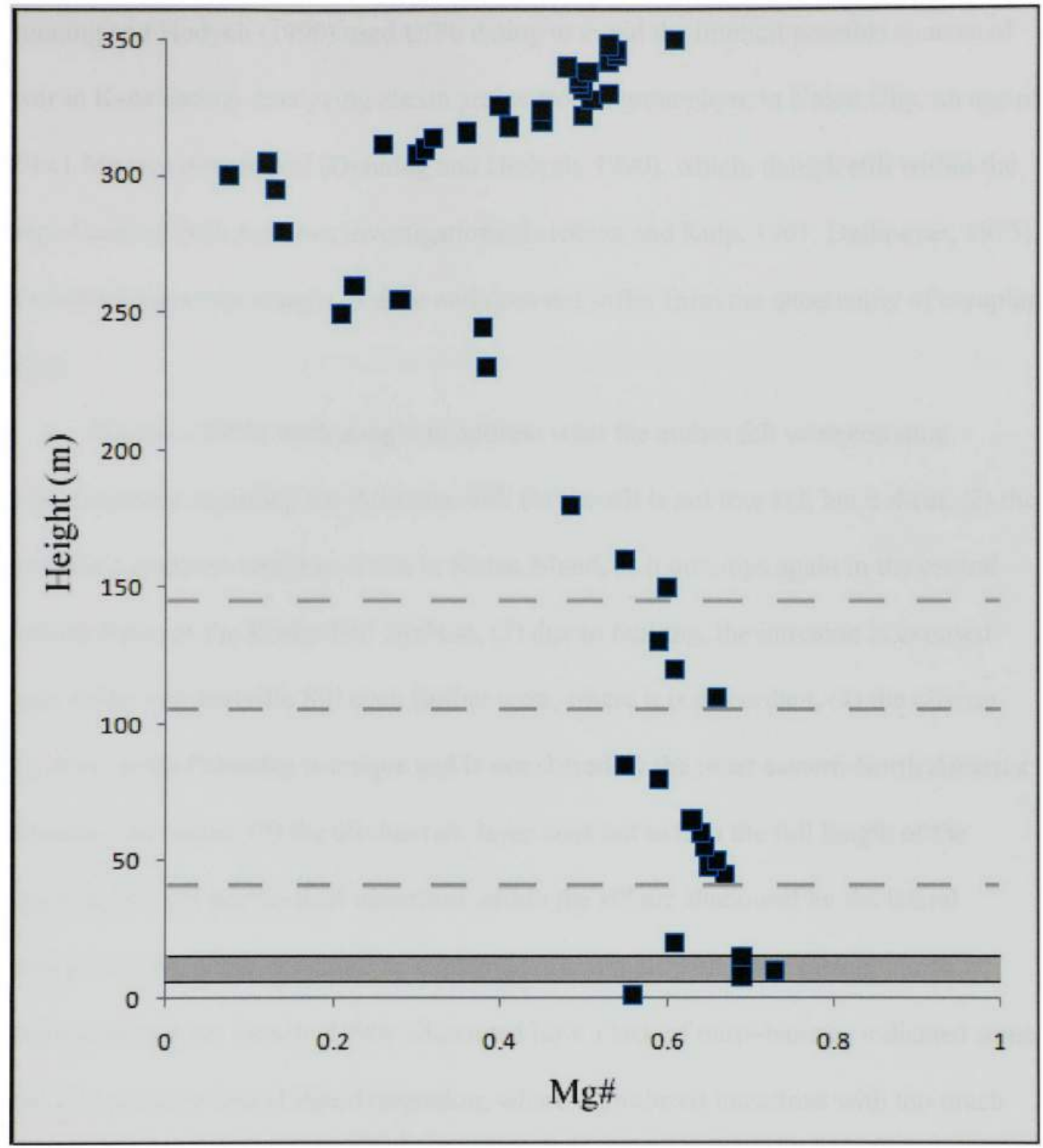

Figure 5. Vertical variation of whole rock $\mathrm{Mg} \#$ in the Palisades Sill. Geochemical reversals, in which $\mathrm{Mg} \#$ increases before continuing to decrease, are observed at 10 meters, 45 meters, 110 meters, and 145 meters (dashed, gray lines). The $45 \mathrm{~m}$ and $120 \mathrm{~m}$ reversals are interpreted to be a result of overlap in sampling due to a fault undetected at the time. The gray bar represents the olivine-rich zone, corresponding with the $10 \mathrm{~m}$ reversal. Adapted from Shirley (1987). 
Dunning and Hodych (1990) used U/Pb dating to avoid the implicit possible sources of error in $\mathrm{K}-\mathrm{Ar}$ dating. Analyzing zircon grains from a granophyre in Union City, an age of $201 \pm 1$ Ma was determined (Dunning and Hodych, 1990), which, though still within the range found in both previous investigations (Erickson and Kulp, 1961; Dallmeyer, 1975), has a much narrower margin of error and does not suffer from the uncertainty of escaping argon.

Husch's (1990) work sought to address what the author felt were common misconceptions regarding the Palisades Sill: (1) the sill is not true sill, but a sheet, (2) the intrusion's southern terminus is not in Staten Island, as it outcrops again in the central Newark Basin as the Rocky Hill Diabase, (3) due to faulting, the intrusion is exposed again as the Lambertville Sill even further west, where it is discordant, (4) the olivinerich zone in the Palisades is unique and is not shared by the other eastern North America Mesozoic intrusions, (5) the olivine-rich layer does not extend the full length of the exposure, and (6) any vertical variations within the sill are shadowed by the lateral variations along strike, a feature he explained is common with other eastern North America intrusions. Husch (1990) illustrated how a lack of mass-balance indicated some sort of large-scale lateral liquid migration, where it produced intrusions with too much pyroxene cumulates without enough granophyre and intrusions with too much granophyre without enough pyroxene cumulates, neither of which was in equilibrium with their respective chill margin compositions. His final observation dealt with his determination that bulk-rock geochemistry in the Palisades intrusion was not consistent with significant olivine fractionation (Husch, 1990). 
Steiner et al. (1992) developed a cumulus-transport-decompression (CTD) model to explain not only the olivine zone, but the general lateral discrepancies as well. This model made use of density, velocity, and accumulation calculations for the Cumulus portion, and then applied the results to determine extent of crystal movement for the Transport portion, finally summing any late-stage effects in the Decompression portion (Steiner et al., 1992). Steiner et al. (1992) point out that the olivine-rich zone does not occur in the Upper Nyack section of the sill, at its extreme north, but the presence of a hypersthene and pigeonite dolerite layer is interpreted to be its analog. 


\section{METHODS}

The samples used in this study were collected and prepared by Dr. H. Richard Naslund and Matthew Gorring from an outcrop under the George Washington Bridge in Fort Lee, New Jersey as part of Gorring's M.A. Thesis (1992). 10 - $15 \mathrm{~kg}$ fragments were obtained to ensure homogeneity and their stratigraphic heights were carefully measured. The rock fragments were then cut, polished, mounted onto glass slides, and ground into $30 \mu$ m-thick thin sections. In this study, the word "sample" will refer to these prepared thin sections. The polished thin sections were then examined using a three step procedure: they were first examined with a petrographic microscope. Based on such examination areas of interest were selected for electron microprobe imaging and analysis. Selected areas were first imaged with a back-scattered electron (BSE) detector, which gave a micron-scale resolution of chemical variation (more precisely, mean atomic number variation) within and between grains of individual mineral species. In the third step, in situ microchemical analyses on fixed spots were obtained.

Petrographic analysis was conducted using petrographic microscopes, primarily an Olympus BH-2, utilizing both plane-polarized light and cross-polarized light. The principle objectives used were $4 \mathrm{x}$ and $10 \mathrm{x}$, though a $1 \mathrm{x}$ objective was used for visual estimation of modal abundances of the different phases. Photomicrographs were taken with a QImaging MicroPublisher 3.3 RTV microscope camera, which had the effect of producing images at twice the magnification seen through the oculars. 
Back-scattered electron images and in situ microchemical analyses of minerals were obtained with a JEOL JXA-8900 electron microprobe housed in the Florida Center for Advanced Electron Microscopy (FCAEM). The analytical conditions were $15 \mathrm{kV}$ accelerating potential, 10 nanoamp beam current, and $\sim 1 \mu \mathrm{m}$ beam diameter. Collection times were 10 seconds for $\mathrm{SiO}_{2}, \mathrm{MgO}, \mathrm{FeO}, \mathrm{CaO}, \mathrm{Al}_{2} \mathrm{O}_{3}, \mathrm{~K} 2 \mathrm{O}$, and $\mathrm{P}_{2} \mathrm{O}_{5}$, and 15 seconds for $\mathrm{Na}_{2} \mathrm{O}, \mathrm{MnO}, \mathrm{NiO}, \mathrm{TiO}_{2}$, and $\mathrm{Cr}_{2} \mathrm{O}_{3}$. Two sigma uncertainty is $+2 \%$ for the major elements and $5-8 \%$ for the volatile elements ( $\mathrm{Na}$ and $\mathrm{K})$.

A stepwise procedure was followed. Standard 9 element analyses of multiple grains (core and rim on each grain) of an individual mineral were first obtained in order to gain a sense of the overall chemical variation within an individual sample. In an effort to avoid any interference from contamination, analyzed spots were selected away from fractures or alteration areas. Unless zoning was detected, analyses consisted of one spot per grain. In case of zoning, core-to-rim line scans with 0.5 micron steps were analyzed. Olivine grains were analyzed for $\mathrm{SiO}_{2}, \mathrm{MgO}, \mathrm{FeO}, \mathrm{CaO}$, and $\mathrm{NiO}$, while plagioclase, clinopyroxene, orthopyroxene, biotite, ilmenite and iron oxide were analyzed for $\mathrm{SiO}_{2}$, $\mathrm{MgO}, \mathrm{FeO}, \mathrm{CaO}, \mathrm{Na}_{2} \mathrm{O}, \mathrm{Al}_{2} \mathrm{O}_{3}, \mathrm{MnO}, \mathrm{NiO}, \mathrm{K} 2 \mathrm{O}, \mathrm{TiO}_{2}$, and $\mathrm{Cr}_{2} \mathrm{O}_{3}$; apatite was also analyzed for $\mathrm{P}_{2} \mathrm{O}_{5}$. Quality of the analyses were determined on the basis of oxide wt $\%$ totals and structural formulae calculated on the basis of fixed oxygen atoms: for example, in case of olivine, only analyses that had a total of $100 \pm 1$ oxide total and a cation total of 3 for 4 fixed oxygen anions were selected. For the hydrous phases, the oxide totals were around $98 \%$ because of the presence of $(\mathrm{OH})$ in the structure of such minerals. 


\section{CHAPTER IV}

\section{PETROGRAPHY}

With the exception of the extremely fine-grained samples from the chill margins, individual crystals range from 0.5 to $20 \mathrm{~mm}$ in length throughout the interior of the sill, making it very easy to gather textural and microchemical information on the individual rock samples. Below is a petrographic description of some selected samples from the sill.

\section{Chill Margin}

Samples from the lower chill margin (Figure 6) are aphanitic. The groundmass is generally uniform, consisting of sub-millimeter $(\sim 0.1 \mathrm{~mm}$ long, $\sim 0.05 \mathrm{~mm}$ wide) plagioclase crystals $(\sim 50 \%)$, pyroxene $(\sim 30 \%)$, and quenched glass $(\sim 20 \%)$; the pyroxenes in the groundmass seem to occur in both the clinopyroxene and orthopyroxene variety, but their minute size makes it difficult to accurately determine the distribution. Upon closer inspection at higher magnification, some areas display a higher concentration of plagioclase, while others show a higher glass and pyroxene percentage, but within the scale of a thin section slide as a whole there is uniformity. There is a sporadic presence of microphenocrysts ( $<5 \%$ by mode), the phase assemblage consisting primarily of plagioclase and clinopyroxene, with minor orthopyroxene and olivine; interestingly, olivine is not present in the groundmass assemblage.

Plagioclase microphenocrysts are subhedral ( $\sim 0.5 \mathrm{~mm}$ long and $\sim 0.3 \mathrm{~mm}$ wide); their shapes are subhedral, and their edges are always partially corroded. A few of the 
grains have visible zoning; in one instance, the outer zone is strongly corroded while the inner zone is intact. Such corrosion is indicative of disequilibrium with the magma.

Augite phenocrysts are euhedral to subhedral and prismatic $(0.6 \mathrm{~mm}$ by $0.4 \mathrm{~mm})$. and show minor evidence of reaction with the melt along their boundaries. They occasionally form clusters and show minor resorption around the edges. Undulatory or wavy extinction is common; strain is indicative of stress. There are significantly fewer orthopyroxene microphenocrysts $(<5 \%)$. They are significantly more resorbed along the edges. They tend to be blocky and subhedral to anhedral $(0.5 \mathrm{~mm}$ by $0.5 \mathrm{~mm})$. A single orthopyroxene crystal is rimmed by clinopyroxene.

The olivine grains are heavily altered, at times completely altering to iddingsite. The ones that are relatively unaltered are anhedral. In one spot, five small grains form a glomeroporphyritic cluster.

\section{Interior of the Sill}

The thin sections analyzed from the interior of the Palisades Sill (Figures 7, 8, 9) are generally similar to each other in terms of grain size and texture, with the exception of the olivine-rich zone and sandwich horizon samples. The samples are characterized by sub-ophitic texture defined by partial inclusion of euhedral tabular to lath-shaped plagioclase crystals by augite crystals. Closer to the upper and lower chill zones, plagioclase and pyroxene crystals are around $0.5 \mathrm{~mm}$ long and 0.1 to $0.3 \mathrm{~mm}$ wide; the crystals progressively increase in size toward the center of the intrusion, reaching a maximum of $2-3 \mathrm{~mm}$ in length and $0.5-1 \mathrm{~mm}$ in width. 
Plagioclase grains are lath-shaped or stubby, they often show twinning, though not always; they constitute about $35 \%$ by mode . Augite crystals, about $35 \%$ by mode, are generally euhedral with some showing slight resorption along grain boundaries. Many augite crystals show exsolution along the $\{100\}$ plane, indicating the exsolution of orthopyroxene.

While plagioclase and augite are the most dominant phases, orthopyroxene and inverted pigeonite are also present, comprising $20 \%$ or less of the rock. The orthopyroxene grains are noticeably subhedral to anhedral and are slightly larger (4-5 $\mathrm{mm}$ by $2-3 \mathrm{~mm}$ ) than the coexisting plagioclase grains or augite crystals. Many orthopyroxene grains show exsolution of augite along $\{100\}$ (Figure 7).

Inverted pigeonite crystals comprise less than $10 \%$ by mode and are identified on the basis of their herringbone exsolution; exsolved augite can be seen parallel to the $\{001\}$ plane. The grains are $1-2 \mathrm{~mm}$ long and $0.5 \mathrm{~mm}$ wide and are subhedral. The exsolution lamellae are well-developed and often cover almost the entirety of the crystals (Figure 8).

Minor phases comprising less than $5 \%$ include olivine, biotite, apatite, opaque oxides, and interstitial granophyre.

Olivine is rarely found in the main body of the Palisades Sill, although it is present in small amounts ( $<2 \%$ by mode) in the lowermost and uppermost levels of the intrusion. Where present, it is generally small $(\sim 0.5 \mathrm{~mm})$ and equant.

Biotite is extremely minor, less than $1 \%$ by mode, and some thin sections do not contain it at all. It is small $(\sim 0.5 \mathrm{~mm})$ and flaky in appearance and is often seen mounted around other minerals. Apatite is also quite sparse $(<1 \%$ by mode) and is extremely small 
$(<0.1 \mathrm{~mm})$. The oxide phases, consisting of iron oxide (hematite or magnetite) and ilmenite, are small in size $(\sim 0.5 \mathrm{~mm})$ and do not make up more than $1 \%$ by mode.

Microgranophyre (Figure 9) is ubiquitous, its modal percentage varies from about $1 \%$ in the chill margins and the extreme lower and upper levels to about $10 \%$ in samples nearing the sandwich horizon. The size of the microgranophyre patches is small at the chill boundaries $\left(\sim 0.5 \mathrm{~mm}^{2}\right)$ and is about $4 \mathrm{~mm}^{2}$ toward the interior.

The sandwich horizon, though a section of the interior of the sill, is sufficiently different to warrant separate discussion. Sandwich horizon rocks are much coarsergrained (Figure 10) with a much greater abundance of microgranophyre $(20 \%)$ relative to the other parts of the sill. The plagioclase crystals ( $25 \%$ by mode) are larger (up to 20 $\mathrm{mm}$ by $10 \mathrm{~mm}$ ) and more tabular. Augite crystals ( $25 \%$ by mode) are bladed (up to 20 $\mathrm{mm}$ by $5 \mathrm{~mm})$.

A fayalitic variety of olivine occurs interstitially. The crystals are small ( $3 \mathrm{~mm})$ and equant and are often resorbed with subhedral forms. The maximum modal percentage observed is about $10 \%$. Amphibole grains are minor and anhedral; they reach up to $1 \mathrm{~mm}$ along the longest axis.

Other minor phases, comprising less than $5 \%$ by mode, include alkali feldspar, biotite, apatite, and oxides.

\section{Olivine-rich Zone}

The olivine-rich zone (Figure 11) is well known for its high modal content (15 $25 \%$ ) of olivine. There are two morphologically distinct populations of olivine: a larger $\left(\sim 1 \mathrm{~mm}^{2}\right)$ euhedral group and a small $\left(\sim 0.1 \mathrm{~mm}^{2}\right)$ anhedral group; the contrast in 
appearance indicates that the two populations are two separate generations, though both have the same compositional range $\left(\mathrm{Fo}_{67}-\mathrm{Fo}_{81}\right.$; olivine chemistry presented in the next chapter). The larger crystals form chains and are included by plagioclase, augite, and orthopyroxene crystals. These chains show no preference to host crystal interiors or interstices. They can extend for several millimeters at a time, branching off in different directions and across different mineral crystals. The smaller anhedral olivine grains can also be found within these chains, though in much smaller quantities. More often, however, this latter group are occurs as isolated crystals within the cores of large plagioclase or pyroxene grains. On several occasions, a few of these small olivines are found within small $(<1 \mathrm{~mm}$-long) plagioclase crystals, which are in turn entirely enclosed by large orthopyroxenes (Figure 12). In one case, two small olivine grains appear to have a perfectly flat surface resting against the same twinning plane of a small, stubby plagioclase crystal (Figure 13). The olivine chains give the appearance of aligned cumulus crystals that were subsequently enclosed by the other phases.

Plagioclase and augite make up $60 \%$ of the rocks of the ORZ. Plagioclase forms laths ranging from $0.1 \mathrm{~mm}$ to $5 \mathrm{~mm}$ in their long dimension. They are often found entirely closed by augite and orthopyroxene. Augite crystals are more subhedral to equant $(1 \mathrm{~mm}$ to $2 \mathrm{~mm})$ and are generally free of the exsolution features that are so common in the specimens from the interior of the sill; only a handful display any exsolution.

Orthopyroxene crystals are larger $(4 \mathrm{~mm}$ by $3 \mathrm{~mm}$ ) and more anhedral than those found elsewhere in the sill. They comprise $30 \%$ of the rock, and as with augite, conspicuous exsolution is absent. 
As mentioned above, plagioclase grains are often enclosed entirely within augite, though they are often embedded within orthopyroxene as well. The uniform sizes and shapes observed within sections of the sill are not seen in samples from the olivine-rich zone; instead, plagioclase crystals range from $0.1 \mathrm{~mm}$ to $5 \mathrm{~mm}$, and while some are still euhedral, many display visibly resorbed boundaries in their anhedral shapes.

In the olivine-rich zone, minor phases occur in trace amounts and consist of biotite and $\mathrm{Fe}$ - and $\mathrm{Fe}-\mathrm{Ti}$-oxide minerals. Oxide grains are often rimmed by biotite. Interestingly, which are common throughout the sill, do not occur in the olivine-rich zone.

One sample, PS-14-90, is unique for the ORZ. It has an anomalously low olivine presence (only 7 grains) and displays strong exsolution in the pyroxenes. There is also more noticeable corrosion of many of the grains, indicating a higher degree of disequilibrium. It bears a stronger resemblance to samples from the sill's main body than from the olivine-rich zone, an observation that will be supported in the geochemistry chapter.

Summary and Discussion of Petrography

The following points are deduced from the observations in the petrographic portion of this study:

1. The sill is tholeiitic as evidenced by the presence of orthopyroxene and interstitial microgranophyre and quartz.

2. The presence of $2 \%$ modal percent olivine in the form of microphenocrysts in the chill margins indicates that the bulk sill magma was olivine-saturated. The 
occurrence of plagioclase, augite, and orthopyroxene suggests that the sill magma was multiphase saturated at low pressure $(\sim 3 \mathrm{kbar}$, based on the emplacement depth of the sill) and therefore could not have been a mantle-equilibrated primary magma.

3. The presence of biotite and amphibole, though in trace amounts, indicates that a hydrous component became important in the final stages of crystallization of the sill. Based on the observation that they are present throughout the entirety of the sill, it seems likely that the water is residual from crystallization of the bulk of the minerals in the sill and was not introduced from the wall rocks.

4. The exsolution features in the pyroxenes of the interior of the sill are consistent with extremely slow cooling of the sill after the magma had already solidified. The lack of exsolution features in the pyroxenes of the ORZ are consistent with more rapid cooling after solidification. Pyroxene thermometric estimates are discussed in the next chapter.

5. Granophyric intergrowth is generally accepted to represent residual pockets of evolved melt. Perfect compaction, as detailed by Shirley (1987), leads to complete extraction of the residual melt to the maximum differentiated zone within an intrusion (i.e., the sandwich horizon). The presence of the microgranophyre pockets distributed throughout the interior of the Palisades Sill is evidence that, though there is evidence of compaction, it was imperfect in that it was not able to extract all the interstitial melt and generate significant differentiation.

6. The conspicuous differences between the olivine-rich zone and the rest of the intrusion are as follows: (A) the high modal olivine in the ORZ, (B) the absence 
of granophyre in the ORZ and its common presence in the rest of the sill, and (C) the general lack of exsolution features in the pyroxenes of the ORZ while such features are common in the rest of the sill.

The origin of the olivine in the ORZ is a matter of some debate (as discussed earlier) and will be discussed further in Chapter VI. The lack of granophyre in the ORZ suggests that either the interstitial melt did not reach alkali feldspar + quartz saturation or the interstitial melt was driven out of the crystal network through compaction and filter pressing. The viability of these options will be discussed in Chapters V and VI. 


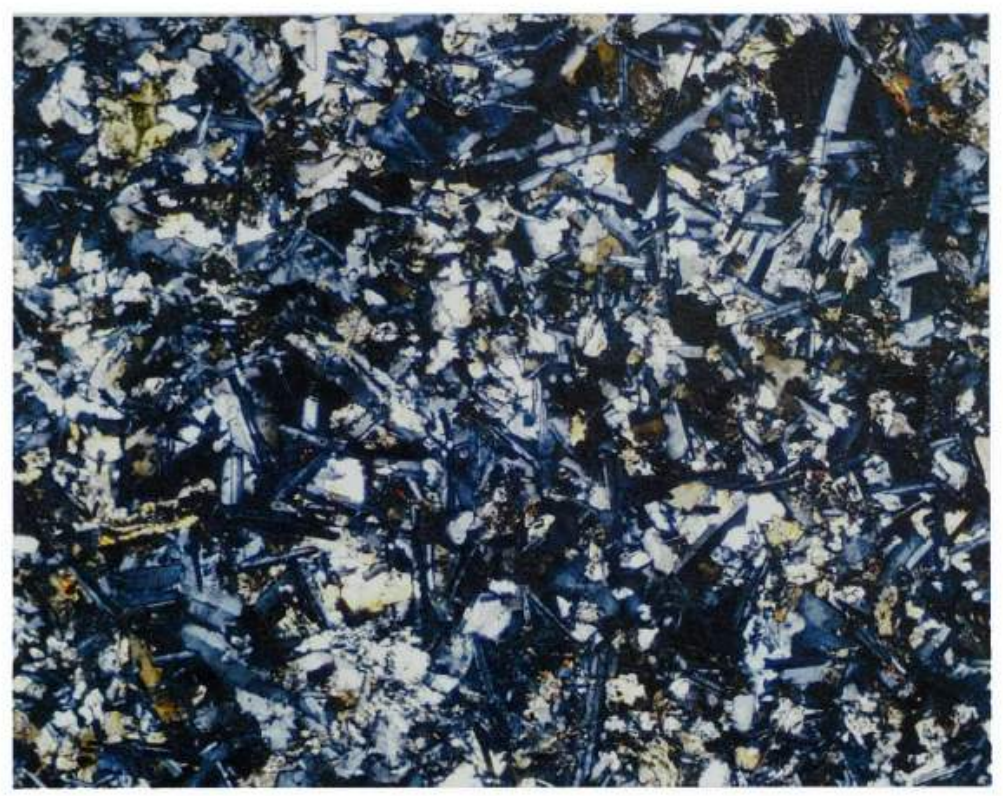

Figure 6. Photomicrograph of the chill margin, 40x, crosspolarized light. The groundmass is dominated by gray plagioclase crystals, yellow pyroxene crystals, and glass.

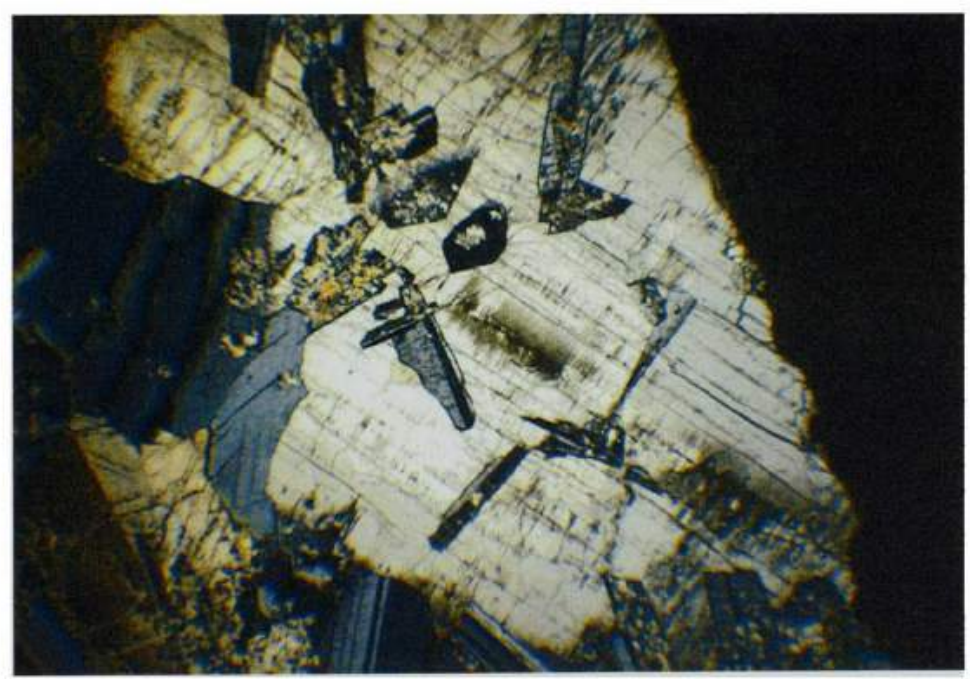

Figure 7. Photomicrograph of the interior of the sill, 40x, cross-polarized light. Fine exsolution lamellae are visible within the large, pale yellow orthopyroxene grain.

Various fragments of plagioclase can be seen within the opx. 


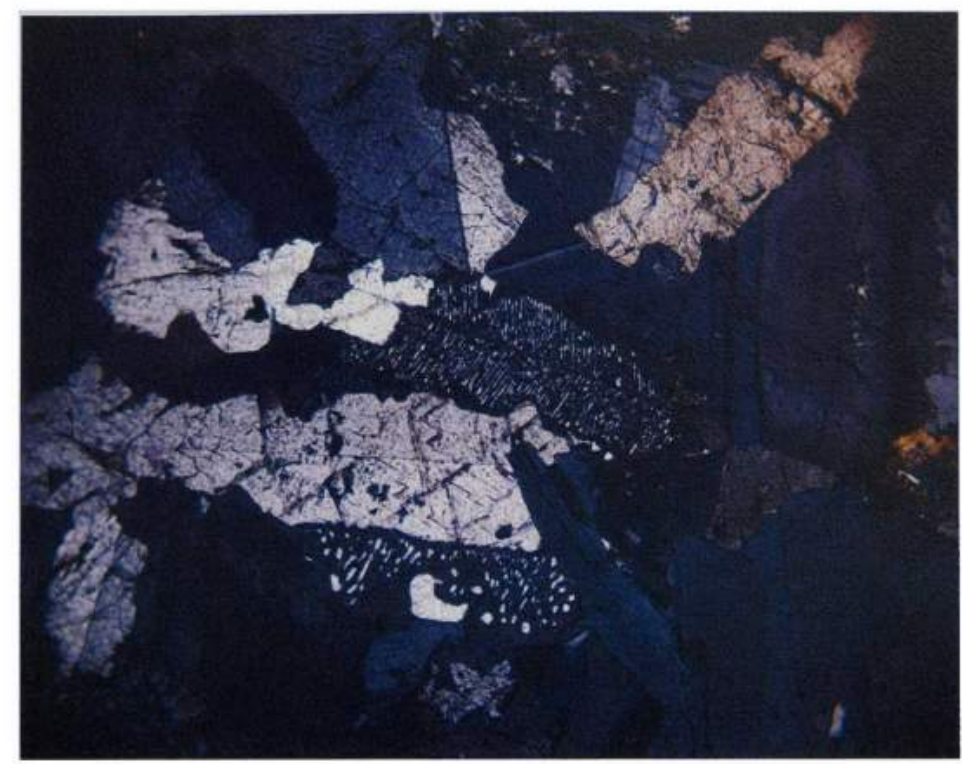

Figure 8. Photomicrograph of the interior of the sill, 40x, cross-polarized light. The center grain is an inverted pigeonite showing typical herringbone exsolution. The grains at the top left and right are plagioclase feldspar. The yellow grain at the top right is orthopyroxene.

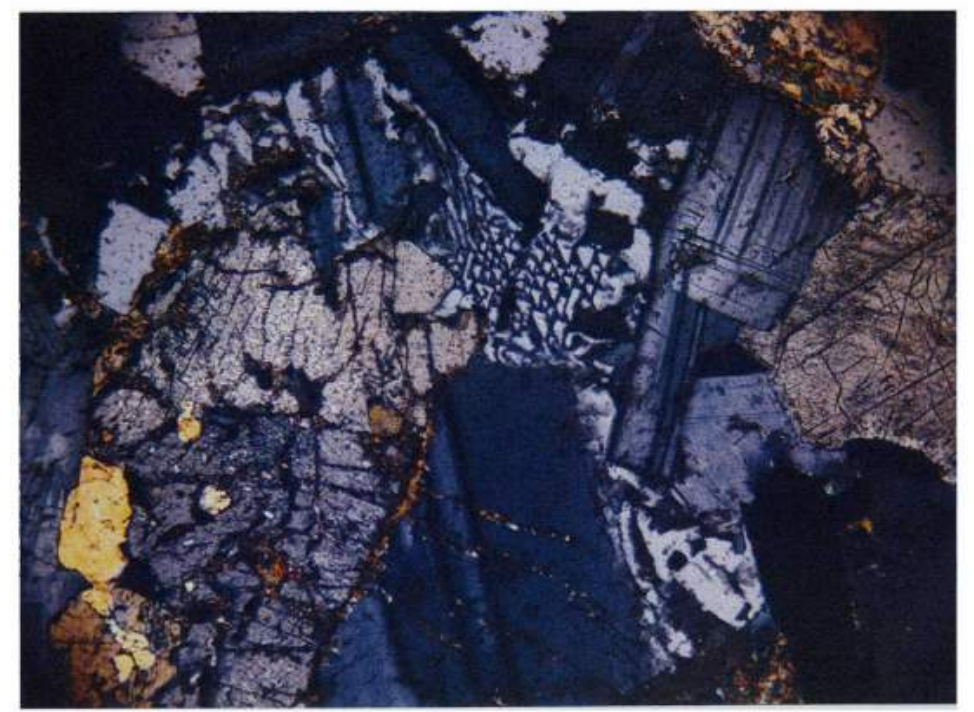

Figure 9. Photomicrograph of the interior of the sill, 40x, cross polarized light. The mottled patch in the upper center is granophyre. The dark gray crystals are plagioclase, the light gray are orthopyroxene. 


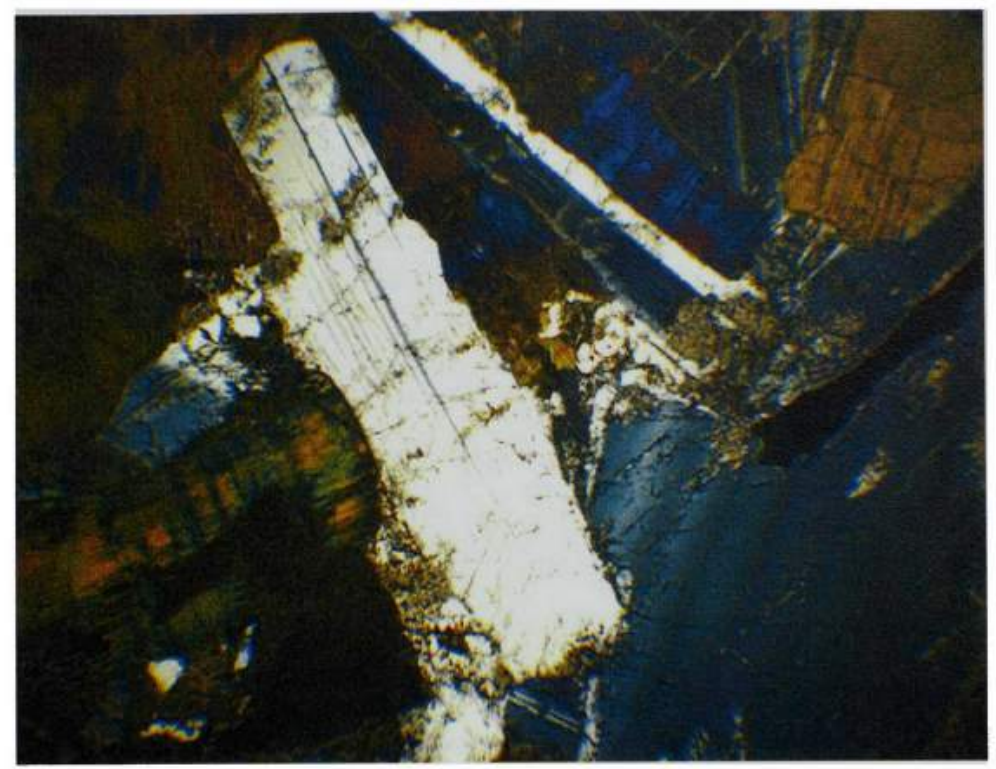

Figure 10. Photomicrograph of the sandwich horizon. The large, light gray grain in the center is plagioclase feldspar. The blue and yellow grains at top right and left are clinopyroxene showing exsolution. The dim, gray crystal at the bottom right is alkaline feldspar.

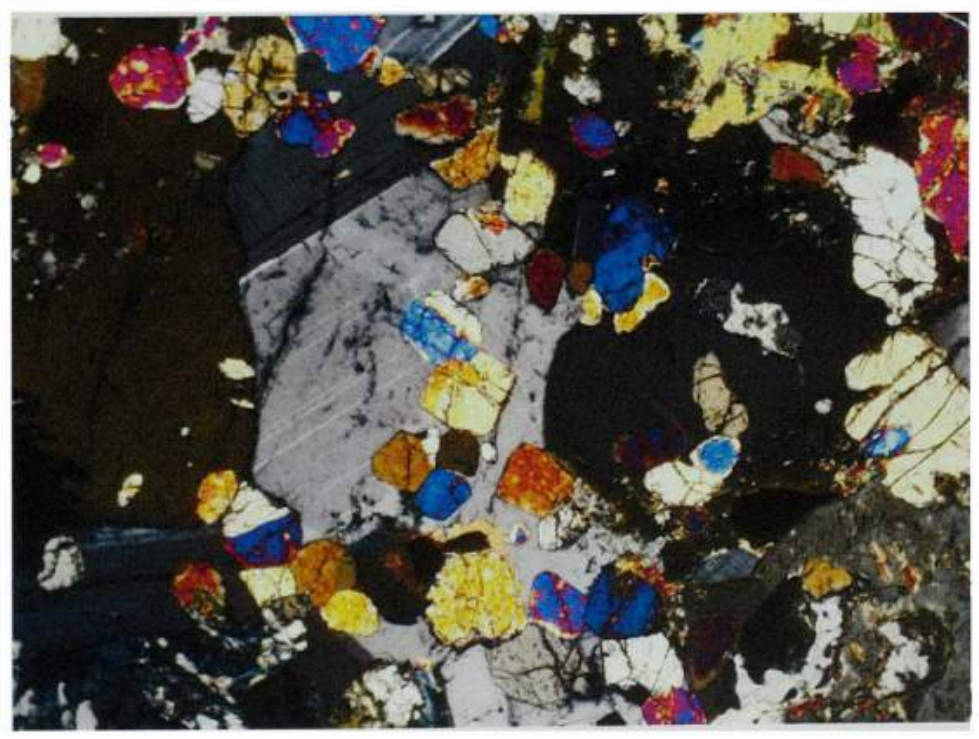

Figure 11. Photomicrograph of the olivine-rich zone, 40x, cross-polarized light. The bright, high-relief grains are olivine, shown forming a chain. The large, gray crystals are plagioclase feldspar. The yellow grain at the top right is clinopyroxene. 


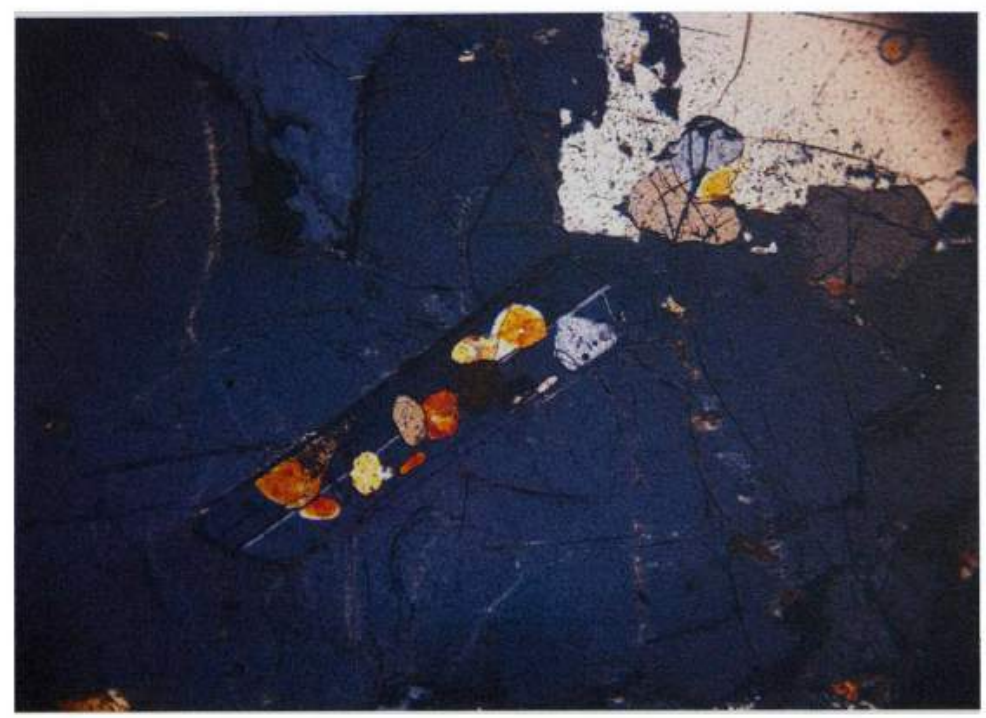

Figure 12. Photomicrograph of the olivine-rich zone, 40x, cross-polarized light. Small olivine crystals within a plagioclase crystal which is in turn within a large orthopyroxene grain.

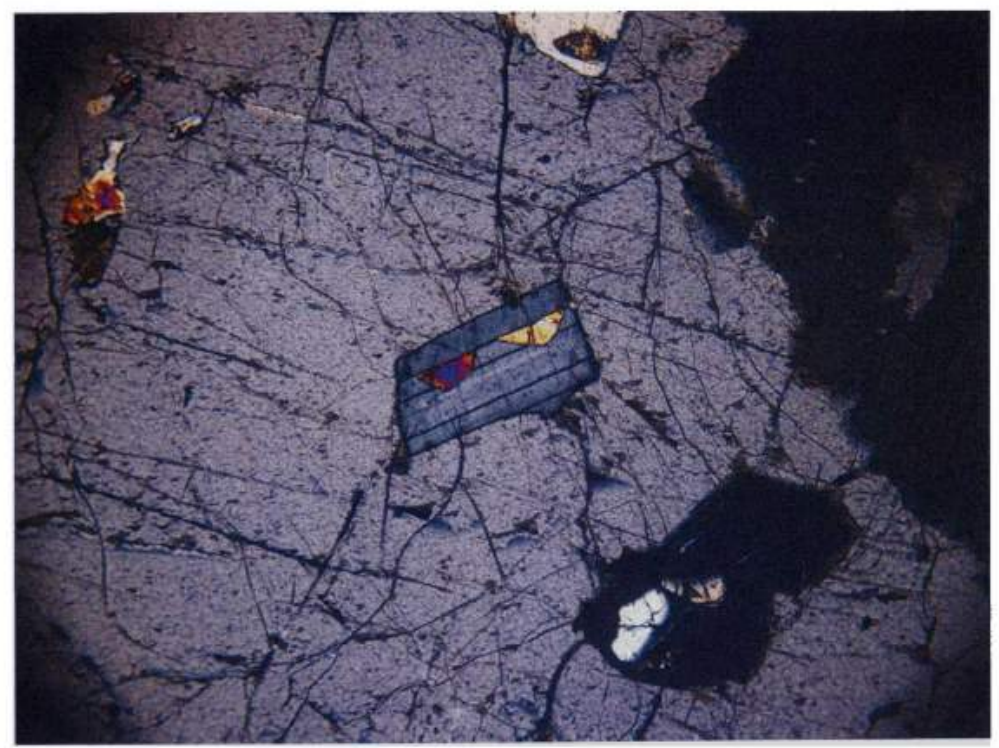

Figure 13. Photomicrograph of the olivine-rich zone, 40x, cross-polarized light. Two small olivine crystals are seen with flat surfaces against the same twinning plane of a small plagioclase crystal. The large, surrounding grain is orthopyroxene. 


\section{CHAPTER V}

\section{GEOCHEMISTRY AND MINERAL CHEMISTRY OF THE PALISADES SILL WITH EMPHASIS ON THE OLIVINE-RICH ZONE}

Whole rock samples were not analyzed for their bulk chemical composition in this study because a substantial volume of high quality data already exists. In this work, I carried out detailed mineral chemical analyses with an electron microprobe. Both kinds of data are necessary to make reasonable inferences about the igneous processes that led to the formation of the olivine-rich zone.

The chill margin composition (Table 1) suggests that the magma that fed the main Palisades Sill was a high-Ti quartz normative tholeiite. As Table 1 shows, the chill margin composition reported by Shirley (1987) is substantially different in being unusually high in $\mathrm{SiO}_{2}$ relative to the analyses reported by two other workers (Walker 1969; Gorring and Naslund, 1995). It is unlikely that such a substantial difference existed laterally within the magma. A more likely interpretation is that Shirley's (1987) sample was affected by local contamination by wall rocks. As mentioned in chapter 1 , the whole rock compositions change, as reflected in variations in decreasing $\mathrm{Mg} /(\mathrm{Mg}+\mathrm{Fe})$ ratio (Figure 5) and increasing $\mathrm{TiO}_{2}$ (Figure 14; Table 1) and $\mathrm{Na}_{2} \mathrm{O}+\mathrm{K}_{2} \mathrm{O}$ (Figure 15; Table 1) from the base and the roof toward the sandwich horizon, where maximum differentiated rocks occur (F. Walker, 1940; K. Walker, 1969; Shirley, 1987).

The average plagioclase composition near the upper and lower boundaries of the Sill is $\sim \mathrm{An}_{66}$, while it is $\sim \mathrm{An}_{37}$ at the sandwich horizon (K. Walker, 1969). Augite is present at the base with an average composition of $\mathrm{Ca}_{40} \mathrm{Mg}_{46} \mathrm{Fe}_{14}$ and it gradually changes to $\mathrm{Ca}_{31} \mathrm{Mg}_{33} \mathrm{Fe}_{36}$ at the most evolved levels (K. Walker, 1969). At the base, 


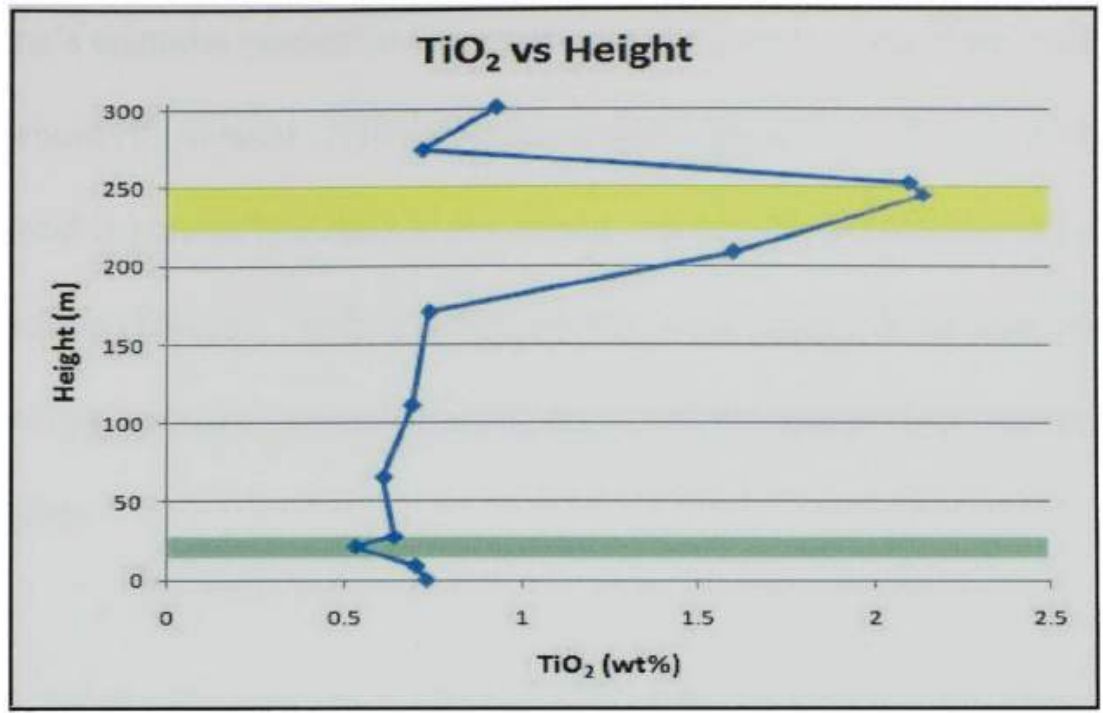

Figure 14. Whole rock $\mathrm{TiO}_{2}$ versus height in the Palisades Sill. TiO2 shows gradual enrichment moving away from the Palisades Sill's upper $(300 \mathrm{~m})$ and lower $(0 \mathrm{~m})$ boundaries. There is significant enrichment in the sandwich horizon (yellow), where the last melts were gathered. The ORZ (green) corresponds with the least enrichment. Data from Walker (1969).

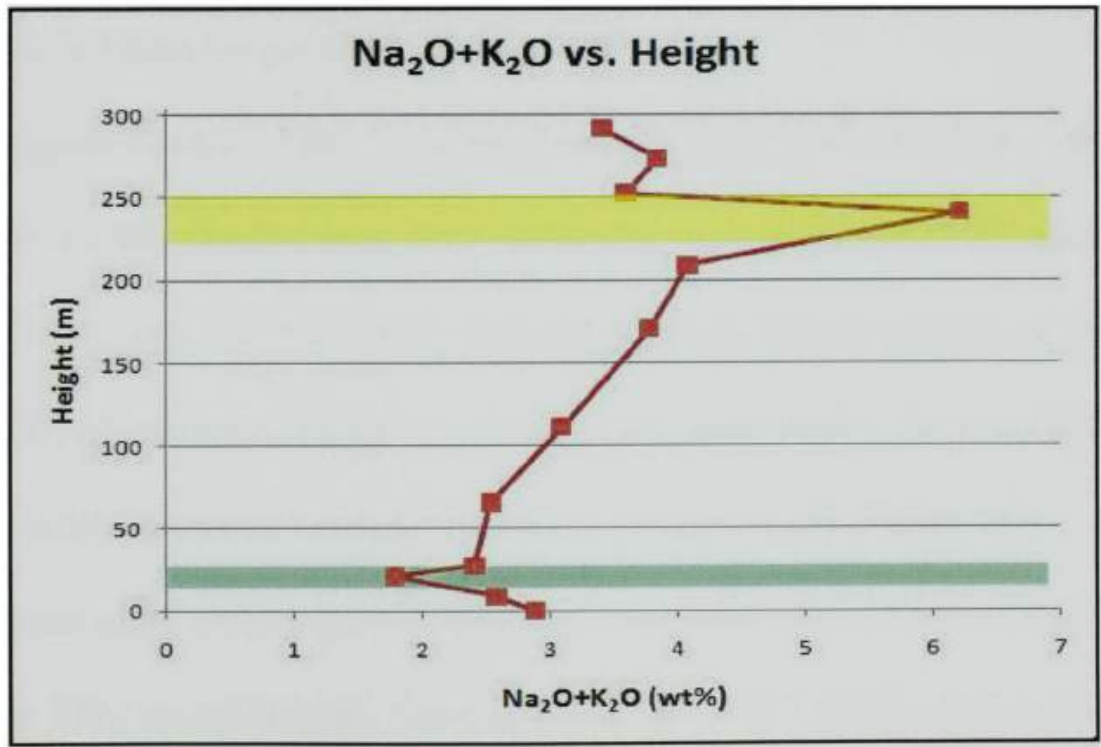

Figure 15. Whole rock $\mathrm{Na}_{2} \mathrm{O}+\mathrm{K}_{2} \mathrm{O}$ versus height in the Palisades Sill. There is enrichment moving away from the sill's boundaries $(0 \mathrm{~m}$ and $300 \mathrm{~m}$ ), with a strong peak at the sandwich horizon (yellow). The ORZ (green) corresponds with the least enrichment. Data from Walker (1969). 
orthopyroxene's enstatite content averages at $\mathrm{En}_{83}$ and it evolves to $\mathrm{En}_{32.5}$ near the sandwich horizon (K. Walker, 1969). Olivine is most magnesian $\left(\mathrm{Fo}_{81.5-79}\right)$ near the lower chill margin and is generally absent in the interior of the sill; in the sandwich horizon, olivine is fayalitic $\left(\mathrm{Fo}_{10} ; \mathrm{K}\right.$. Walker, 1969). In this study, detailed analyses were performed on key minerals; a detailed analyses of olivine, plagioclase, and pyroxene is discussed below.

\section{$\underline{\text { Olivine }}$}

In this study, I analyzed cores of almost every grain, irrespective of grain size or form, in four specimens representing four different depths within the ORZ. For each specimen, some grains were selected for core and rim analyses to check whether any such grain was zoned. Such analyses revealed that individual olivine grains are unzoned. The detailed analytical data are given in the appendix.

As Figures 16 and 17 show, the maximum forsteritic olivine (Fo81) occurs in specimen PSb-15-90, which comes from the central part of the ORZ. The least forsteritic olivine $\left(\mathrm{Fo}_{57}\right)$ was found in PSb-14-90. Olivine grains in individual thin sections show broad compositional ranges, though the ranges vary considerably from sample to sample separated by only a meter of vertical separation within the sill (Figure 16).

Analyses of 55 olivine grains from the lowermost specimen from the ORZ (PSb13-90; Figure 17A) reveal that the fine-grained olivines $\left(0.1 \mathrm{~mm}^{2}\right)$ show a wider spread $\left(\mathrm{Fo}_{65-75}\right)$ than the coarser $\left(1 \mathrm{~mm}^{2}\right)$ crystals $\left(\mathrm{Fo}_{66-68}\right)$. There are only 5 finer crystals that are more magnesian than $\mathrm{Fo}_{68}$. Examination of the data plotted on a frequency histogram 


\begin{tabular}{|c|c|c|c|c|c|c|c|c|c|c|}
\hline & (m) & $\mathrm{SiO}_{2}$ & $\mathrm{TiO}_{2}$ & $\mathrm{Al}_{2} \mathrm{O}_{3}$ & $\mathrm{FeO}^{*}$ & $\mathrm{MnO}$ & $\mathrm{MgO}$ & $\mathrm{CaO}$ & $\mathrm{Na}_{2} \mathrm{O}$ & $\mathrm{K}_{2} \mathrm{O}$ \\
\hline $\begin{array}{l}\text { Chill Margin } \\
\text { (Walker, 1969) }\end{array}$ & 0 & 52.00 & 1.20 & 14.50 & 10.25 & 0.15 & 7.60 & 10.30 & 2.00 & 0.85 \\
\hline $\begin{array}{l}\text { Chill Margin } \\
\text { (Shirley,1987) }\end{array}$ & 0 & 55.40 & 2.05 & 14.27 & 8.96 & 0.16 & 6.60 & 9.09 & 1.75 & 0.64 \\
\hline $\begin{array}{l}\text { Chill Margin } \\
\text { (Gorring\& Naslund, 1995) }\end{array}$ & 0 & 52.77 & 1.15 & 14.22 & 10.31 & 0.18 & 7.44 & 10.51 & 2.03 & 0.77 \\
\hline $\begin{array}{l}\text { ORZ } \\
\text { (Shirley,1987) }\end{array}$ & 15 & 51.87 & 0.73 & 10.53 & 11.45 & 0.18 & 14.19 & 10.60 & 1.49 & 0.43 \\
\hline $\begin{array}{l}\text { ORZ } \\
\text { (Gorring\&Naslund, 1995) }\end{array}$ & 15 & 47.97 & 0.75 & 8.92 & 13.49 & 0.21 & 20.37 & 7.03 & 1.15 & 0.39 \\
\hline $\begin{array}{l}\text { ORZ } \\
\text { (Walket, 1969) }\end{array}$ & 21 & 47.41 & 0.89 & 8.66 & 13.96 & 0.20 & 19.29 & 6.76 & 1.35 & 0.43 \\
\hline $\begin{array}{l}\text { Interior } \\
\text { (Walker, 1969) }\end{array}$ & 66 & 52.2 & 1.02 & 14.23 & 9.63 & 0.16 & 8.50 & 11.44 & 2.07 & 0.46 \\
\hline $\begin{array}{l}\text { Interior } \\
\text { (Walker, 1969) }\end{array}$ & 171 & 52.05 & 1.24 & 16.59 & 10.11 & 0.15 & 5.08 & 9.80 & 2.96 & 0.81 \\
\hline $\begin{array}{l}\text { Interior } \\
\text { (Walker, 1969) }\end{array}$ & 209 & 52.67 & 2.76 & 11.94 & 14.98 & 0.19 & 3.94 & 8.06 & 2.78 & 1.29 \\
\hline $\begin{array}{l}\text { Sandwich } \\
\text { (Walker, 1969) }\end{array}$ & 241 & 58.59 & 1.56 & 11.26 & 13.80 & 0.19 & 1.35 & 3.66 & 3.68 & 2.52 \\
\hline $\begin{array}{l}\text { Sandwich } \\
\text { (Shirley, 1987) }\end{array}$ & 250 & 62.67 & 1.29 & 12.02 & 11.34 & 0.13 & 0.43 & 3.17 & 4.27 & 2.38 \\
\hline $\begin{array}{l}\text { Interior } \\
\text { (Walker, 1969) }\end{array}$ & 274 & 51.5 & 1.2 & 14.9 & 9.8 & 0.15 & 7.00 & 10.00 & 2.40 & 1.00 \\
\hline
\end{tabular}

Table 1. Whole-rock chemical data from the Palisades Sill lower chill margin, olivine-rich zone, interior, and sandwich horizon. Adapted from Walker, 1969; Shirley, 1987; and Gorring and Naslund, 1995. 
reveals a strong mode at $\mathrm{Fo}_{67-68}$. Lack of zoning and large inter-grain compositional variation within an individual specimen like this is best explained as having resulted from mixing between two or more magma batches carrying different olivine phenocrysts. The strong mode at $\mathrm{Fo}_{67-68}$ is likely to be the olivine in the volumetrically dominant magma.

Specimen PSb-14-90 (1\% modal olivine; Figure 17B) is only $1 \mathrm{~m}$ above PSb-1390 ( $20 \%$ by mode) and yet has significantly less-forsteritic olivine $\left(\mathrm{Fo}_{53}-56\right)$ than the least forsteritic olivine $\left(\mathrm{Fo}_{67}\right)$ in PSb-13-90. Such a large difference between two specimens so closely proximal attests to high variability in mode and phase composition within the ORZ and thus observation is not compatible with an ORZ origin by crystal settling.

Specimen PSb-15-90 (25\% modal olivine), which occurs $1 \mathrm{~m}$ above PSb-14-90 by 2 and 1 meters, contains the most forsteritic olivine crystals ( $\mathrm{Fo}_{69-81}$ for the 109 crystals analyzed; Figure 17C). Again, it is worth mentioning that simple crystal settling would result in less magnesian olivines higher in the ORZ, as opposed to what is observed. The frequency histogram (Figure 17C) shows a strong mode at $\mathrm{Fo}_{71-72}$ and a weak mode at $\mathrm{Fo}_{76-77}$. The frequency drops away rather quickly outside the broadly bimodal central population. This type of modal variation is seen in PSB-13-90 as well, and as discussed above, is likely to have resulted from magma mixing between at least two magmas in which the strong mode at $\mathrm{Fo}_{71-72}$ represents the olivine in the dominant magma.

PS-17-90 (15\% modal olivine) is located just 2 meters above PSb-15-90 (Figure 17D). Fifty nine analyzed olivine grains in this specimen gave a slightly less forsteritic composition $\left(\mathrm{Fo}_{61-70}\right)$ than PSb-13-90 or PSb-15-90. There was a strong peak at $\mathrm{Fo}_{63-64}$, with the frequency dropping off rapidly on either side. 
In an effort to make some sense of the extent of disequilibrium that is indicated by the large olivine compositional range, I calculated the composition of the potential olivine that would have been in equilibrium with the whole rock, assuming that the whole rock was like a bulk melt. Using the well-established olivine-liquid $\mathrm{Fe} / \mathrm{Mg}$ partition coefficient of 0.3 (Roeder and Emslie, 1970), I calculate potential equilibrium olivines to be $\mathrm{Fo}_{89}, \mathrm{Fo}_{88}, \mathrm{Fo}_{88}$, and $\mathrm{Fo}_{87}$ for PSb-13-90, PS-14-90, PSb-15-90, and PS-17-90, respectively (Figure 16). This olivine composition is much more forsteritic than any of the olivine in the actual specimen, which is a puzzling observation at the outset. In order to understand the effect of olivine crystal accumulation (i.e., having extra olivine in a bulk rock), I carried out a simple numerical calculation by adding $\mathrm{Fo}_{81}$ olivine to an initial melt that would be in equilibrium with $\mathrm{Fo}_{81}$ olivine (Fig. 18). The effect is that increasing accumulation of such an olivine can raise $\mathrm{MgO}$ content of a whole rock much more rapidly than $\mathrm{FeO}^{*}\left(\mathrm{FeO}^{*}=\mathrm{FeO}+\mathrm{Fe}_{2} \mathrm{O}_{3}\right)$. One can thus end up with a whole rock with very high $\mathrm{MgO}$ by simply having too much olivine, and the potential olivine of such a rock would be much higher in forsterite than the olivine that "actually accumulated" in it. Figure 19 shows $\mathrm{MgO}$ plotted against $\mathrm{FeO} *$ for three calculated trends, using the same $\mathrm{Fo}_{81}$ data, but also adding $\mathrm{F}_{75}$ and $\mathrm{Fo}_{68}$; these forsterite values are found in measured ORZ olivines. It can be seen that olivine compositions with a range of $\mathrm{Fo}_{75-81}$ had to have been added to match the whole rock values of the ORZ samples. PS-14-90 appears to require the addition of Fo81 olivine, PSb-15-90 and PS-17-90 appear to require excess Fo75 olivine, and PSb-13-90 requires a forsterite value between the two. Excess olivine could easily have been introduced into the melt during the magma's rising and emplacement. If there was a sub-Palisades magma chamber, as possibility supported by 
Shirley's (1987) interpretation that the Palisades diabase and the ORZ magma shared a common source, it is not uncommon for olivine crystals to be plucked from a magma chamber's wall during movement of the magma.

One consistent feature of three of the samples with greater modal olivine is that in each only a few of the finer olivine grains stretch the Fo-range to higher values. These more magnesian grains are clearly earlier-formed crystals than the coarser (as well as the other finer crystals) crystals in the same rock; in that sense they should have been of the largest size. A possibility is that they were larger at one time, and have since reacted to their present state. This is supported by their anhedral texture and the interpretation that the ORZ magma has evolved significantly. It is also possible that they were shattered by grinding action of a slowly moving crystal-rich mush. In sum, the olivine data can be best explained as having resulted from mixing of two or more batches of olivine-carrying magma. Crystal percentage of the input magma batches may have been very high and variable.

\section{Plagioclase Feldspar}

Plagioclase (Figure 20) shows the largest compositional ranges within individual sections. Zoning was observed, and so analysis consisted of both crystal cores and rims.

46 analyses of cores and rims from PSb-13-90 show the range to be $\mathrm{An}_{7-89}$ (Figure 21A). When plotted on a histogram, the data are highly skewed; the cores show a prominent peak at $\mathrm{An}_{80-85}$ while the rims show a peak at $\mathrm{An}_{40-45}$. While the cores range from $\mathrm{An}_{55-90}$, the rims show a range of $\mathrm{An}_{5-80}$. There is a gap at $\mathrm{An}_{10-30}$, which is likely not a true compositional gap, but a gap in the data sampling. 
Sample PS-14-90 yielded a similarly broad range of $\mathrm{An}_{0.5-84}$ and multiple "peaks" (50 analyses, Figure 21B). The cores are concentrated at higher anorthite contents, mainly in the range of $\mathrm{An}_{60-85}$, though there are two outliers at $\mathrm{An}_{45-55}$ and one at $\mathrm{An}_{15-20}$. The rims range from $\mathrm{An0.5-84}$, though there are gaps at $\mathrm{An}_{5-10}, \mathrm{An}_{20-30}$, and $\mathrm{An}_{55-60}$.

PSb-15-90 (38 analyses) shows a range of $\mathrm{An}_{5-84}$ and is similar to PSb-13-90 in that it shows a similar frequency distribution, with the exception that the second peak at $\mathrm{An}_{40-45}$ is missing (Figure 21C). The cores are strongly concentrated at $\mathrm{An}_{80-85}$, and frequency gradually decreases to $\mathrm{An}_{65-70}$. The rims show the same distribution, but there is a small population at $\mathrm{An}_{30-50}$ and one grain at $\mathrm{An}_{05-10}$.

Cores of plagioclase crystals were more An-rich than the rims (i.e., normal zoning). The bulk of the coarser plagioclase laths in all thin sections gave a range in compositions from $\mathrm{An}_{45}$ to $\mathrm{An}_{85}$, with a single core at $\mathrm{An}_{16}$. The rims of the plagioclase crystals, often asymmetrically extending into the interstices, extended the range down to almost pure albite $\left(\mathrm{An}_{0.5}\right)$. The highly albitic interstitial grains were often found to be juxtaposed against quartz and biotite, confirming that they are clearly products of final residual melt after near-complete solidification of the olivine-rich zone.

The large range of plagioclase compositions extending to almost pure albite is quite impressive and suggests extreme fractionation of the interstitial melt. At least two distinct modes in three of the samples are again consistent with magma mixing (as with olivine, discussed above). 


\section{$\underline{\text { Pyroxenes }}$}

Both Ca-rich (i.e., augitic) pyroxenes and Ca-poor pyroxenes (both primary orthopyroxene and inverted pigeonite) occur in these rocks. Figure 22 shows a comparison of experimentally derived isotherms (Lindsley, 1983) with pyroxenes in PSb13-90, PS-14-90, and PSb-15-90.

The augite-subcalcic augite in all three specimens form "trends" that are at a sharp angle to the equilibrium isotherms and are likely a result of rapid, nonequilibrium crystallization (Lindsley, 1983). PSb-13-90 (Figure 22A) shows one subcalcic augite advanced along the $1100^{\circ} \mathrm{C}$ isotherm; this analysis is from an exsolution lamellae in one of the few pyroxenes of the ORZ that show exsolution. PS-14-90 (Figure 22B) shows the clinopyroxene analyses extending farther into the disequilibrium field, while its orthopyroxene crystals seem to be more at equilibrium, than the other samples. PSb-1590 (Figure 22C) resembles PSb-13-90 more closely, with the exception of any exsolved phases.

These analyses suggest that crystallization of the pyroxenes in the olivine-rich zone started at equilibrium conditions around $1100^{\circ} \mathrm{C}$, and further crystallization occurred rather rapidly from the melt, showing significant disequilibrium. The general absence of exsolution features further demonstrates this point.

\section{Summary and Discussion of Geochemistry and Mineral Chemistry}

The following points are interpreted from the results of the geochemical portion of this study: 
1. Large compositional ranges in olivine and plagioclase are evidence of extreme differentiation. Because compaction and filter pressing, as seen in other parts of the sill (Shirley, 1987), would have driven out interstitial liquid (except in the remaining microgranophyre patches), the chemical evidence indicates that a significant degree of compaction did not occur.

2. Olivine compositions are not in equilibrium with $\mathrm{ORZ}$ whole rock compositions. This is possibly due to excess olivine in the rocks giving higher $\mathrm{MgO}$ values. Olivine phenocrysts may have been introduced during the ORZ magma's ascent, and could explain the different populations of olivine seen in the thin sections.

3. Pyroxene compositions show disequilibrium trends indicative of rapid cooling. This is consistent with the near-complete absence of exsolution features in ORZ pyroxenes, in opposition to the highly exsolved pyroxenes throughout the rest of the sill. These differences in cooling rates highlight different histories of the rocks; this does not support the crystal settling model. 


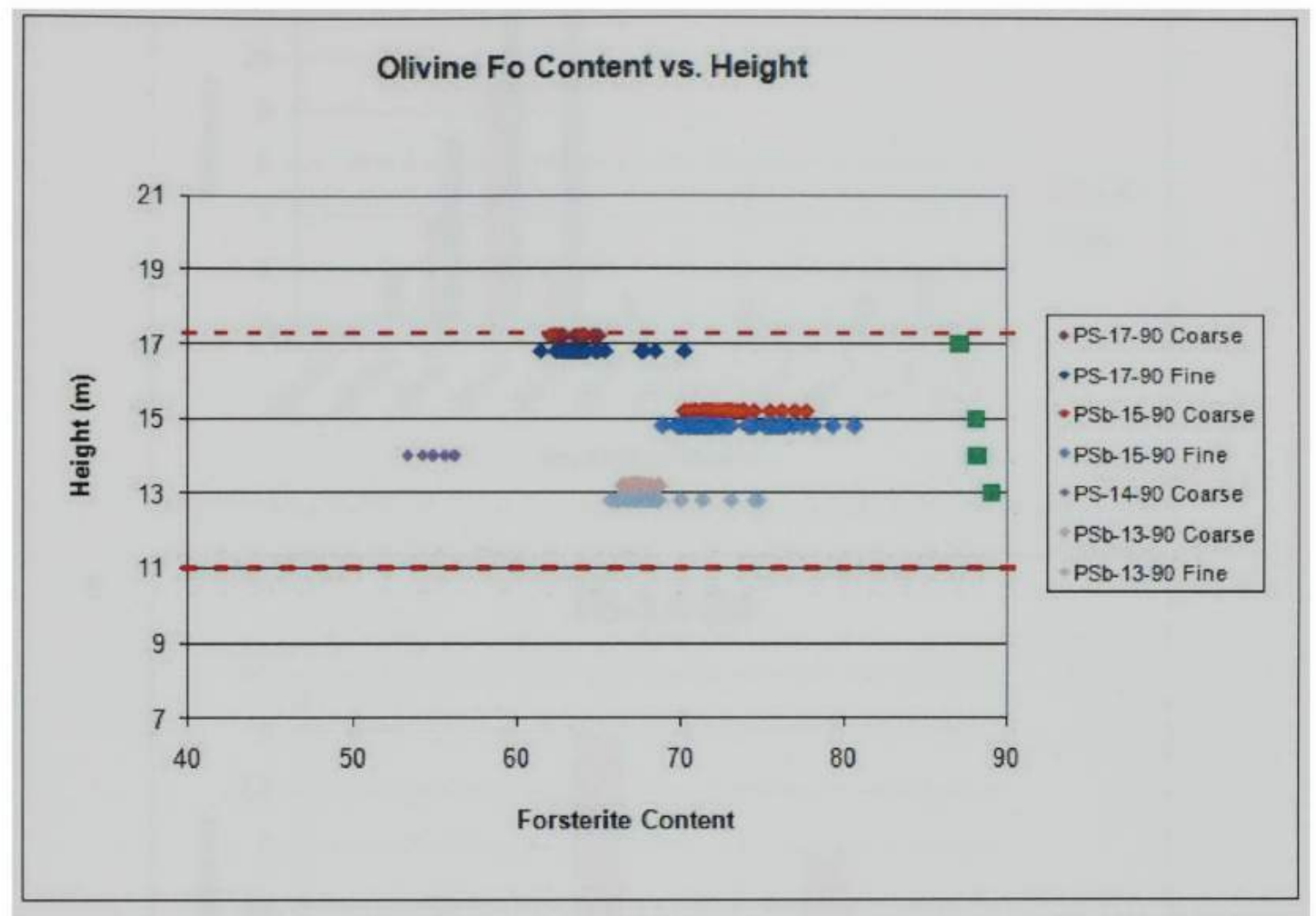

Figure 16. Forsterite content versus pseudo-stratigraphic height. The compositional ranges are plotted with respect to the corresponding height of the samples. Coarse and fine populations are distinguished by different colors. The green squares represent the calculated Fo contents of olivine in equilibrium with the whole rock compositions from Gorring (1992). The dashed, red lines represent the approximate boundaries of the olivine-rich zone in this location. 


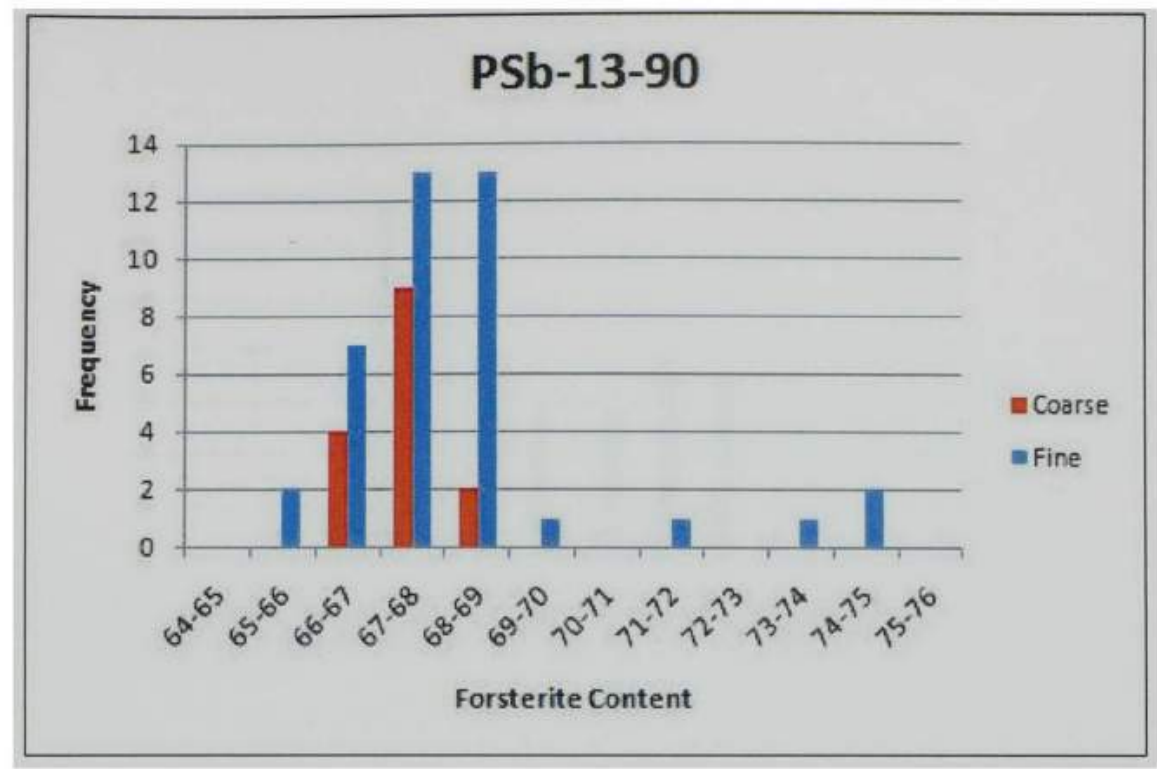

B

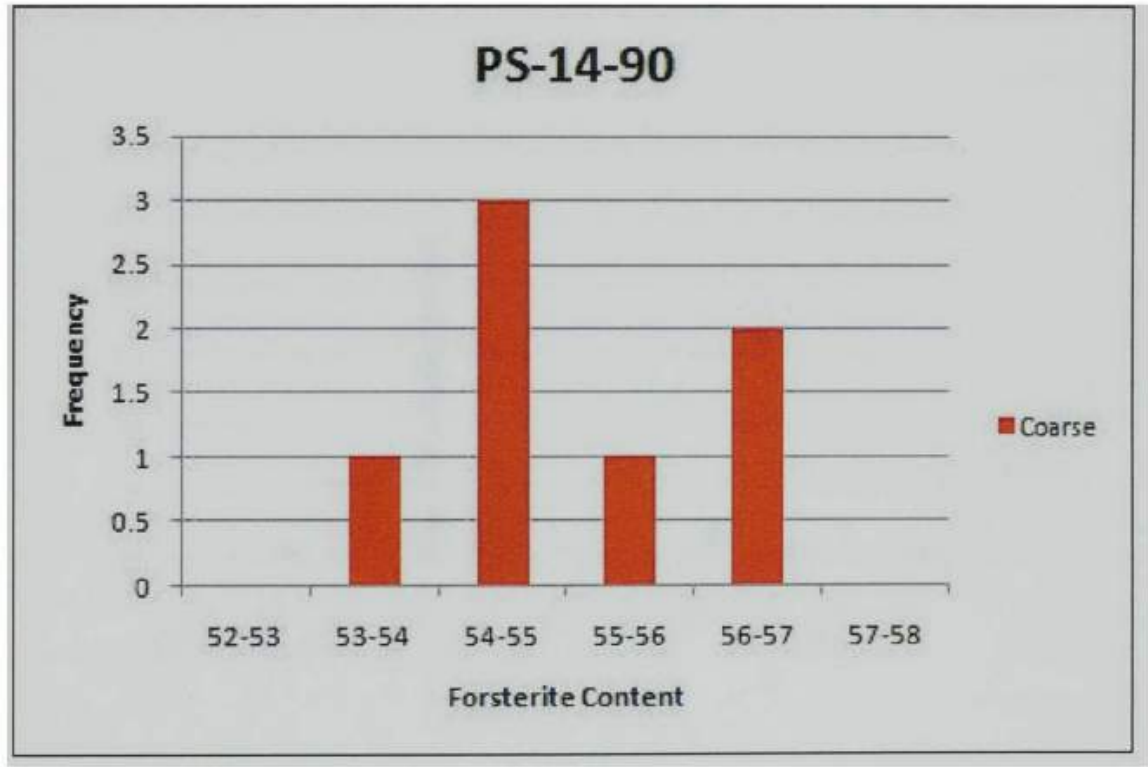

Figure $17 \mathrm{~A}$ and $\mathrm{B}$. Frequency graphs showing forsterite content in samples from the olivine-rich zone. Coarse grains are shown in red, fine grains are shown in blue. A. PSb-13-90. B. PS-14-90. 
C

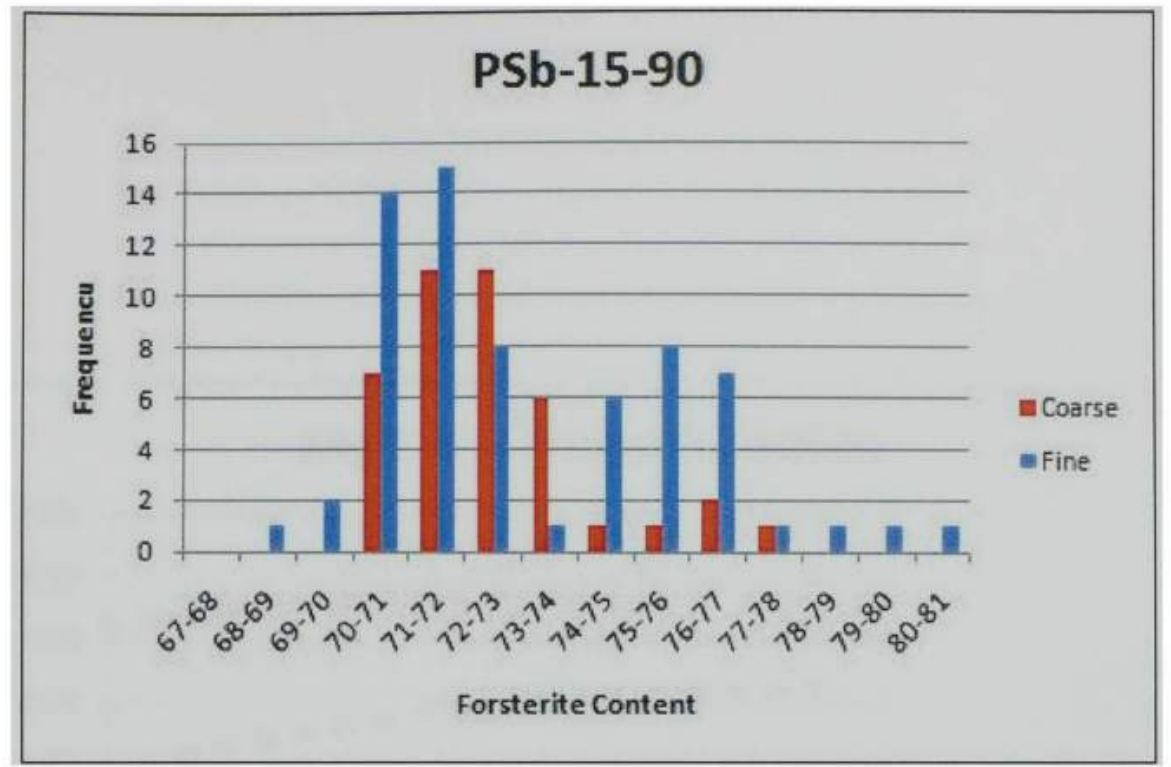

D

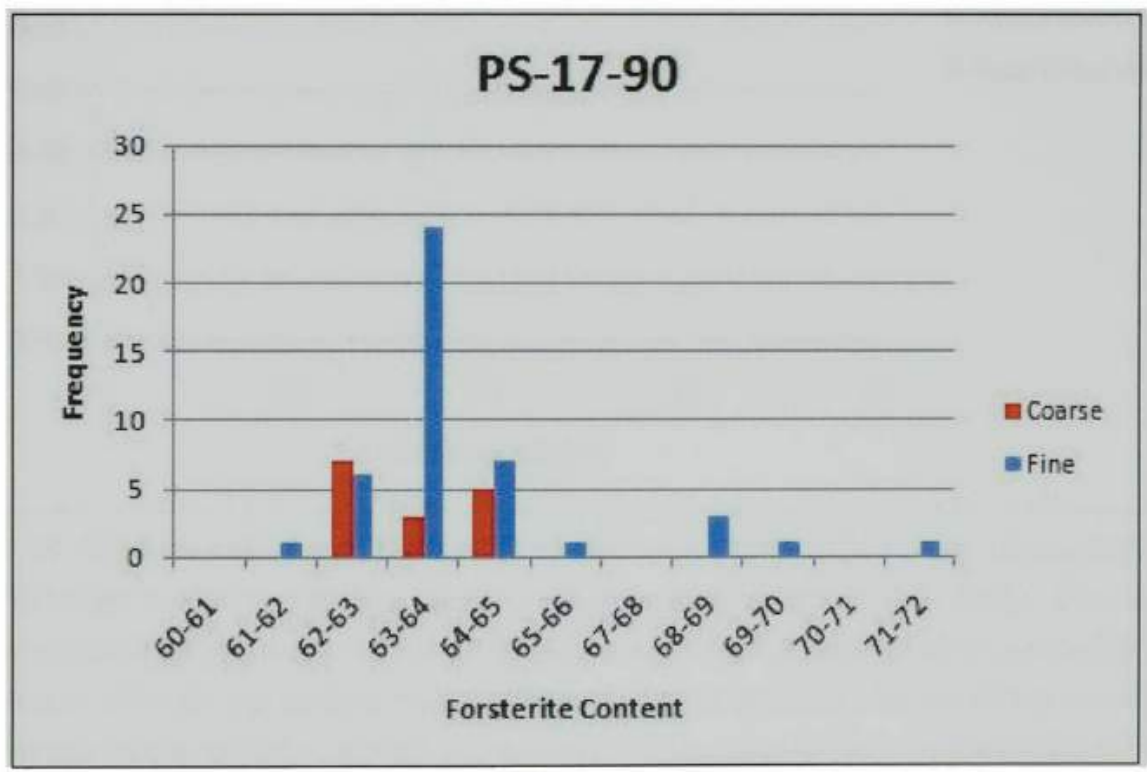

Figure $17 \mathrm{C}$ and D. Frequency graphs showing forsterite content in samples from the olivine-rich zone. Coarse grains are shown in red, fine grains are shown in blue. C. PSb-15-90. D. PS-17-90 


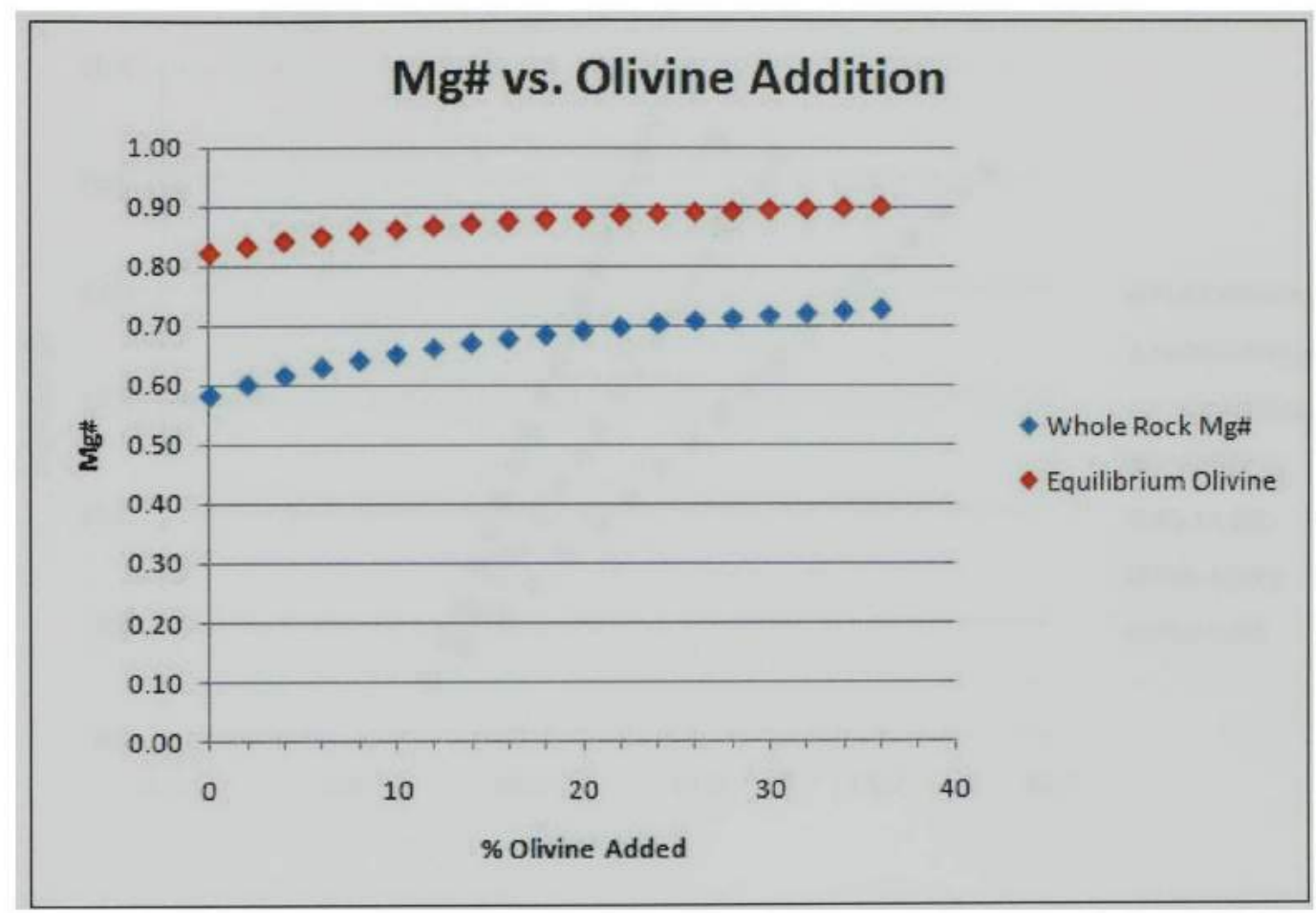

Figure 18. Mg\# vs. Olivine Addition. A whole rock composition was calculated to be in equilibrium with $\mathrm{Fo}_{81}$ olivine, the most magnesian olivine in this study. $\mathrm{Fo}_{81}$ olivine was then added in $2 \%$ increments to the whole rock composition (blue symbols). After $38 \%$ excess olivine was added, the whole rock liquid would be in equilibrium with $\mathrm{FO}_{90}$ olivine (red symbols), which is consistent with calculations on Palisades ORZ whole rock data using a $\mathrm{Kd}$ value of 0.3 . 


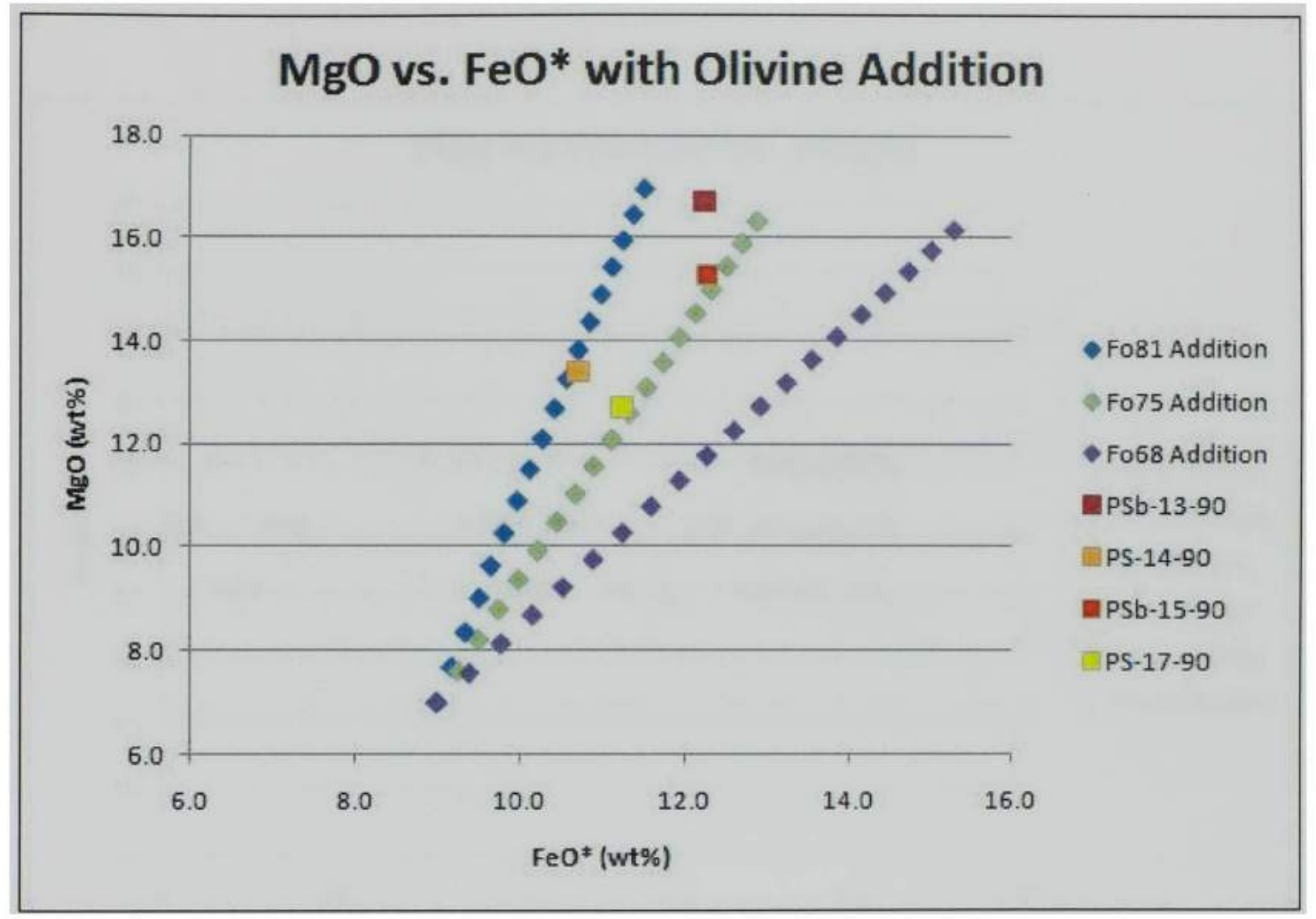

Figure 19. $\mathrm{MgO}$ vs. $\mathrm{FeO}^{*}$ with Olivine Addition. Three calculated evolution trends are shown from a starting composition in which Fo81, Fo75, and Fo68 olivine is added in $2 \%$ increments. These forsterite values represent measured olivine compositions from the ORZ. The whole rock values of Gorring (1992) are shown for the four samples from the ORZ. 


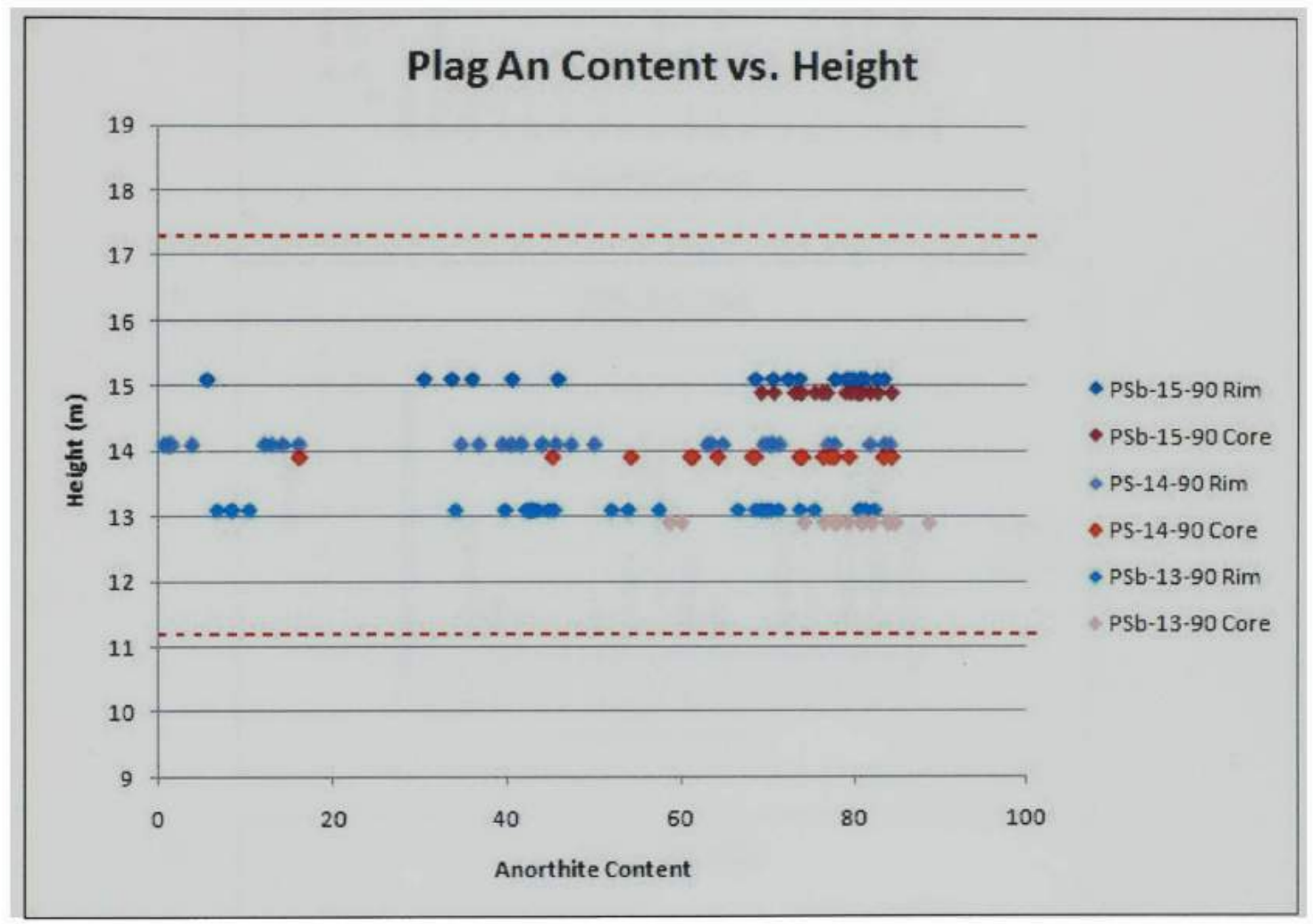

Figure 20. Plagioclase anorthite content versus pseudo -stratigraphic height. The compositional ranges are plotted with respect to the corresponding height of the samples. Crystal rims and cores are differentiated by different colors. The dashed, red lines represent the approximate boundaries of the olivine-rich zone in this location. 
A

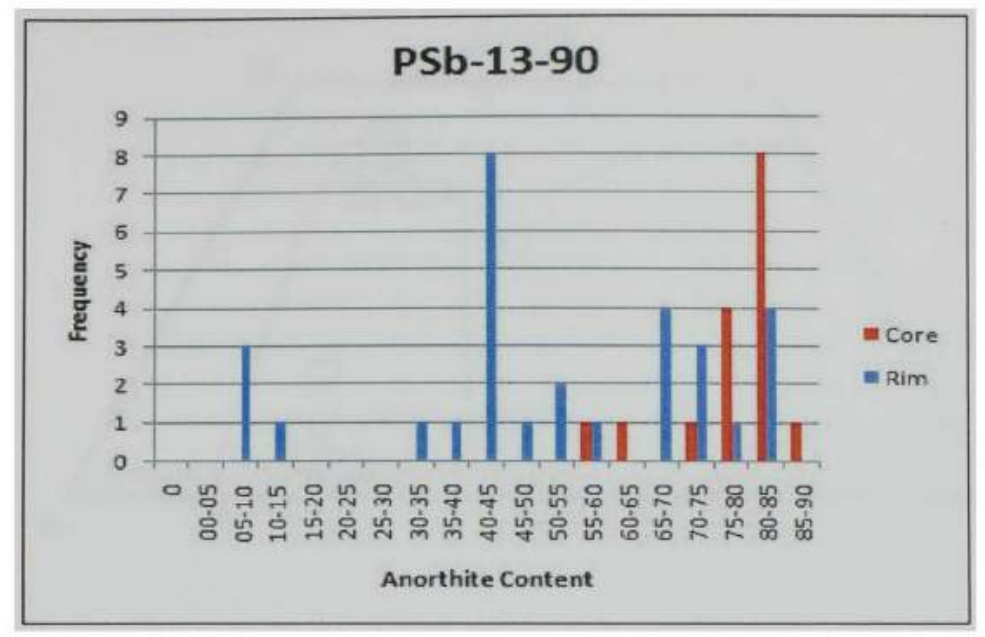

B

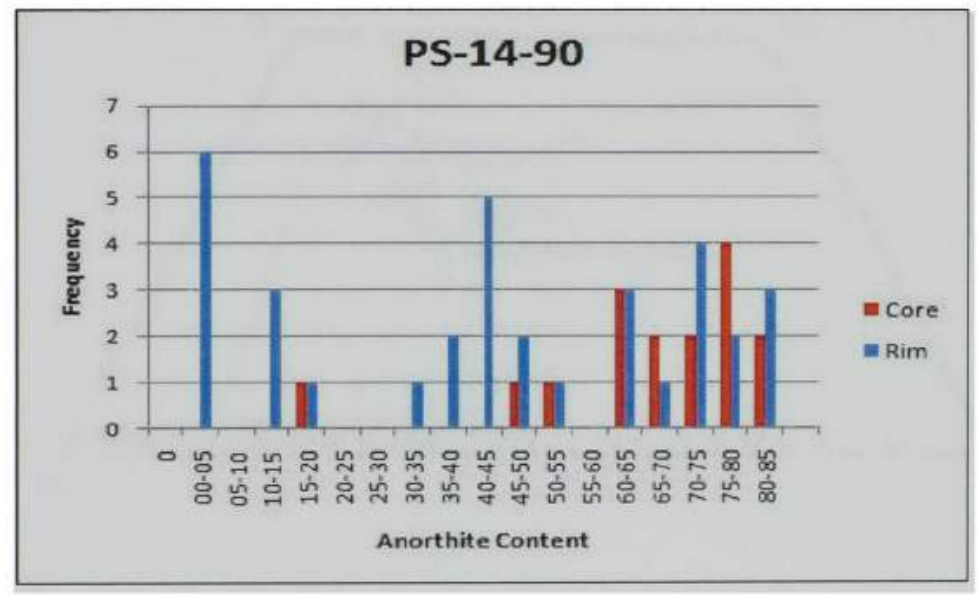

C

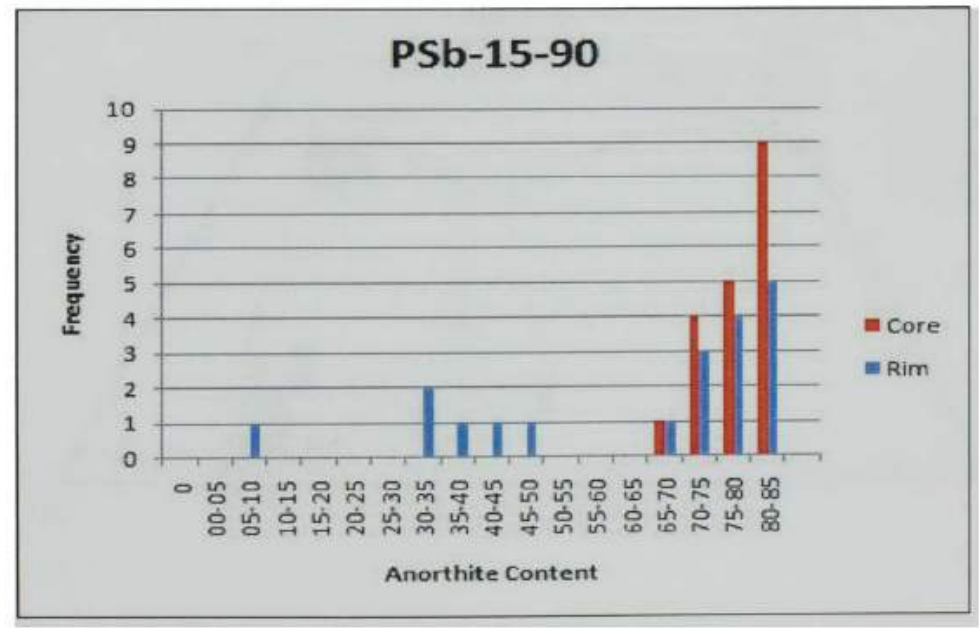

Figure 21. Frequency graphs showing anorthite content from samples of the olivine-rich zone. Cores are shown in red, rims are shown in blue. A. PSb-1390. B. PS-14-90. C. PSb-15-90. 
A

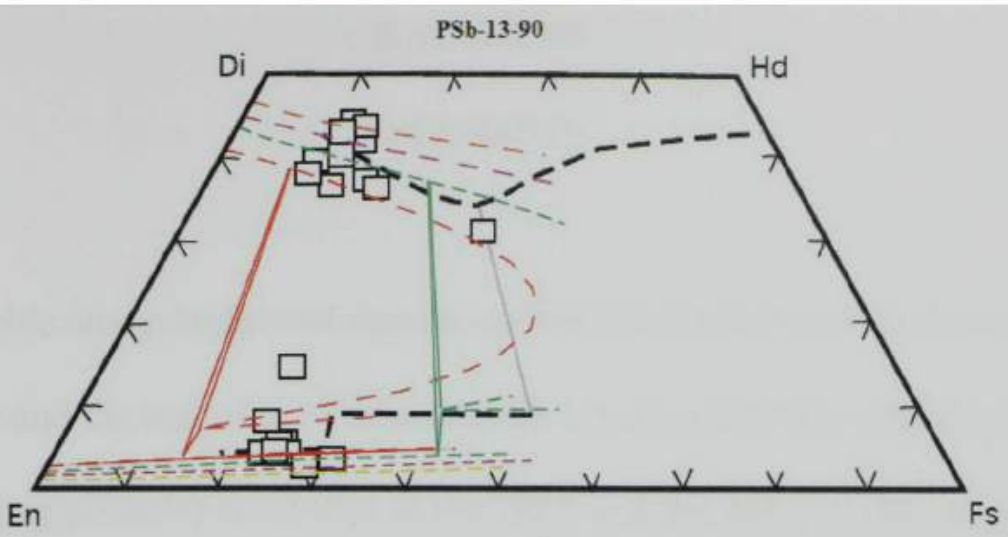

B

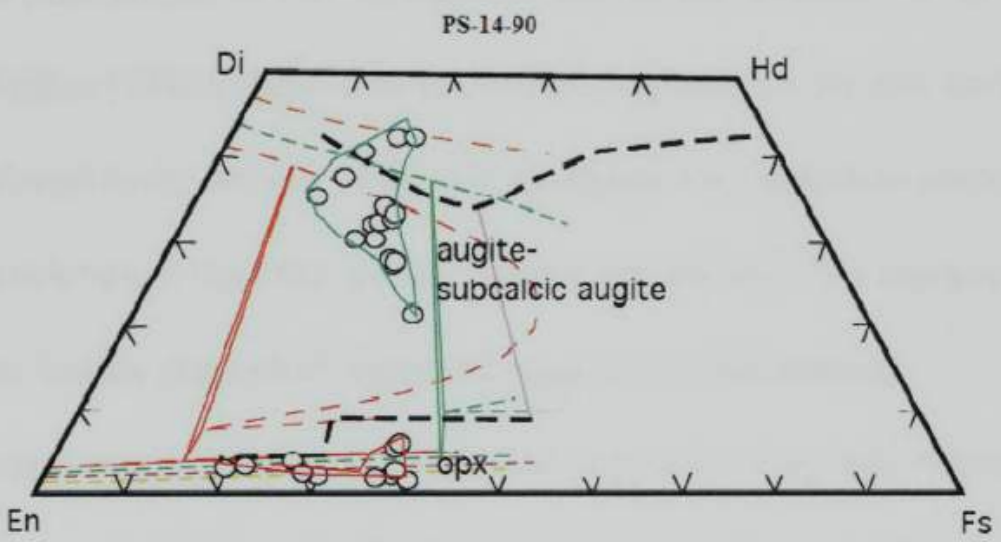

C

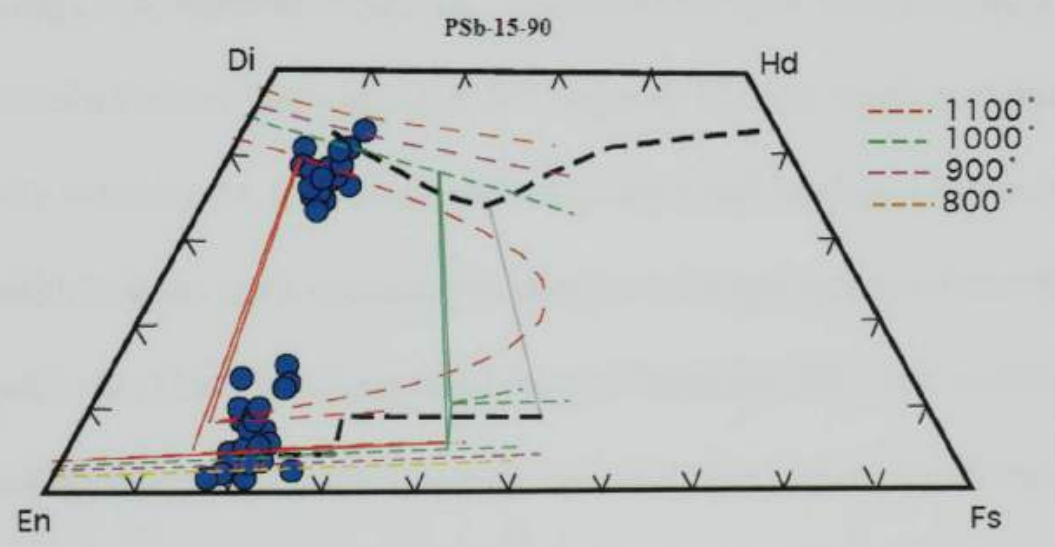

Figure 22. Pyroxene data from samples of the olivine-rich zone plotted on pyroxene quadrilaterals. Experimentally-derived isotherms from Lindsley (1983) are also plotted. A. PSb-13-90. B. PS-14-90. C. PSb-15-90. 


\section{CHAPTER VI}

\section{DISCUSSION}

Petrographic analysis showed significant differences between samples from the olivine-rich zone and the rest of the Palisades Sill. The most obvious difference between the two is the strong presence of olivine in the ORZ and the near-absence of it in the main portion of the sill. Had olivine in fact crystallized and settled, as proposed by Lewis (1908a) and F. Walker (1940), there is no reasonable explanation for that facts that: 1) olivine is not be found at the bottom of the sill, as opposed to 10 meters above it, and 2) the 10 meters of rock below the ORZ contain hardly any olivine. The sharpness of the layer's boundaries further strengthen arguments against crystal settling.

The abundant exsolution features observed in pyroxene crystals within the interior of the sill are almost entirely absent in the olivine-rich zone. In general, exsolution occurs in pyroxenes during slow subsolidus cooling. Taken in that light, the presence of exsolution in the main body of the Palisades Sill suggests that the interior of the sill cooled very slowly whereas the lack of exsolution in the ORZ implies a rapid cooling of the latter. In a solidification front scenario, in which cooling progresses from the directions of greatest heat loss (roof and floor for the Palisades Sill), one would not expect a slow cooling rate to suddenly speed up and form ten meters of olivine-rich rock before suddenly slowing down again. This difference in cooling rates highlights a difference in origin of the ORZ versus the main body of the sill - the ORZ was a later injection that intruded the Palisades sill and thereafter cooled rather rapidly. The 
emplacement of the ORZ as a separate intrusion is consistent with the secondary injection model of Shirley (1987), but not with the crystal settling model.

As discussed in the earlier chapter, the evidence of rapid quenching of the ORZ is further supported by the metastable compositional trends shown largely by the augite crystals, where such trends cut across equilibrium isotherms. Orthopyroxene crystals in all but one specimen do not show strong evidence of metastable crystallization. They are also larger in grain size, and therefore it is possible that these did not form locally by quench crystallization from the melt. The presence of coarse orthopyroxene crystals in the interior of the sill suggests that this phase formed from the main Palisades Sill magma.

The petrographic observations illustrating the relationship between plagioclase and the pyroxenes also show a difference in melt evolution between the main portion of the Palisades Sill and the olivine-rich zone. Within the main portions of the interior, plagioclase and augite appear to have crystallized together, with orthopyroxene shortly after, which is consistent with their occurrence as phenocrysts/microphenocrysts in the fine groundmass of the chill margins. This indicates that plagioclase and augite were on or very near the liquidus for the bulk Palisades magma, with orthopyroxene just below it. However, within the olivine-rich zone, olivine clearly crystallized before the other phases, and plagioclase crystallized before the pyroxenes. This implies that olivine was the sole liquidus phase for that composition, with plagioclase as the next phase, and the pyroxenes some time later. This difference is in inferred crystallization sequence between the ORZ and the interior of the sill is significant because it implies a fundamental 
difference in parental magma compositions. This, again, is consistent with the idea of the ORZ being a separate magma altogether.

In brief, the evidence against the origin of the ORZ by simple crystal settling as presented by early workers (Lewis, 1908; F. Walker, 1940) is overwhelming: (1) rapid quenching in the ORZ versus slow cooling in the interior of the sill, (2) sharpness of the upper and lower boundaries of the ORZ, (3) location of the ORZ well above the base of the sill, and (3) contrasting crystallization sequence between the ORZ and the main sill. An in situ process would not produce a layer with a different starting composition, different cooling rate, and dissimilar physical processes during crystallization. Thus, one can rule out the internal flow model of Steiner et al. (1992). The evidence, however, supports the separate injection model first proposed by K. Walker (1969) and later modified by Shirley (1987). These observations are consistent with the emplacement of at least a second olivine-rich magma at the ORZ when the main sill was largely crystalline, which is further discussed in the next section.

\section{Magma Mixing and Compaction in the Olivine-rich Zone}

There are textural and geochemical features of the ORZ rocks that are better explained by magma mixing (as explained in the previous chapter) - for example, bimodal to weakly polymodal phase compositions, large range in compositions within individual compositions, sharp differences in mode between specimens separated by only a meter or so, finer olivine grains extending to the maximum forsteritic compositions. Critical questions at this stage would be to evaluate the conditions under which the magma mixing occurred - more specifically: 
- Since cooling and crystallization progress toward the interior from contacts against the wall rocks, was the sill entirely crystalline, largely crystalline (say, $>75 \%$ crystals $)$, or significantly molten $(25-50 \%$ crystals $)$ at the level where the ORZ formed?

- Which minerals had crystallized from the main sill magma, from the secondary magma (s), and from the mixed melt? For example, did the olivine come from the intruding melt or from the original magma?

- Could the ORZ have formed primarily by crystal settling and perhaps a later magma was emplaced?

- Why was the later magma emplaced parallel to the lower contact of the sill and simply be a discordant intrusive?

- Being emplaced at such a low level in the intrusion why was not the secondary melt squeezed out to higher levels by filter-pressing or compaction? These questions cannot all be definitively answered in the present study and will require future $\mathrm{Sr}$ or $\mathrm{Pb}$ isotopic investigation of the sill. However, some strong constraints can be placed on the origin of the ORZ based on the information gathered in this study. The compositional ranges of the early phases in the olivine-rich melt, olivine and plagioclase, are the most remarkable results of this study. With olivine crystals ranging almost $30 \%$ of olivine's solid solution series $\left(\mathrm{Fo}_{81-53}\right)$ and plagioclase ranging almost $90 \%$ of its series $\left(\mathrm{An}_{89-0.5}\right)$, it is clear that the melt in the ORZ was allowed to evolve to its fullest potential. For comparison, the anorthite range for the Palisades Sill as a whole is $\mathrm{An}_{67-33}$ (K. Walker, 1969). 
The implication is that after the principal minerals crystallized, the remaining melt continued to evolve in place, that is, the interstitial melt was not squeezed out by compaction or filter-pressing. This is inconsistent with Shirley's (1987) compaction and filter-pressing model, whose effects were demonstrated by Shirley for the rest of the intrusion. Being located close to the base of the Sill, it would be logical to expect that the intruded ORZ magma to suffer significant compaction that is at least equal to the effects observed in the main body of the intrusion. The lack of such effects in the ORZ is curious and there must have been some sort of mechanical effect that prevented the interstitial liquids from being extracted from the crystal network. It appears possible that the main body of the sill was so advanced in crystallization that it may have been either completely solid or a dense crystalline mush with very little interstitial melt at the time of the intrusion of the ORZ magma. According to Marsh's $(1989,1996)$ "solidification front" model, a crystal-liquid mush containing more than $50-75 \%$ crystals effectively seal off intergrain porosity and accompanying melt migration via porous flow. In the field, we did not see any evidence (such as veins or pipes) cutting across or rooted in the ORZ, which would suggest that pipe flow or other types of permeable flow perhaps did not occur during the formation of the ORZ, either. Heterogeneity within the ORZ, as demonstrated in PS-14-90, is possibly a result of a portion of the intrusion's original rock becoming trapped within the olivine-rich magma upon emplacement of the latter; textures and compositions within this rock are possibly evidence of mixing between the magma and the fragment.

I suggest that the reason why the interstitial melts within the ORZ differentiated to such a large degree while remaining in place is because there was a solid, impermeable 
barrier above and below preventing the liquids from moving. This "barrier" could be a crystal-liquid mush with 50-75\% crystals. Mixing of magmas, as outlined before, would suggest that some melt was already present when the second melt was emplaced. The $\mathrm{ORZ}$ is thus envisioned as a mixed layer in which orthopyroxene, some olivine (based on low modal olivine in the chill zone rocks), and plagioclase and may be some augite crystals crystallized from the main magma. Additional olivine and plagioclase were "dumped" by the later batch of magma. Using Shirley's calculations, solidification time for the full volume would have been roughly 1000 years; for the lower 40 meters, roughly 100 years must have passed. Therefore, the olivine-rich zone must have been emplaced at least 100 years after the initial magmatic injection. 
CONCLUSIONS

\section{Origin of the Olivine-rich Zone}

It is clear that the very broad ranges in compositions found within single samples cannot have coexisted with a single parental magma. Petrographic and geochemical examination shows that interstitial liquid pockets in these rocks were well-encapsulated by the crystals. Because any compaction would have squeezed out the interstitial melts, evidence for encapsulation is clearly inconsistent with the generally accepted idea of compaction and filter pressing proposed to be responsible for the presence of the sandwich horizon and an S-shaped geochemical profile in the Palisades sill (Shirley, 1987). In addition, the fact that the olivine-rich zone is so near the base of the sill, and therefore has $90 \%$ of the sill above it, would only enhance the effect of overburdeninduced compaction.

My preferred interpretation is a modification of the secondary pulse proposed by some (K. Walker, 1969; Shirley, 1987; Husch, 1990; Gorring and Naslund,1995). In their scenario, this pulse would likely result in a bimodal population in compositions of the crystal populations due to mixing or mingling. However, if the secondary pulse was injected into a mostly- or wholly-solid section of the intrusion, there would be very little interaction, at least with the magma in the center of this pulse, and the overburden pressure would have no effect on the new magma for the simple reason that the interstitial liquid would have nowhere to escape. By being effectively trapped, the liquid would eventually be completely divided into small, closed systems by the growing crystal 
network, and the numerous pockets of melt would be allowed to differentiate to their fullest potential. Additionally, a secondary injection into the solid diabase would explain why the boundaries of the olivine-rich zone are so well-defined and sharp. Combined with the fact that the olivine-rich zone does not extend along the entire sill (Walker, 1969; Husch, 1990) and that it pinches and swells along strike (Walker, 1969), I interpret that the olivine-rich zone of the Palisades Sill is a secondary magmatic pulse, an intrusion within a nearly solidified crystal-liquid mush.

\section{Sequence of Events}

In light of this evidence, a generalized sequence of events can be proposed for the emplacement of the Palisades Sill. After the initial formation of the half-graben that is the Newark Basin and subsequent sediment deposition, a large volume of magma was injected into the arkoses and sandstones, forming the main body of the Palisades Sill. Slowly, this magma was crystallized from the edges inward, creating two principal solidification fronts; a process like Shirley's (1987) compaction model would have affected these rocks, and their interstitial liquids would have been almost entirely extracted from overburden pressure. After at least 100 years (estimated from Shirley's (1987) solidification calculation), there would have been several meters of solid or mostly-solid diabase at the roof and base. It is after this point that an olivine-rich magma would have been injected, emplacing roughly 10 meters from the base of the intrusion. While cooling, solidification, and filter pressing would continue in the levels above, the olivine-rich zone would be trapped within a solid or near-solid environment, allowing it to evolve as a closed system, with the last residual pockets of melt crystallizing and 
evolving to their fullest potential. Relatively shortly after, two more pulses would be injected into the main body of the sill, but since there is not a noticeable physical disparity between them and the sill, they were either of similar composition to the original Palisades magma or they were emplaced in a part that was still liquid. Filter pressing would cause the majority of the insterstitial liquids to collect and gather between the two approaching solidification fronts, where they finally crystallized, forming the sandwich horizon. Finally, the grand outcrop we see today was exposed after millions of years of uplift and erosion.

\section{Future Work}

Additional research on the Palisades Sill could provide further information beneficial to our understanding of sill emplacement and the evolution of mafic magma. A complete suite of samples from the intrusion consisting of regularly-spaced vertical transects would more closely confine chemical variations and heterogeneities and their spatial context. Sampling of the sill along its lateral extent will provide important insight into lateral variations in chemistry and petrography. Such data could be valuable for understanding the large scale emplacement and differentiation processes in the Palisades Sill.

$\mathrm{Sr}$ and $\mathrm{Pb}$ isotopic analyses could provide unique insight into similarities and differences between the magmas involved in the intrusion, and the relative contribution of the crust-contaminated melts to the magmas that built the Palisades Sill. Extending the sampling and data collection to contemporaneous igneous rocks associated with the 
Central Atlantic Magmatic Province could provide a large-scale view of the igneous processes responsible for the emplacement of the CAMP. 


\section{REFERENCES}

Andreae, A., and Osann, A., 1893, Tiefencontacte an den intrusiven Diabasen von New Jersey, in Naturhistorisch-medizinischen Verein, H., ed., Verhandlungen des naturhistorischmedicinischen Vereins zu Heidelberg, Volume 5th Bd.: Heidelberg, Selbtsverlag., p. 1627.

Bowen, N.L., 1928, The Evolution of Igneous Rocks, Dover Publications.

Dallmeyer, R.D., 1975, The Palisades sill: A Jurassic intrusion? Evidence from ${ }^{40} \mathrm{~K}-{ }^{39} \mathrm{Ar}$ incremental release ages: Geology, v. 3, p. 243-245.

Dunning, G.R., and Hodych, J.P., 1990, U/Pb zircon and baddeleyite ages for the Palisades and Gettysburg sills of northeastern United States: Implications for the age of the Triassic/Jurassic boundray: Geology, v. 18, p. 795-798.

Erickson, G.P., and Kulp, J.L., 1961, Potassium-Argon Measurements of the Palisades Sill, New Jersey: Geological Society of America Bulletin, v. 72, p. 649-652.

Gorring, M.L., 1992, The Petrologogy and Geochemistry of the Lower 105m of the Palisades Sill, New Jersey: Binghamton, State University of New York.

Husch, J.M., 1990, Palisades sill: Origin of the olivine zone by separate magmatic injection rather than gravity settling: Geology, v. 18, p. 699-702.

Lewis, J.V., 1908a, The Palisade diabase of New Jersey: American Journal of Science, v. 26, p. 155-162.

Lewis, J.V., 1908b, Petrography of the Newark Igneous Rocks of New Jersey: Trenton. Lindsley, D.H., 1983, Pyroxene Thermometry: American Mineralogist, v. 68, p. 477 - 493. Marsh, B.D., 1989, Magma chambers: Annual Review of Earth and Planetary Sciences, v. 17, p. $439-474$. 
Marsh, B.D., 1996, Solidification fronts and magmatic evolution: Mineralogical Magazine, v. 60, p. $5-40$.

Marzoli, A., Renne, P.R., Piccirillo, E.M., Ernesto, M., Bellieni, G., and De Min, A., 1999, Extensive 200-Million-Year-Old Continental Flood Basalts of the Central Atlantic Magmatic Province: Science, v. 284, p. 616-618.

McHone, J.G., and Butler, J.R., 1984, Mesozoic igneous provinces of New England and the opening of the North Atlantic Ocean: Geological Society of America Bulletin, v. 95, p. 757-765.

Puffer, J.H., Geiger, F.J., and Camano, E.J., 1982, Mesozoic Igneous Rocks of Rockland County, New York: Northeastern Geology, v. 4, p. 121-130.

Roeder, P.L., and Emslie, R.F., 1970, Olivine-liquid Equilibrium: Contributions to Mineralogy and Petrology, v. 29, p. 279 - 289.

Russell, I.C., 1878, On the Intrusive Nature of the Triassic Trap sheets of New Jersey: American Journal of Science, v. 15, p. 277-280.

Russell, I.C., 1880, On the Former Extent of the Triassic Formation of the Atlantic States: The American Naturalist, p. 703-712.

Shirley, D.N., 1986, Magmatic Differentiation in Partially Molten Systems: Applications to the Moon and the Palisades Sill: Los Angeles, University of California, Los Angeles.

Shirley, D.N., 1987, Differentiation and Compaction of the Palisades Sill, New Jersey: Journal of Petrology, v. 28, p. 835-865.

Steiner, J.C., Walker, R.J., Warner, R.D., and Olson, T.R., 1992, A cumulus-transport-deposition model of the differentiation of the Palisades sill: Geological Society of America Special Paper, v. 268, p. 193-217.

Walker, F., 1940, The differentiation of the Palisade diabase, New Jersey: Geological Society of America Bulletin, v. 51, p. 1059-1106. 
Walker, K.R., 1969, The Palisades Sill, New Jersey: A Reinvestigation: Geological Society of America Special Paper, v. 111, p. 178 p. 


\begin{tabular}{|c|c|c|c|c|c|c|}
\hline $\mathrm{SiO} 2$ & $\mathrm{FeO}$ & $\mathrm{MgO}$ & $\mathrm{CaO}$ & $\mathrm{NiO}$ & Total & \\
\hline 37.77 & 29.335 & 33.103 & 0.087 & 0.156 & 100.451 & Coarse \\
\hline 37.066 & 27.993 & 34.324 & 0.068 & 0.187 & 99.638 & Fine \\
\hline 37.513 & 28.642 & 33.435 & 0.08 & 0.131 & 99.801 & Coarse \\
\hline 37.351 & 28.068 & 33.704 & 0.213 & 0.161 & 99.497 & Coarse \\
\hline 37.478 & 28.815 & 33.342 & 0.106 & 0.188 & 99.929 & Coarse-Core \\
\hline 37.096 & 28.805 & 33.426 & 0.109 & 0.134 & 99.57 & Coarse-Rim \\
\hline 37.505 & 27.974 & 34.065 & 0.09 & 0.119 & 99.753 & Fine \\
\hline 37.438 & 28.205 & 33.169 & 0.066 & 0.142 & 99.02 & Fine \\
\hline 38.314 & 23.061 & 38.313 & 0.082 & 0.133 & 99.903 & Fine \\
\hline 38.106 & 23.076 & 37.85 & 0.079 & 0.071 & 99.182 & Fine \\
\hline 37.646 & 29.1 & 33.311 & 0.099 & 0.169 & 100.325 & Fine \\
\hline 37.701 & 27.68 & 33.938 & 0.064 & 0.149 & 99.532 & Fine \\
\hline 37.133 & 28.241 & 34.506 & 0.105 & 0.194 & 100.179 & Fine \\
\hline 37.516 & 28.325 & 34.147 & 0.062 & 0.123 & 100.173 & Fine \\
\hline 36.754 & 28.487 & 33.72 & 0.071 & 0.156 & 99.188 & Fine \\
\hline 36.673 & 28.149 & 34.429 & 0.063 & 0.158 & 99.472 & Fine \\
\hline 37.355 & 29.477 & 33.447 & 0.089 & 0.156 & 100.524 & Coarse \\
\hline 37.205 & 28.533 & 33.513 & 0.066 & 0.165 & 99.482 & Fine \\
\hline 37.147 & 28.928 & 33.319 & 0.1 & 0.193 & 99.687 & Coarse \\
\hline 37.83 & 28.21 & 34.575 & 0.084 & 0.136 & 100.835 & Fine \\
\hline 37.653 & 29.237 & 32.828 & 0.092 & 0.106 & 99.916 & Coarse \\
\hline 37.366 & 29.957 & 33.016 & 0.052 & 0.194 & 100.585 & Fine \\
\hline 37.842 & 29.229 & 33.019 & 0.097 & 0.174 & 100.361 & Fine \\
\hline 36.795 & 28.233 & 34.226 & 0.16 & 0.171 & 99.585 & Fine \\
\hline 37.06 & 29.919 & 32.862 & 0.049 & 0.185 & 100.075 & Fine \\
\hline 36.088 & 28.735 & 34.41 & 0.111 & 0.127 & 99.471 & Fine \\
\hline 37.456 & 29.076 & 33.715 & 0.087 & 0.126 & 100.46 & Fine \\
\hline 37.233 & 29.46 & 33.772 & 0.068 & 0.117 & 100.65 & Fine \\
\hline 36.874 & 29.408 & 33.516 & 0.078 & 0.152 & 100.028 & Coarse \\
\hline 37.209 & 30.357 & 32.645 & 0.034 & 0.173 & 100.418 & Fine \\
\hline 37.054 & 28.847 & 33.629 & 0.081 & 0.167 & 99.778 & Coarse \\
\hline 37.266 & 28.955 & 33.431 & 0.102 & 0.135 & 99.889 & Fine \\
\hline 37.101 & 27.88 & 34.29 & 0.06 & 0.152 & 99.483 & Coarse \\
\hline 37.328 & 28.161 & 33.939 & 0.061 & 0.123 & 99.612 & Fine \\
\hline 37.327 & 28.855 & 33.091 & 0.058 & 0.167 & 99.498 & Fine \\
\hline 37.239 & 28.91 & 33.457 & 0.046 & 0.195 & 99.847 & Fine \\
\hline 37.127 & 29.197 & 33.348 & 0.048 & 0.094 & 99.814 & Fine \\
\hline 37.005 & 29.461 & 33.707 & 0.081 & 0.193 & 100.447 & Fine \\
\hline 36.921 & 29.97 & 32.657 & 0.101 & 0.16 & 99.809 & Fine \\
\hline 37.211 & 29.947 & 32.872 & 0.061 & 0.164 & 100.255 & Fine \\
\hline 38.196 & 24.203 & 36.879 & 0.079 & 0.106 & 99.463 & Fine \\
\hline 37.775 & 28.513 & 33.671 & 0.16 & 0.128 & 100.247 & Coarse-Rim \\
\hline 37.076 & 29.024 & 33.388 & 0.133 & 0.189 & 99.81 & Coarse - Core \\
\hline
\end{tabular}

Appendix 1. PSb-13-90 olivine data. 


\begin{tabular}{|c|c|c|c|c|c|c|}
\hline $\mathrm{SiO} 2$ & $\mathrm{FeO}$ & $\mathrm{MgO}$ & $\mathrm{CaO}$ & $\mathrm{NiO}$ & Total & \\
\hline 36.167 & 37.625 & 26.465 & 0.08 & 0.087 & 100.424 & Coarse \\
\hline 36.352 & 36.477 & 26.345 & 0.09 & 0.121 & 99.385 & Coarse \\
\hline 36.361 & 37.004 & 26.595 & 0.065 & 0.092 & 100.117 & Coarse \\
\hline 35.691 & 37.045 & 25.257 & 0.076 & 0.14 & 98.209 & Coarse - Core \\
\hline 35.954 & 38.266 & 25.455 & 0.069 & 0.098 & 99.842 & Coarse - Rim \\
\hline 36.031 & 37.762 & 25.817 & 0.064 & 0.054 & 99.728 & Coarse \\
\hline 35.694 & 38.314 & 24.574 & 0.176 & 0.078 & 98.836 & Coarse \\
\hline
\end{tabular}

Appendix 2. PS-14-90 olivine data. 


\begin{tabular}{|c|c|c|c|c|c|c|}
\hline $\mathrm{SiO} 2$ & $\mathrm{FeO}$ & $\mathrm{MgO}$ & $\mathrm{CaO}$ & $\mathrm{NiO}$ & Total & \\
\hline 38.278 & 25.446 & 34.437 & 0.096 & 0.195 & 98.452 & Fine \\
\hline 37.919 & 26.571 & 34.803 & 0.067 & 0.175 & 99.535 & Fine \\
\hline 38.407 & 26.067 & 35.105 & 0.057 & 0.185 & 99.821 & Coarse \\
\hline 38.573 & 25.684 & 35.935 & 0.085 & 0.153 & 100.43 & Coarse \\
\hline 38.449 & 25.044 & 35.819 & 0.096 & 0.137 & 99.545 & Fine \\
\hline 38.53 & 24.276 & 36.443 & 0.075 & 0.214 & 99.538 & Coarse \\
\hline 38.748 & 23.921 & 36.683 & 0.1 & 0.16 & 99.612 & Coarse \\
\hline 39.112 & 22.84 & 37.426 & 0.097 & 0.158 & 99.633 & Coarse \\
\hline 38.645 & 25.064 & 36.191 & 0.081 & 0.161 & 100.142 & Coarse \\
\hline 38.084 & 25.187 & 35.994 & 0.072 & 0.169 & 99.506 & Coarse \\
\hline 38.489 & 26.216 & 35.668 & 0.083 & 0.129 & 100.585 & Coarse-Core \\
\hline 38.563 & 23.603 & 36.673 & 0.112 & 0.17 & 99.121 & Coarse-Rim \\
\hline 38.609 & 23.978 & 36.409 & 0.077 & 0.153 & 99.226 & Coarse \\
\hline 38.334 & 25.891 & 35.372 & 0.032 & 0.193 & 99.822 & Fine \\
\hline 38.098 & 25.317 & 35.791 & 0.086 & 0.127 & 99.419 & Coarse \\
\hline 38.317 & 25.288 & 36.128 & 0.097 & 0.156 & 99.986 & Coarse \\
\hline 38.465 & 25.024 & 35.642 & 0.105 & 0.153 & 99.389 & Coarse \\
\hline 38.325 & 25.411 & 35.817 & 0.11 & 0.131 & 99.794 & Fine \\
\hline 38.194 & 24.695 & 36.137 & 0.088 & 0.156 & 99.27 & Coarse \\
\hline 38.144 & 24.698 & 36.387 & 0.136 & 0.15 & 99.515 & Fine \\
\hline 38.79 & 21.576 & 38.593 & 0.084 & 0.145 & 99.188 & Fine \\
\hline 38.91 & 22.191 & 39.001 & 0.096 & 0.2 & 100.398 & Fine \\
\hline 38.719 & 21.168 & 39.534 & 0.108 & 0.148 & 99.677 & Fine \\
\hline 39.43 & 22.027 & 38.975 & 0.095 & 0.097 & 100.624 & Fine \\
\hline 38.525 & 23.039 & 37.727 & 0.089 & 0.163 & 99.543 & Fine \\
\hline 38.773 & 23.171 & 37.944 & 0.065 & 0.159 & 100.112 & Fine \\
\hline 38.325 & 22.303 & 38.236 & 0.105 & 0.215 & 99.184 & Fine \\
\hline 38.925 & 22.181 & 38.37 & 0.114 & 0.117 & 99.707 & Fine \\
\hline 38.774 & 22.332 & 38.091 & 0.121 & 0.212 & 99.53 & Fine \\
\hline 38.248 & 24.465 & 36.844 & 0.07 & 0.146 & 99.773 & Coarse \\
\hline 38.734 & 23.283 & 37.391 & 0.094 & 0.147 & 99.649 & Fine \\
\hline 38.748 & 23.322 & 37.635 & 0.11 & 0.141 & 99.956 & Fine \\
\hline 38.939 & 23.357 & 37.973 & 0.035 & 0.159 & 100.463 & Fine \\
\hline 38.544 & 23.555 & 37.947 & 0.092 & 0.101 & 100.239 & Fine \\
\hline 39.018 & 22.296 & 38.898 & 0.089 & 0.142 & 100.443 & Fine \\
\hline 38.674 & 21.455 & 38.899 & 0.083 & 0.131 & 99.242 & Fine \\
\hline 38.371 & 22.374 & 38.623 & 0.103 & 0.118 & 99.589 & Fine \\
\hline 38.781 & 25.709 & 36.404 & 0.032 & 0.192 & 101.118 & Fine \\
\hline 38.515 & 25.437 & 36.603 & 0.062 & 0.178 & 100.795 & Fine \\
\hline 38.309 & 25.543 & 35.211 & 0.052 & 0.171 & 99.286 & Fine \\
\hline 38.415 & 22.567 & 38.3 & 0.084 & 0.14 & 99.506 & Fine \\
\hline 38.542 & 26.098 & 35.779 & 0.083 & 0.221 & 100.723 & Coarse \\
\hline 38.44 & 24.796 & 36.251 & 0.089 & 0.13 & 99.706 & Fine \\
\hline
\end{tabular}

Appendix 3. PSb-15-90 olivine data. 


\begin{tabular}{|c|c|c|c|c|c|c|}
\hline $\mathrm{SiO} 2$ & $\mathrm{FeO}$ & $\mathrm{MgO}$ & $\mathrm{CaO}$ & $\mathrm{NiO}$ & Total & \\
\hline 38.139 & 24.851 & 36.661 & 0.088 & 0.162 & 99.901 & Coarse - Core \\
\hline 37.86 & 25.188 & 35.937 & 0.035 & 0.124 & 99.144 & Coarse - Rim \\
\hline 38.173 & 25.55 & 35.845 & 0.09 & 0.169 & 99.827 & Coarse - Rim \\
\hline 38.659 & 26.199 & 35.111 & 0.054 & 0.211 & 100.234 & Fine \\
\hline 38.938 & 25.83 & 35.118 & 0.067 & 0.214 & 100.167 & Fine \\
\hline 38.296 & 26.446 & 35.096 & 0.094 & 0.225 & 100.157 & Fine \\
\hline 38.552 & 26.041 & 36.026 & 0.07 & 0.157 & 100.846 & Fine \\
\hline 38.087 & 26.054 & 35.995 & 0.058 & 0.187 & 100.381 & Fine \\
\hline 38.671 & 25.937 & 36.106 & 0.064 & 0.146 & 100.924 & Fine \\
\hline 38.861 & 21.462 & 39.029 & 0.083 & 0.152 & 99.587 & Fine \\
\hline 38.785 & 21.464 & 38.629 & 0.065 & 0.177 & 99.12 & Fine \\
\hline 38.834 & 21.555 & 38.651 & 0.114 & 0.162 & 99.316 & Coarse \\
\hline 38.9 & 20.526 & 40.005 & 0.115 & 0.175 & 99.721 & Coarse \\
\hline 38.938 & 20.335 & 39.18 & 0.067 & 0.157 & 98.677 & Fine \\
\hline 38.801 & 21.152 & 39.594 & 0.07 & 0.145 & 99.762 & Coarse \\
\hline 38.598 & 23.802 & 37.645 & 0.083 & 0.175 & 100.303 & Coarse \\
\hline 38.6 & 24.681 & 37.336 & 0.075 & 0.166 & 100.858 & Fine \\
\hline 38.326 & 26.861 & 35.27 & 0.065 & 0.161 & 100.683 & Fine \\
\hline 37.911 & 26.02 & 35.444 & 0.078 & 0.116 & 99.569 & Fine \\
\hline 37.964 & 26.807 & 35.136 & 0.061 & 0.125 & 100.093 & Fine \\
\hline 37.846 & 26.047 & 35.288 & 0.057 & 0.164 & 99.402 & Fine \\
\hline 38.185 & 25.089 & 36.126 & 0.088 & 0.159 & 99.647 & Fine \\
\hline 38.106 & 24.51 & 35.88 & 0.074 & 0.169 & 98.739 & Fine \\
\hline 38.115 & 24.514 & 36.55 & 0.129 & 0.193 & 99.501 & Coarse \\
\hline 38.115 & 24.261 & 36.664 & 0.058 & 0.148 & 99.246 & Coarse \\
\hline 38.517 & 23.848 & 35.867 & 0.112 & 0.179 & 98.523 & Coarse \\
\hline 38.32 & 24.094 & 36.417 & 0.099 & 0.125 & 99.055 & Coarse \\
\hline 37.905 & 24.785 & 36.196 & 0.075 & 0.195 & 99.156 & Fine \\
\hline 37.718 & 24.752 & 37.539 & 0.094 & 0.159 & 100.262 & Fine \\
\hline 37.629 & 25.686 & 36.491 & 0.09 & 0.155 & 100.051 & Fine \\
\hline 38.231 & 26.275 & 36.025 & 0.087 & 0.137 & 100.755 & Coarse \\
\hline 38.717 & 22.274 & 39.874 & 0.076 & 0.176 & 101.456 & Fine \\
\hline 38.09 & 25.883 & 36.567 & 0.077 & 0.114 & 100.731 & Fine \\
\hline 38.989 & 20.324 & 40.717 & 0.076 & 0.155 & 100.261 & Fine \\
\hline & & & & & & \\
\hline
\end{tabular}

Appendix 3 (continued). PSb-15-90 olivine data. 


\begin{tabular}{|c|c|c|c|c|c|c|}
\hline SiO2 & FeO & MgO & CaO & NiO & Total & \\
\hline 37.329 & 31.182 & 30.3 & 0.038 & 0.218 & 99.067 & Fine \\
\hline 37.357 & 31.224 & 30.48 & 0.038 & 0.132 & 99.231 & Fine \\
\hline 37.315 & 32.186 & 30.386 & 0.064 & 0.203 & 100.154 & Coarse \\
\hline 37.161 & 31.481 & 30.64 & 0.057 & 0.165 & 99.504 & Fine \\
\hline 37.602 & 30.198 & 31.224 & 0.065 & 0.157 & 99.246 & Fine \\
\hline 37.415 & 31.666 & 30.048 & 0.032 & 0.185 & 99.346 & Coarse \\
\hline 36.984 & 32.521 & 30.277 & 0.031 & 0.114 & 99.927 & Coarse \\
\hline 37.187 & 31.909 & 30.214 & 0.034 & 0.161 & 99.505 & Fine \\
\hline 38.023 & 27.978 & 33.04 & 0.086 & 0.132 & 99.259 & Fine \\
\hline 37.127 & 31.284 & 30.661 & 0 & 0.124 & 99.196 & Fine \\
\hline 37.096 & 32.073 & 29.849 & 0.032 & 0.142 & 99.192 & Fine \\
\hline 37.076 & 31.588 & 30.419 & 0.035 & 0.138 & 99.256 & Fine \\
\hline 37.417 & 31.298 & 30.8 & 0.137 & 0.14 & 99.792 & Coarse \\
\hline 37.764 & 31.08 & 31.15 & 0.062 & 0.13 & 100.186 & Coarse \\
\hline 37.223 & 31.853 & 30.427 & 0.072 & 0.13 & 99.705 & Fine \\
\hline 37.397 & 30.94 & 30.678 & 0.092 & 0.155 & 99.262 & Fine \\
\hline 37.14 & 31.471 & 30.199 & 0.042 & 0.181 & 99.033 & Fine \\
\hline 37.303 & 31.794 & 30.033 & 0.053 & 0.206 & 99.389 & Fine \\
\hline 37.209 & 31.934 & 30.566 & 0.048 & 0.155 & 99.912 & Fine \\
\hline 37.294 & 30.888 & 30.892 & 0.047 & 0.147 & 99.268 & Fine \\
\hline 37.182 & 31.032 & 30.656 & 0.05 & 0.127 & 99.047 & Fine \\
\hline 37.251 & 31.352 & 30.749 & 0.062 & 0.114 & 99.528 & Fine \\
\hline 37.645 & 30.389 & 31.617 & 0.04 & 0.185 & 99.876 & Coarse \\
\hline 37.271 & 31.72 & 29.998 & 0.054 & 0.102 & 99.145 & Fine \\
\hline 37.699 & 28.325 & 33.199 & 0.027 & 0.167 & 99.417 & Fine \\
\hline 37.249 & 31.02 & 30.669 & 0.018 & 0.172 & 99.128 & Fine \\
\hline 37.25 & 31.695 & 30.331 & 0.048 & 0.161 & 99.485 & Fine \\
\hline 36.969 & 32.268 & 30.159 & 0.043 & 0.204 & 99.643 & Fine \\
\hline 37.098 & 32.314 & 29.918 & 0.044 & 0.17 & 99.544 & Coarse \\
\hline 37.27 & 30.993 & 30.746 & 0.038 & 0.207 & 99.254 & Coarse \\
\hline 37.581 & 30.699 & 31.029 & 0.048 & 0.182 & 99.539 & Fine \\
\hline 37.24 & 30.176 & 31.397 & 0.058 & 0.154 & 99.025 & Fine \\
\hline
\end{tabular}

Appendix 4. PS-17-90 olivine data. 


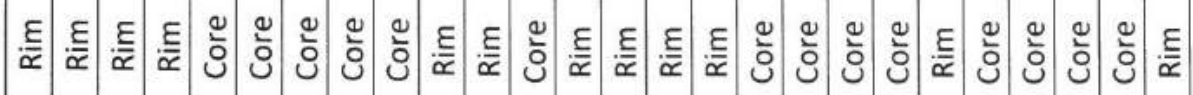

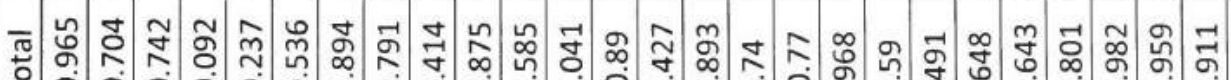

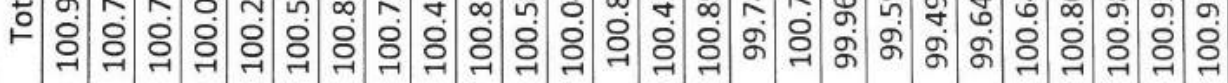

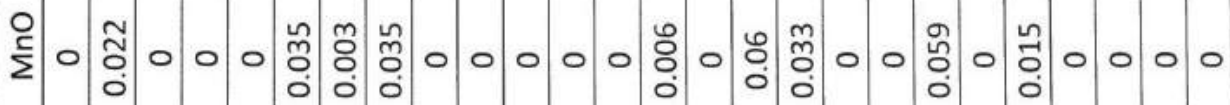

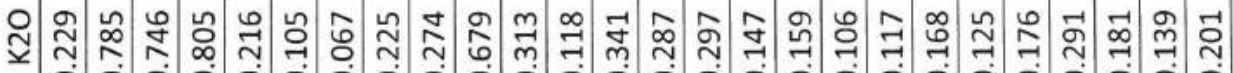
○

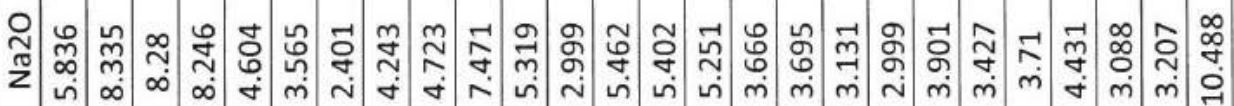

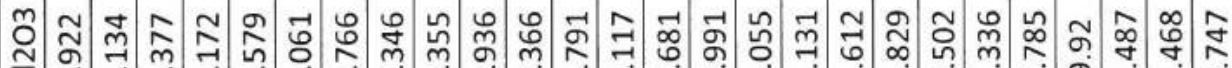

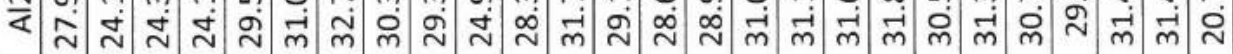

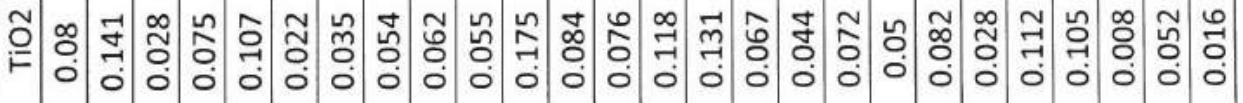

ㅇำ

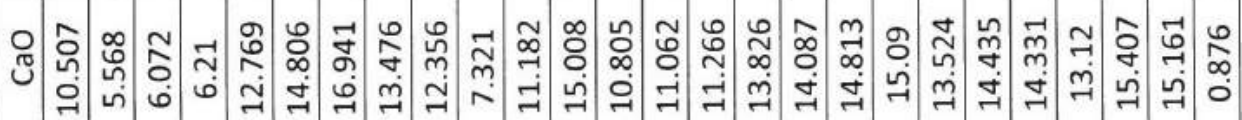

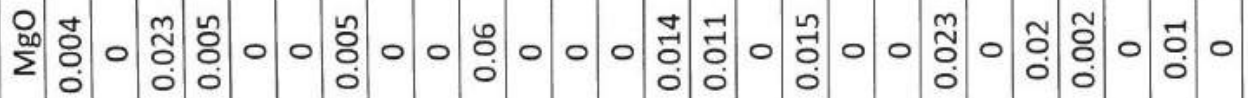

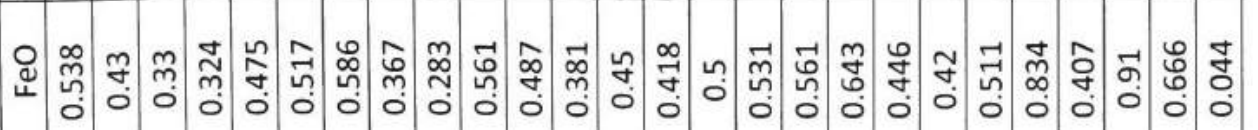

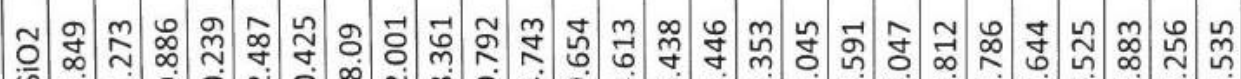

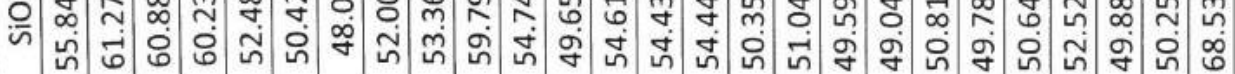




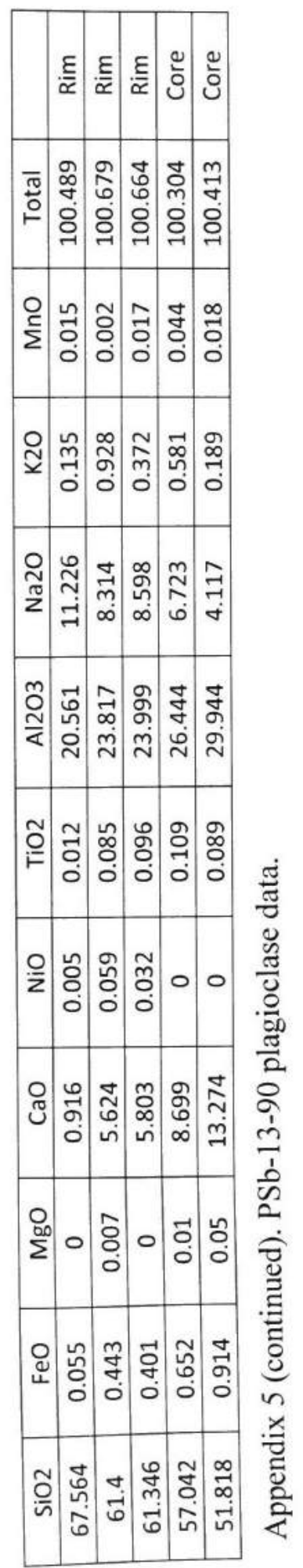


气ั

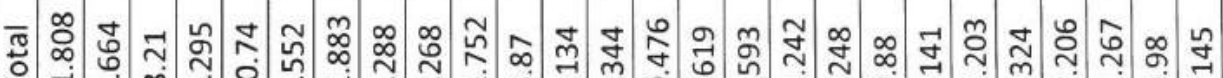

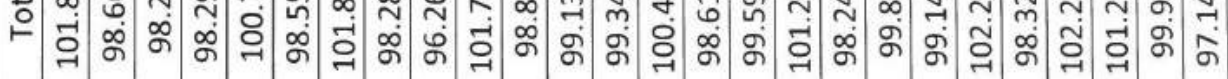

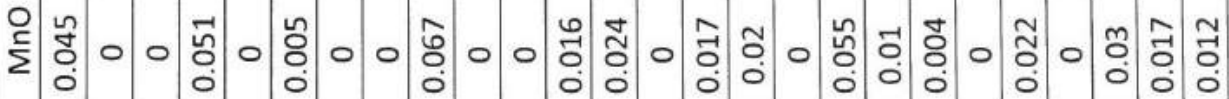

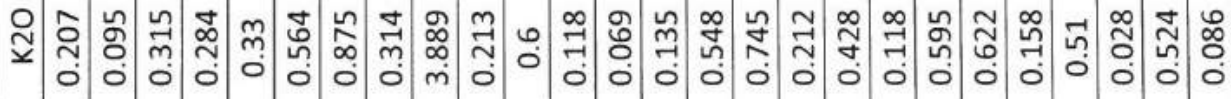

ช

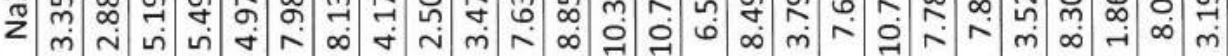

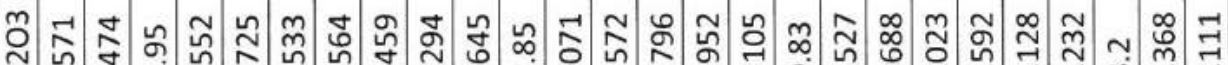

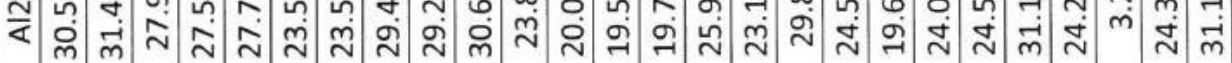

õ

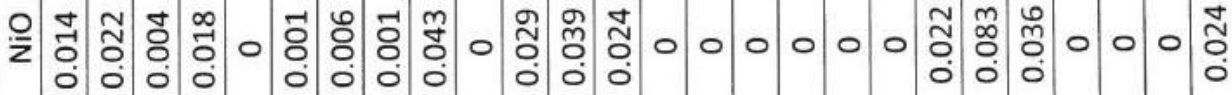

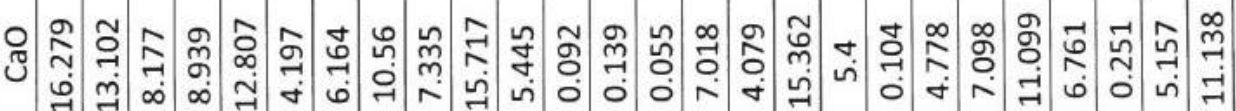

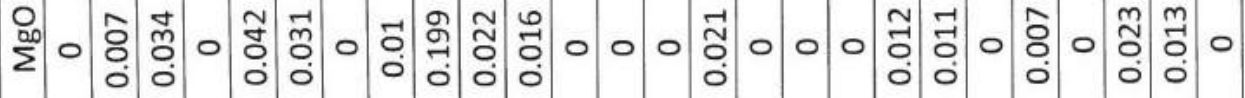

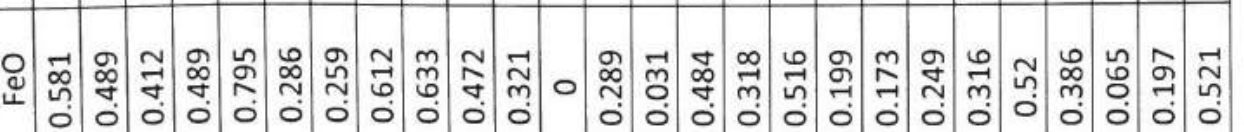

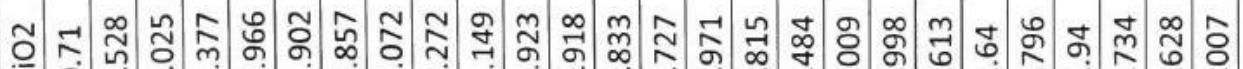

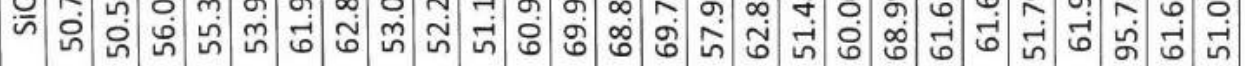

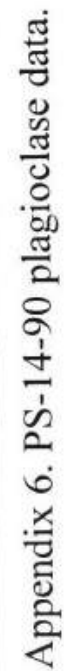




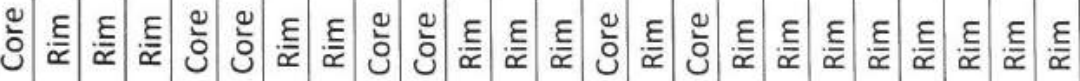

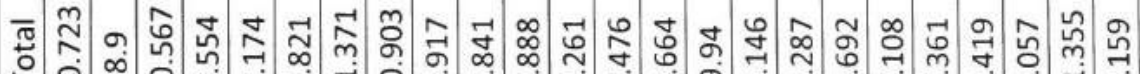

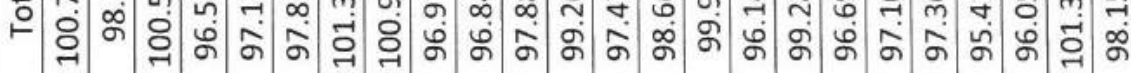

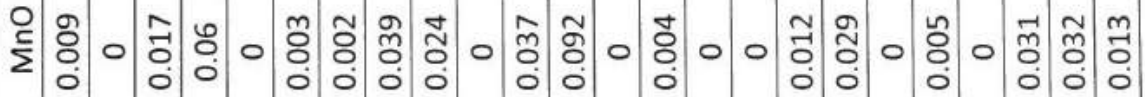

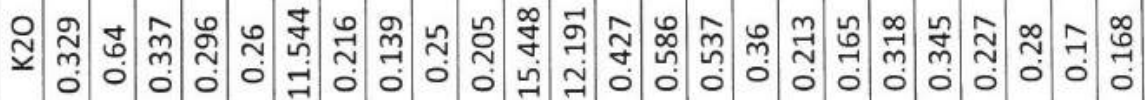

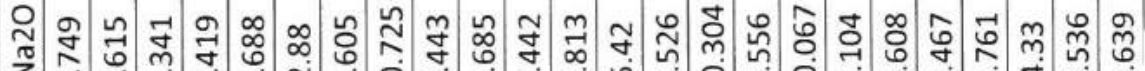

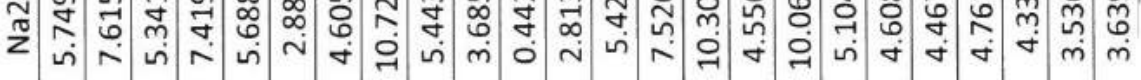

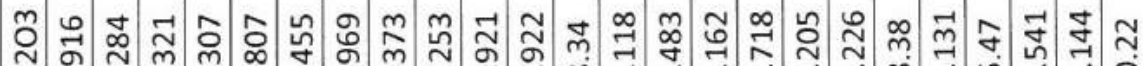

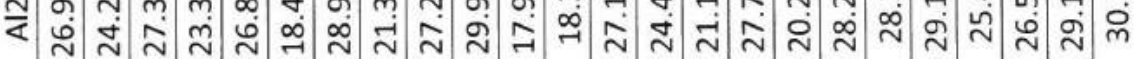

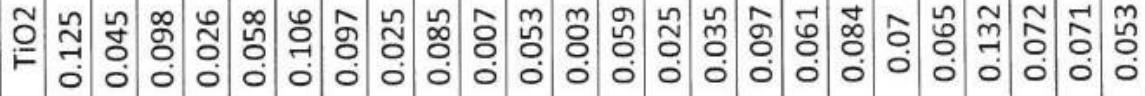

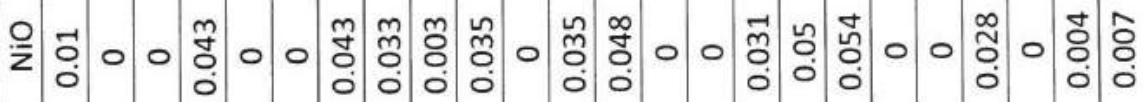

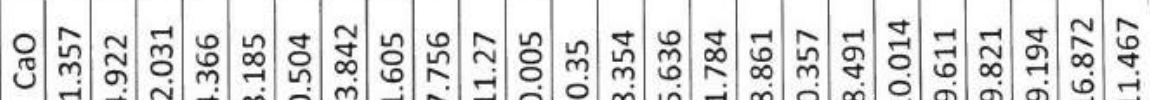
$\cup$ J

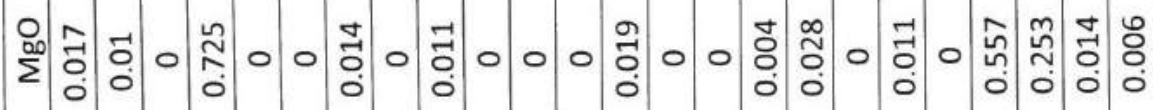

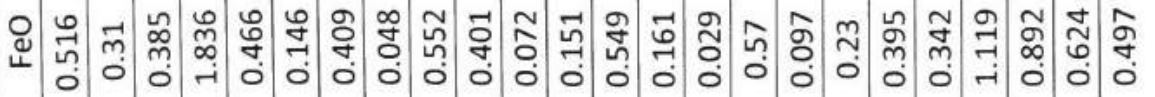

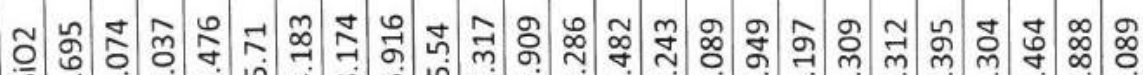

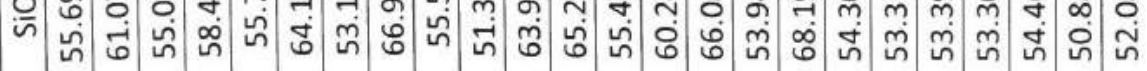




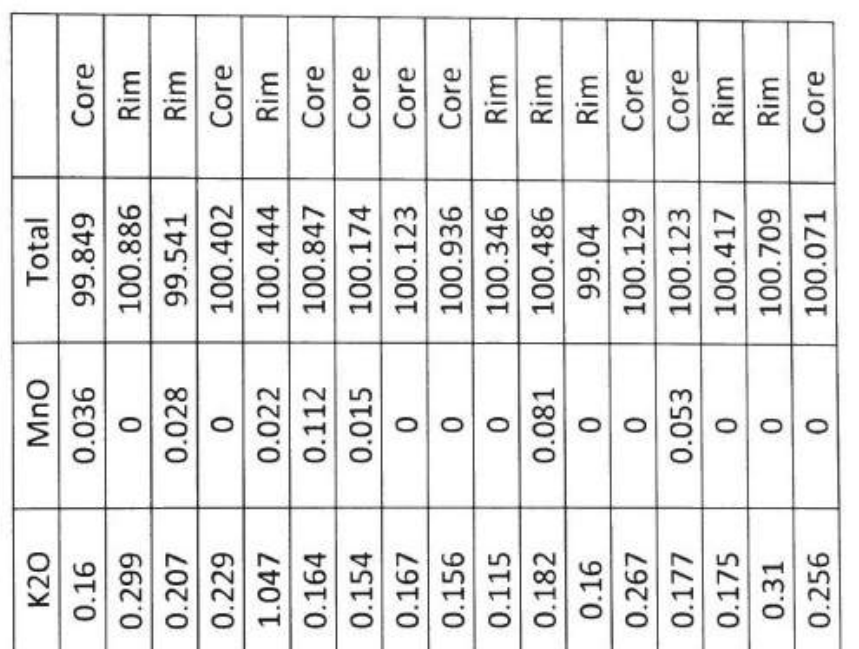

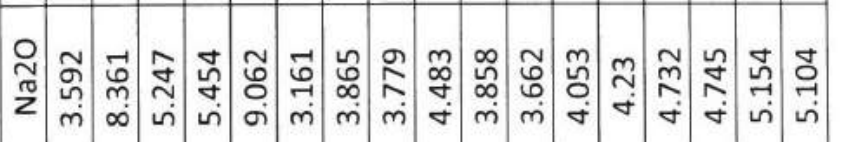

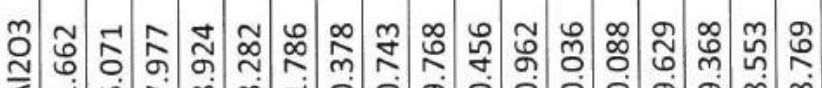

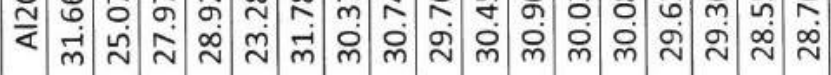

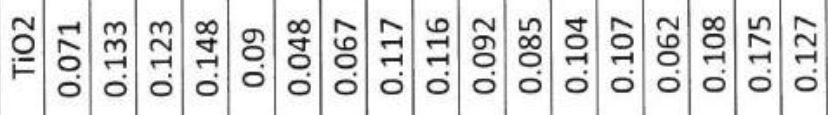

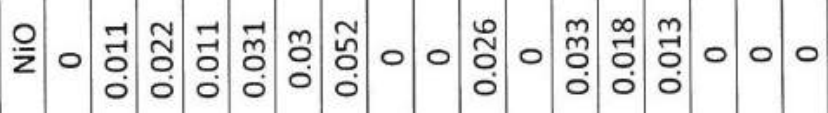

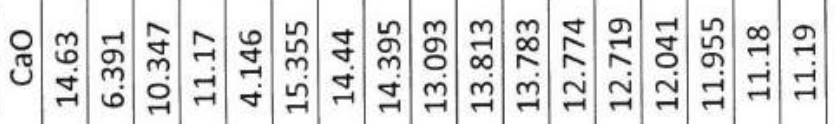

$$
\text { 苂 }
$$

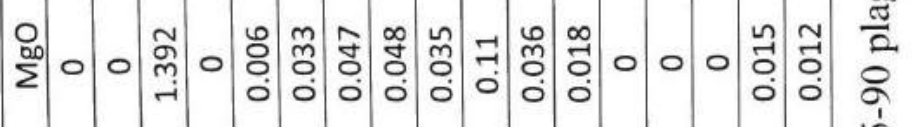

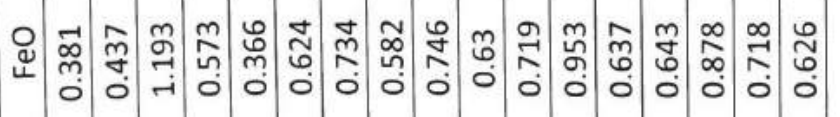

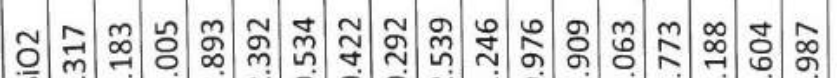

* 


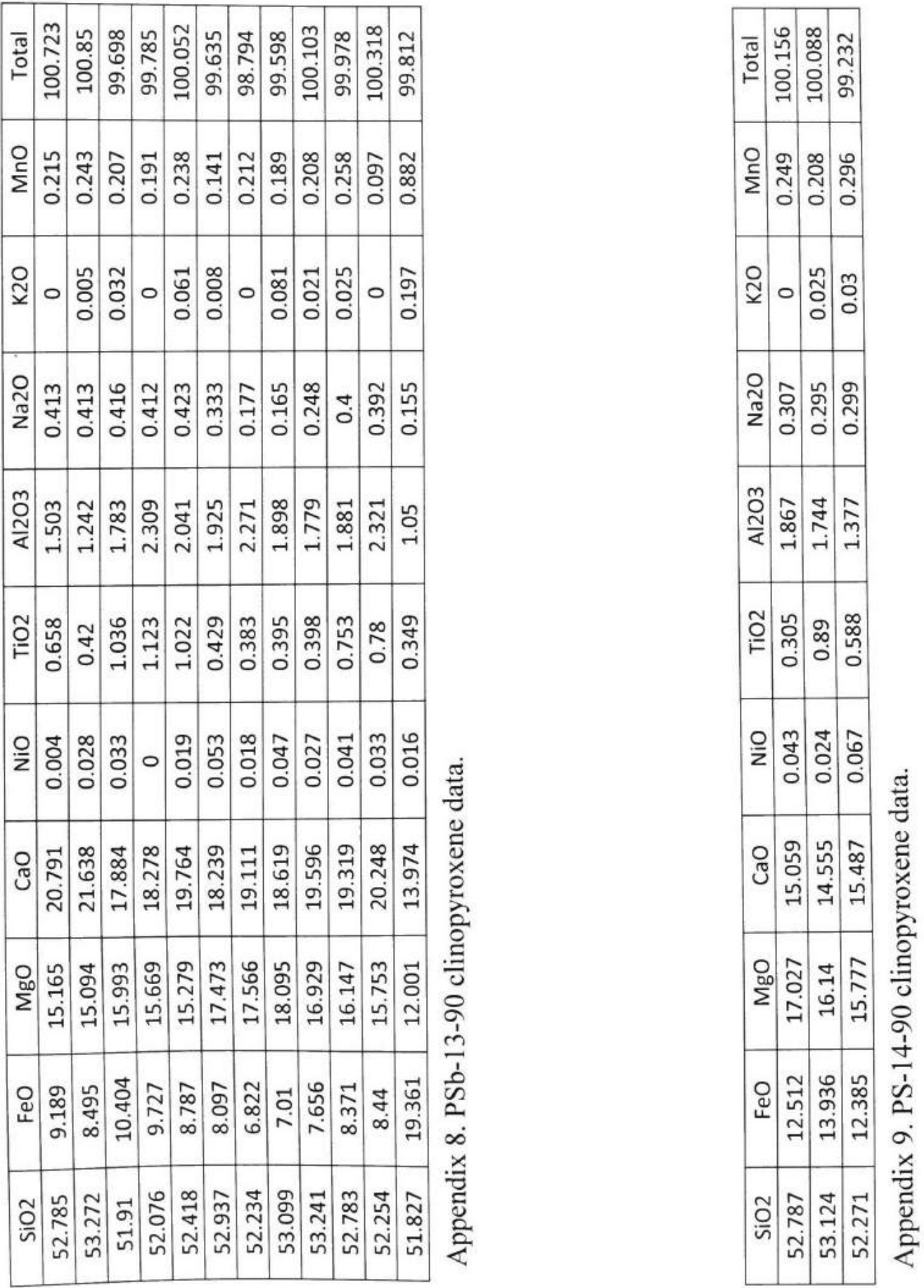




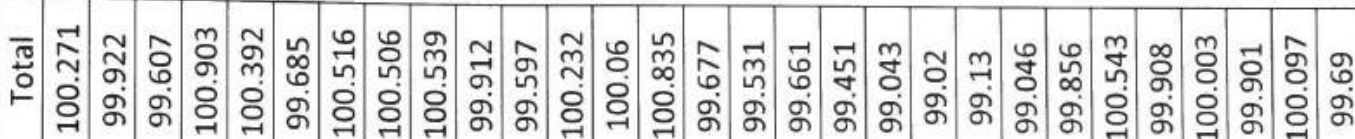

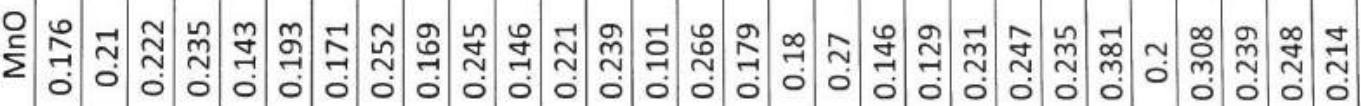

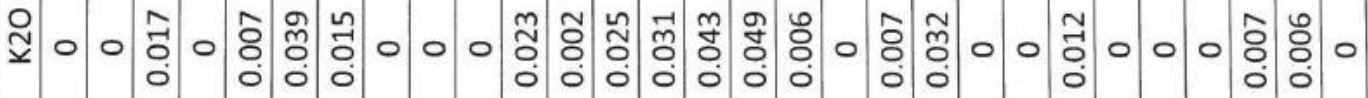

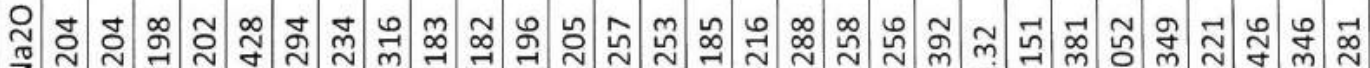

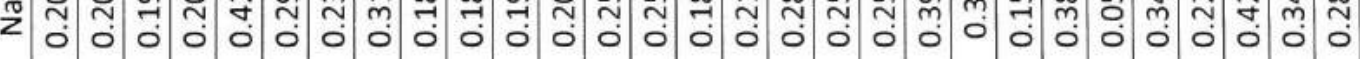

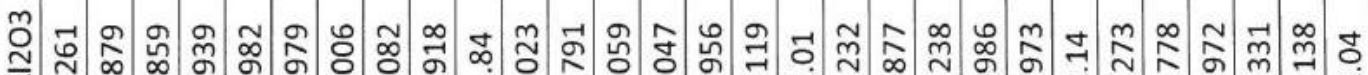
ष ô

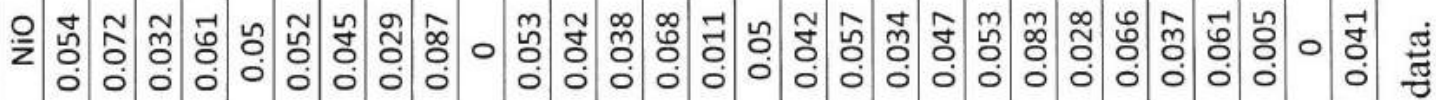

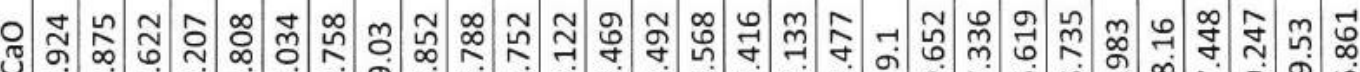

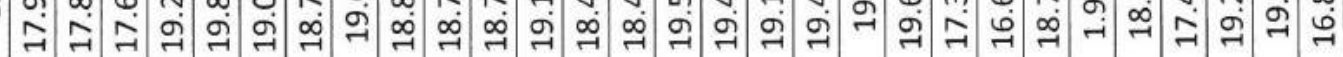

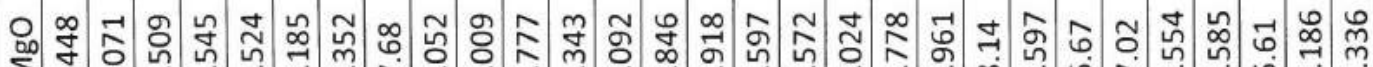

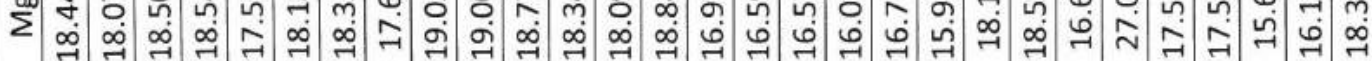

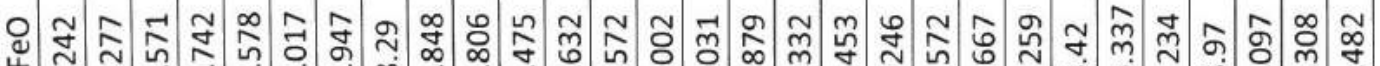
N

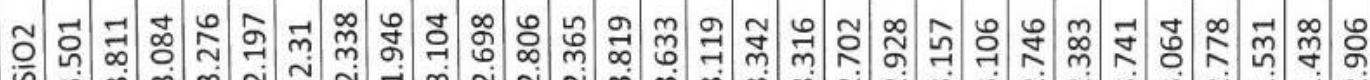

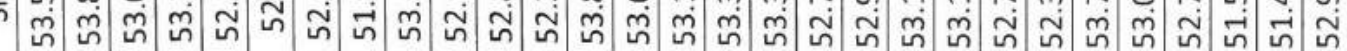




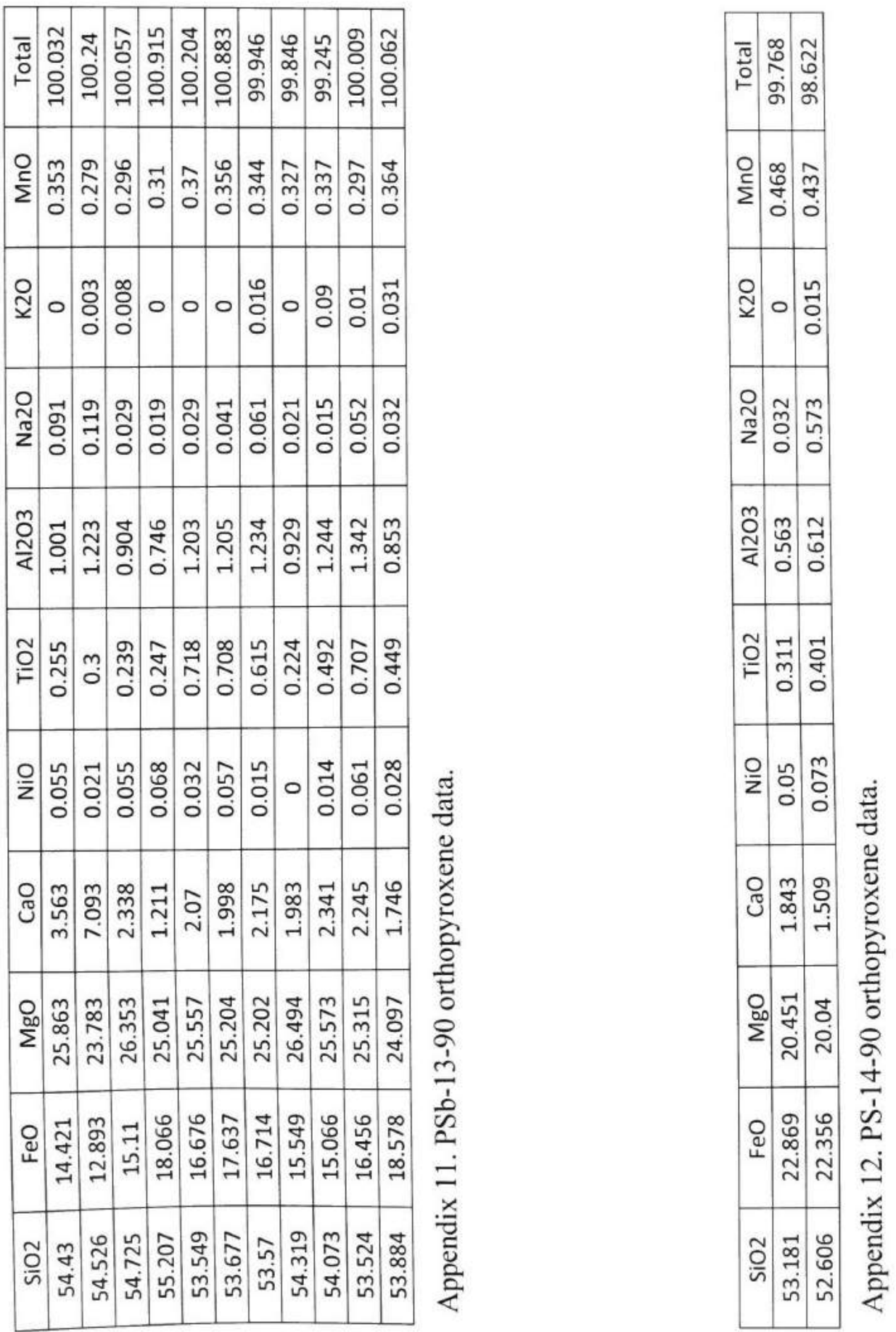




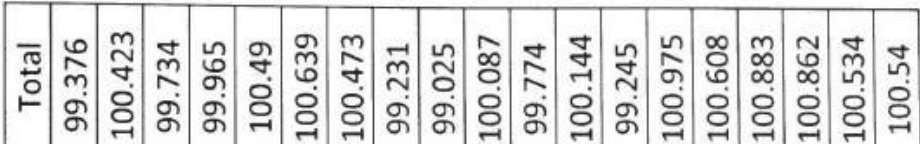

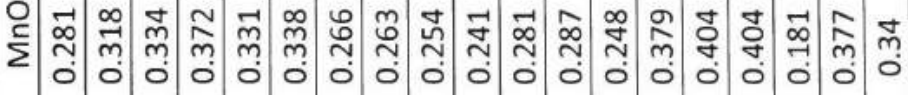

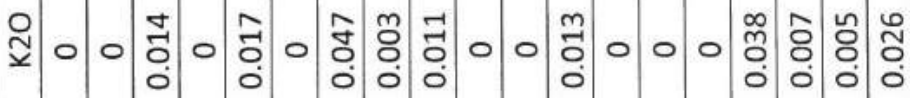

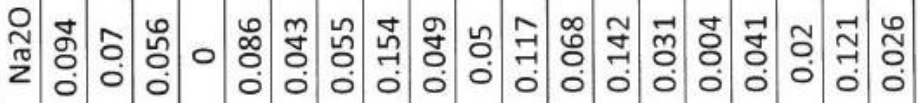

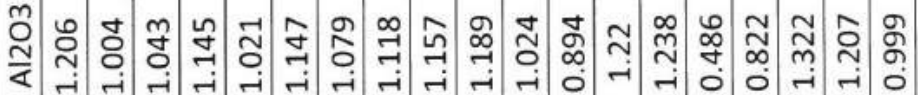

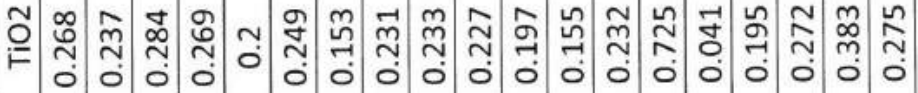

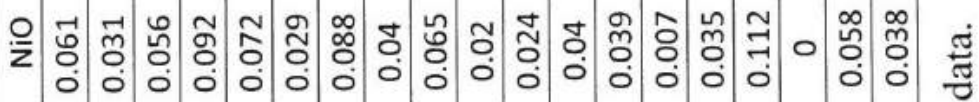

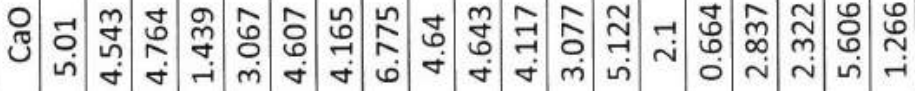

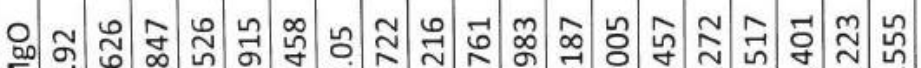

$\Sigma$ nู山

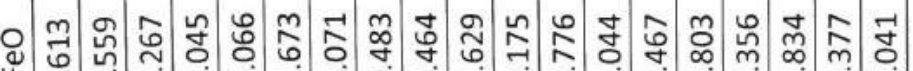

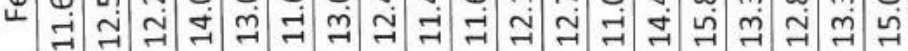

テ ָี

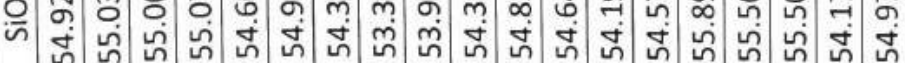

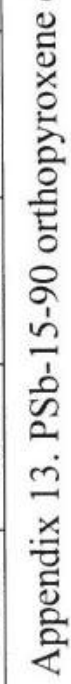




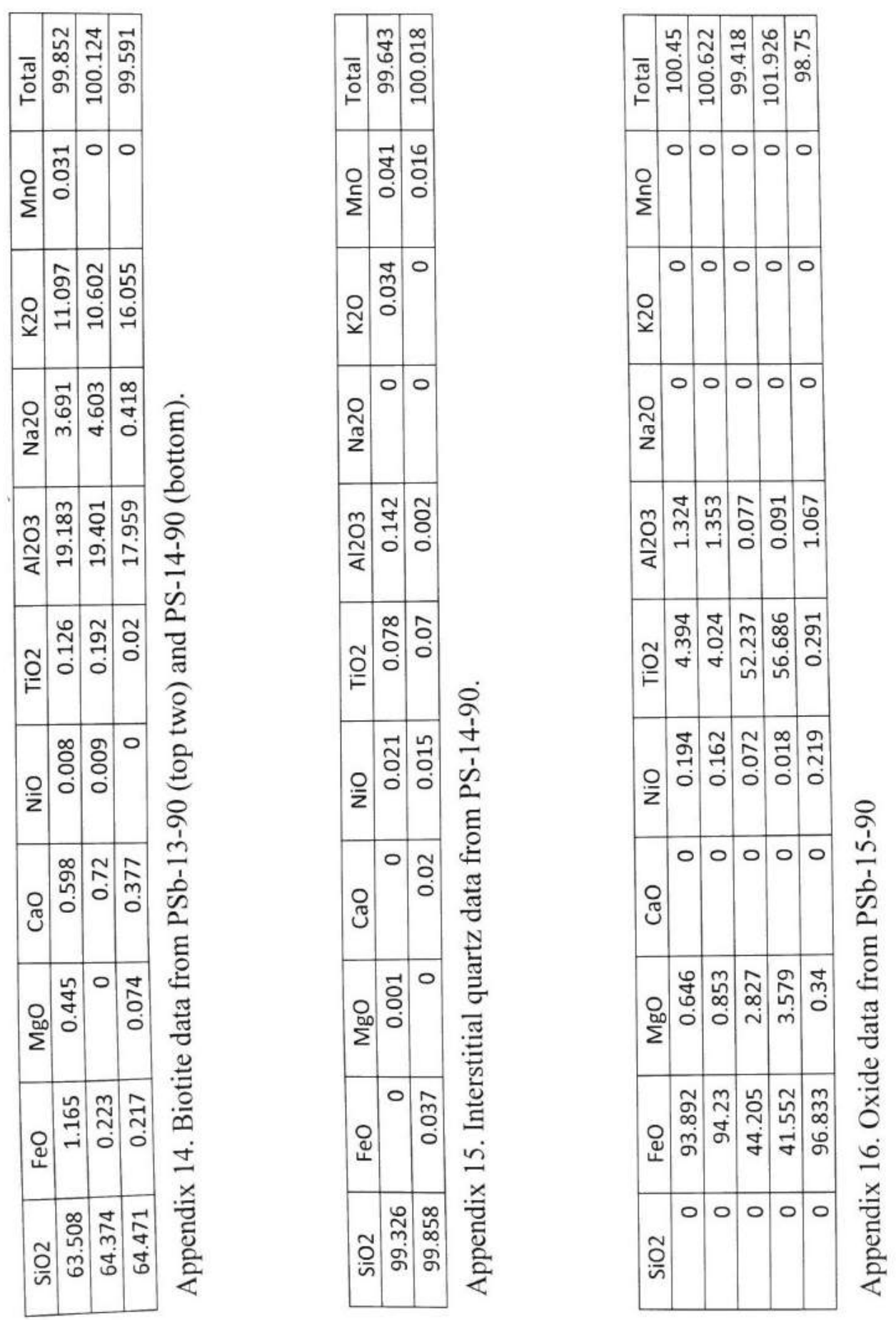

